ISABEL JUNQUEIRA DE ALMEIDA

\title{
Caracterização de fala e linguagem na síndrome corticobasal
}

Dissertação apresentada à Faculdade de

Medicina da Universidade de São Paulo para obtenção do título de Mestre em Ciências

Programa de Ciências da Reabilitação

Orientadora: Profa. Dra. Eliane Schochat

São Paulo

2020 
ISABEL JUNQUEIRA DE ALMEIDA

\title{
Caracterização de fala e linguagem na síndrome corticobasal
}

\author{
Dissertação apresentada à Faculdade de \\ Medicina da Universidade de São Paulo para \\ obtenção do título de Mestre em Ciências \\ Programa de Ciências da Reabilitação \\ Orientadora: Profa. Dra. Eliane Schochat
}

São Paulo 2020 


\section{Dados Internacionais de Catalogação na Publicaçăo (CIP)}

Preparada pela Biblioteca da

Faculdade de Medicina da Universidade de Săo Paulo

Creprodução autorizada pelo autor

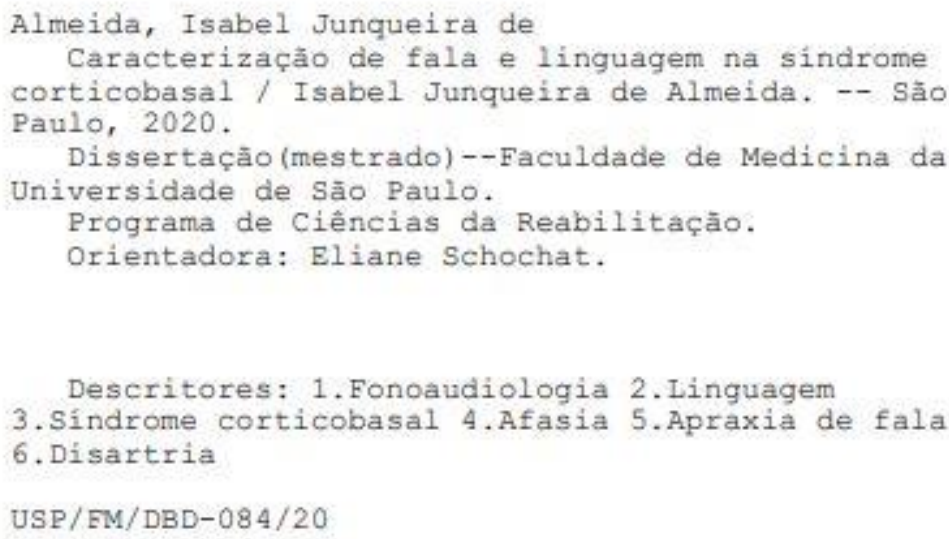

Responsável: Erinalva da Conceiçăo Batista, CRB-8 6755 
À querida professora Letícia Lessa Mansur

(in memoriam), que aprofundou em mim o amor pela linguagem. 


\section{AGRADECIMENTOS}

Esta pesquisa nasceu de uma parceria com o Grupo de Neurologia Cognitiva e do Comportamento (GNCC) do HCFMUSP, a cujos membros eu agradeço profundamente, em especial à Dra. Jacy Parmera e à Profa. Dra. Sônia Brucki, que me mostraram a riqueza de um trabalho multidisciplinar.

Agradeço à minha orientadora, Profa. Dra. Letícia Lessa Mansur (in memoriam), que me sugeriu o tema e me acompanhou ao longo da maior parte desse percurso. Querida professora, obrigada pelo privilégio de ter sido sua aluna. Seu exemplo segue forte em mim.

À querida Dra. Marcela Silagi, que vem me acompanhando desde a graduação e a quem eu recorro em todos os momentos. Agradeço pelas preciosas correções, pelo apoio, pelos ensinamentos, pela amizade.

À Profa. Dra. Eliane Schochat, que me "adotou" como orientanda com tanta generosidade e carinho.

Aos membros da banca de qualificação, Profa. Dra. Maria Teresa Carthery-Goulart, Profa. Dra. Katia Nemr e Profa. Dra. Lúcia Iracema Zanotto de Mendonça, pelas importantes contribuições a este trabalho.

Às queridas colegas e amigas Tharsila Moreira Gomes da Costa e Sueli Zampieri, pelas infinitas horas dispensadas às análises de fala dos meus pacientes.

Às colegas de ambulatório, Karoline Freitas, Heloísa Batista, Marcela Leal, Taynara Barbosa, Giovana Kaila e Eliane Cordeiro, pela parceria, pelas risadas, pela leveza.

Ao Carlos Filho, pelas cuidadosas análises estatísticas.

A todos os voluntários que participaram dessa pesquisa.

Aos meus pais, Junqueirinha e Fernanda, por acreditarem em mim e me incentivarem a seguir esse longo caminho de estudos. Sem esse apoio, este trabalho não existiria.

À minha pequena Laura, que me arranca dos livros e me leva para 0 parque.

Ao meu companheiro de vida, Diogo Maia. 
"A linguagem é o instrumento graças ao qual o homem modela seu pensamento, seu sentimento, suas emoções, seus esforços, sua vontade e seus atos, o instrumento graças ao qual ele influencia e é influenciado, a base última e mais profunda da sociedade humana." 


\section{Normalização adotada}

Esta dissertação está de acordo com as seguintes normas, em vigor no momento desta publicação:

Referências: adaptado de International Committee of Medical Journals Editors (Vancouver).

Universidade de São Paulo. Faculdade de Medicina. Divisão de Biblioteca e Documentação. Guia de apresentação de dissertações, teses e monografias. Elaborado por Anneliese Carneiro da Cunha, Maria Julia de A. L. Freddi, Maria F. Crestana, Marinalva de Souza Aragão, Suely Campos Cardoso, Valéria Vilhena. 3a ed. São Paulo: Divisão de Biblioteca e Documentação; 2011.

Abreviaturas dos títulos dos periódicos de acordo com List of Journals Indexed in Index Medicus. 


\section{Sumário}

Lista de abreviaturas e siglas

Lista de tabelas

Lista de quadros e gráficos

Resumo

Abstract

1. INTRODUÇÃO

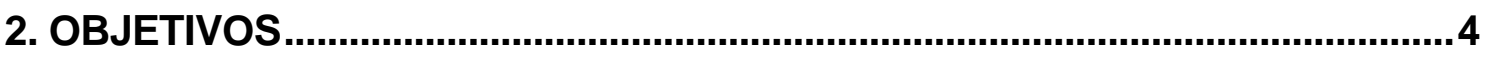

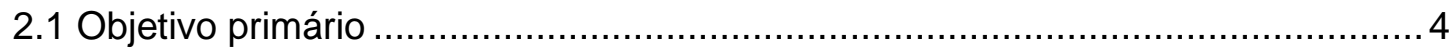

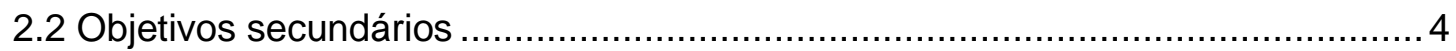

3. REVISÃO DE LITERATURA .........................................................................5

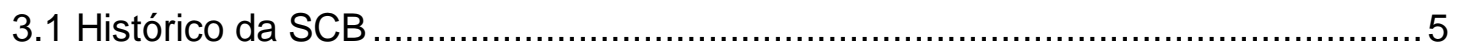

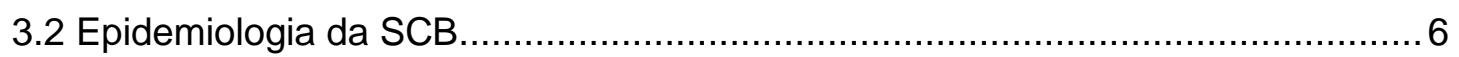

3.3 Características clínicas e critérios diagnósticos da SCB................................. 7

3.4 Neuroimagem e biomarcadores da SCB ......................................................... 9

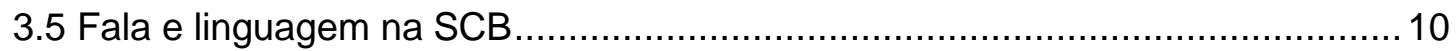

3.6 Atenção, memória e funções executivas na SCB .......................................... 16

3.7 Relação entre habilidades linguísticas, idade e escolaridade ........................... 19

4. MÉTODOS .....................................................................................................21

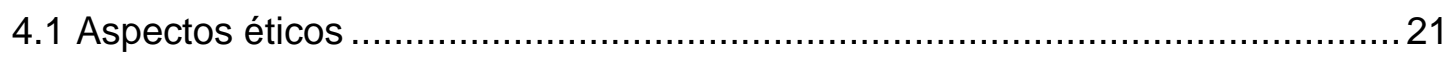

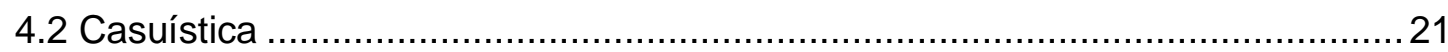

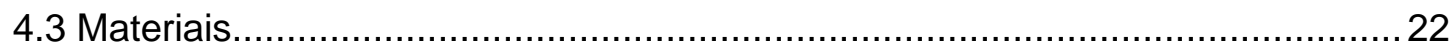

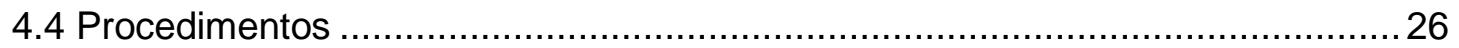

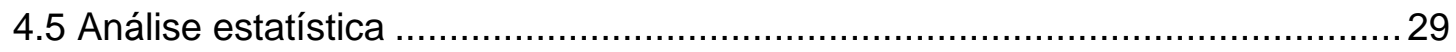

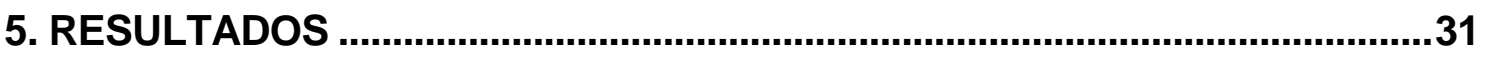

5.1 Caracterização sociodemográfica e clínica dos grupos .....................................31

5.2 Avaliação cognitiva e de linguagem......................................................... 32

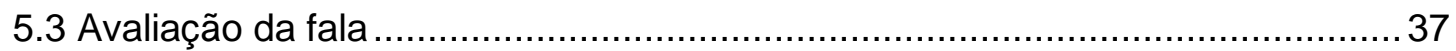

5.4 Escalas de funcionalidade da comunicação e gravidade das alterações de linguagem (ASHA-FACS e Escala PASS).

5.5 Correlação entre habilidades cognitivas, de linguagem e fala e idade, escolaridade e duração da doença

5.6 Comparação dos grupos SCB+ e SCB-.... 
5.7 Proporção de pacientes com desempenho abaixo do GC em relação a cognição, linguagem e fala

6. DISCUSSÃO

6.1 Caracterização sociodemográfica e clínica dos grupos .................................54

6.2 Desempenho nos testes de rastreio cognitivo e de linguagem ..........................55

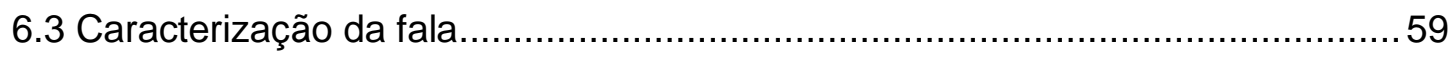

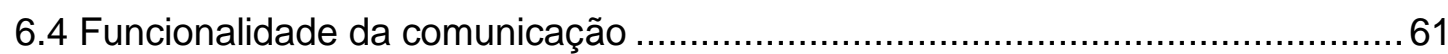

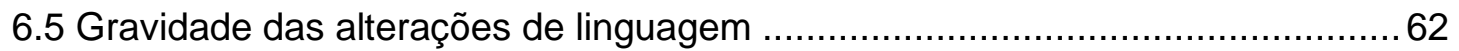

6.6 Correlações entre habilidades cognitivas, de linguagem e fala x idade, escolaridade e duração da doença.......................................................................63

6.7 Comparação entre os grupos SCB+ e SCB-.............................................. 64

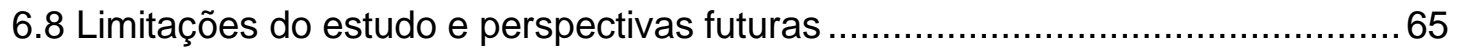

7. CONCLUSÕES.......................................................................................6

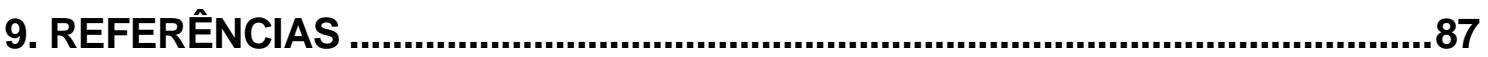




\section{Lista de abreviaturas e siglas}

ACE-R

APP

APP-L

APP-nf

APP-S

ASHA-FACS

AVC

CAPPesq

CEP

DA

DCB

DFT

DFT-vc

DLFT

DP

et al.

GC

GNCC

GSCB

HCFMUSP

InRad
Addenbrooke's Cognitive Examination-Revised

Afasia progressiva primária

Afasia progressiva primária variante logopênica

Afasia progressiva primária variante não-fluente

Afasia progressiva primária variante semântica

American Speech-Language-Hearing Association

Functional Assessment of Communication Skills for Adults

Acidente vascular cerebral

Comissão de Ética para Análise de Projetos de Pesquisa

Comitê de Ética em Pesquisa

Doença de Alzheimer

Degeneração corticobasal

Degeneração frontotemporal

Degeneração frontotemporal variante comportamental

Degeneração lobar frontotemporal

Desvio-padrão

E outros

Grupo-controle

Grupo de Neurologia Cognitiva e do Comportamento

Grupo síndrome corticobasal

Hospital das Clínicas da Faculdade de Medicina da Universidade de São Paulo

Instituto de Radiologia 
MEEM

MOANS

PET

PET-FDG

PET-PiB

PSP

SCB

SPECT

TCLE

TDP-43

UDS

WAB-R
Mini-Exame do Estado Mental

Mayo Older American Normative Studies

Tomografia por emissão de pósitrons, do inglês Positron emission tomography

Tomografia por emissão de pósitrons com marcador fluorodeoxiglicose, do inglês Fludeoxyglucose - Positron emission tomography

Tomografia por emissão de pósitrons com marcador para amiloide - composto farmacológico Pittsburgh compound $B$, do inglês Pittsburgh compound B - Positron emission tomography

Paralisia supranuclear progressiva

Síndrome corticobasal

Tomografia computadorizada por emissão de fóton único, do inglês Single-photon emission computed tomography

Termo de consentimento livre e esclarecido

TAR DNA-binding protein 43

Uniform Data Set

Bateria de Avaliação das Afasias de Western - revisada, do inglês Western Aphasia Battery-Revised 


\section{Lista de tabelas}

Tabela 1 - Características sociodemográficas e clínicas dos grupos.

Tabela 2 - Valores descritivos e análise comparativa dos grupos em relação ao desempenho no ACE-R

Tabela 3 - Valores descritivos e análise comparativa dos grupos em relação ao desempenho no WAB-R

Tabela 4 - Valores descritivos e análise comparativa dos grupos em relação ao desempenho na UDS.

Tabela 5 - Valores descritivos e análise comparativa dos grupos em relação ao desempenho na escala de apraxia de fala

Tabela 6 - Valores descritivos e análise comparativa dos grupos em relação ao desempenho na diadococinesia oral

Tabela 7 - Caracterização do GSCB em relação ao desempenho na escala ASHAFACS 41

Tabela 8 - Caracterização do GSCB em relação ao desempenho na escala PASS

Tabela 9 - Análise de correlação entre pontuação total no ACE-R, quociente de afasia, pontuação total da escala de apraxia de fala e idade, escolaridade e duração da doença para o GSCB

Tabela 10 - Características sociodemográficas e clínicas dos grupos SCB+ e SCB-

Tabela 11 - Valores descritivos e análise comparativa dos grupos SCB+ e SCB- em relação ao desempenho no ACE-R

Tabela 12 - Valores descritivos e análise comparativa dos grupos SCB+ e SCB- em relação ao desempenho no WAB-R

Tabela 13 - Valores descritivos e análise comparativa dos grupos SCB+ e SCB- em relação ao desempenho na UDS 
Tabela 14 - Valores descritivos e análise comparativa dos grupos SCB+ e SCB- em relação ao desempenho na escala de apraxia de fala

Tabela 15 - Valores descritivos e análise comparativa dos grupos SCB+ e SCB- em relação ao desempenho na diadococinesia oral

Tabela 16 - Comparação dos grupos SCB+, SCB- e GSCB em relação à presença de alteração morfossintática, disartria e apraxia de fala

Tabela 17 - Valores descritivos e análise comparativa dos grupos SCB+ e SCB- em relação ao desempenho na ASHA-FACS.

Tabela 18 - Valores descritivos e análise comparativa dos grupos SCB+ e SCB- em relação ao desempenho na escala PASS 


\section{Lista de quadros e gráficos}

Quadro 1 - Testes que compõem as avaliações do GSCB e do GC

Quadro 2 - Descrição das alterações encontradas nos pacientes com disartria..38

Gráfico 1 - Porcentagem de pacientes com desempenho abaixo do GC em provas de cognição, fala e linguagem. 


\section{Resumo}

Almeida IJ. Caracterização de fala e linguagem na síndrome corticobasal [dissertação]. São Paulo: Faculdade de Medicina, Universidade de São Paulo; 2020.

Introdução: A síndrome corticobasal (SCB) é uma doença neurodegenerativa, rara, classificada entre as síndromes parkinsonianas atípicas. Apresenta sintomas motores e cognitivos. No que se refere à caracterização de fala e linguagem, parte das pesquisas aponta para alterações compatíveis com a afasia progressiva primária não-fluente, no entanto, poucos estudos realizaram uma avaliação abrangente desses aspectos. A SCB pode ser a manifestação clínica de diversas patologias subjacentes. Tendo em vista essa heterogeneidade clínico-patológica, há um crescente interesse na busca por características clínicas que auxiliem no diagnóstico antemortem da patologia de base da SCB. O objetivo primário foi caracterizar a fala e a linguagem de pacientes com diagnóstico de SCB provável, em seus aspectos fonéticofonológicos, morfossintáticos e léxico-semânticos, buscando um padrão sugestivo da SCB. Os objetivos secundários foram: 1 - Verificar possíveis impactos de idade, escolaridade e duração da doença nas alterações de fala e linguagem nos pacientes com SCB. 2 - Caracterizar um possível padrão de alteração de fala e linguagem sugestivo da SCB decorrente da doença de Alzheimer (DA). Métodos: Foram constituídos dois grupos: grupo de pacientes com SCB (GSCB, n=20) e grupo-controle ( $G C, n=20$ ). Ambos passaram por avaliação de rastreio cognitivo, linguagem e aspectos motores da fala. O GSCB também foi avaliado quanto à funcionalidade da linguagem e a gravidade das alterações linguísticas. Foram realizadas comparações entre os dois grupos em relação às características sociodemográficas e clínicas e às pontuações nos testes de cognição, fala e linguagem por meio do teste $t$ de Student ou $U$ de Mann-Whitney. Para avaliar a influência da idade, escolaridade e duração da doença nos resultados das avaliações no GSCB, realizou-se análise de correlação de Pearson ou Spearman. Os pacientes do GSCB foram subdivididos 
em dois grupos, de acordo com o resultado do PET-FDG: SCB+ (sugestivo de DA como patologia de base, $n=7)$ e SCB- $(n=13)$. Foram realizadas comparações em relação às características sociodemográficas e clínicas, os testes de rastreio cognitivo, fala e linguagem e as escalas de funcionalidade e gravidade das alterações linguísticas. Foi calculada a proporção de pacientes do GSCB, do $\mathrm{SCB}+$ e SCB- que obteve desempenho abaixo da mediana do GC em testes de cognição, fala e linguagem. Resultados: o GSCB e o GC se diferenciaram em todos os subtestes de cognição e linguagem, sendo que o GSCB teve pior desempenho. A apraxia de fala foi encontrada em $57,9 \%$ dos pacientes e a disartria, em $21,05 \%$. Foi encontrada correlação positiva entre a duração da doença e a gravidade das alterações de fala. Foi encontrada correlação positiva entre a escolaridade e a pontuação total no teste de rastreio cognitivo e correlação negativa entre o mesmo teste e a duração da doença. Na comparação dos grupos SCB+ e SCB- no teste de rastreio cognitivo, houve tendência para maior comprometimento da atenção $(p=0,057)$ e das habilidades visuoespaciais $(p=0,051)$ no grupo SCB+. Não houve diferença estatística entre os grupos nos testes de fala e linguagem. Conclusões: As alterações de linguagem nos pacientes com SCB são heterogêneas e abrangem todos os processamentos linguísticos. Em relação aos aspectos motores da fala, o perfil também é heterogêneo. Na comparação dos grupos SCB+ e SCB-, houve uma tendência para maior comprometimento da atenção e das habilidades visuoespaciais no grupo SCB+. Nos testes de linguagem não houve diferença estatisticamente significante entre os grupos $\mathrm{SCB}+$ e $\mathrm{SCB}$ -

Descritores: Fonoaudiologia. Linguagem. Síndrome corticobasal. Afasia. Apraxia de fala. Disartria. 


\section{Abstract}

Almeida IJ. Speech and language characterization of corticobasal syndrome [dissertation]. São Paulo: Faculdade de Medicina, Universidade de São Paulo; 2020.

Introduction: Corticobasal syndrome (CBS) is a rare neurodegenerative disease, classified among atypical parkinsonian disorders. It presents cognitive and motor symptoms. Regarding the characterization of speech and language, part of the literature points to the non-fluent variant phenotype of the primary progressive aphasia, however, few studies have carried out a comprehensive assessment of these aspects. CBS may be the clinical manifestation of several underlying pathologies. In view of this clinical-pathological heterogeneity, there is a growing interest in the search for clinical characteristics that assist in the antemortem diagnosis of the underlying pathology of CBS. The primary objective was to characterize the speech and language profile of patients with a probable diagnosis of CBS, in its phonetic-phonological, morphosyntactic, and lexicalsemantic aspects, seeking a suggestive pattern of SCB. Secondary objectives: 1 - To verify possible impacts of age, education, and disease duration on speech and language disorders of patients with CBS. 2 - Characterize the speech and language phenotype suggestive of SCB with Alzheimer's Disease (AD). Methods: Two groups were formed: a group of patients with CBS (GCBS, $n=20$ ) and a control group ( $C G, n=20$ ). Both groups underwent an assessment of cognitive screening, language, and motor speech aspects. The GCBS was also assessed for language functionality and the severity of language impairment. The two groups were compared regarding sociodemographic and clinical characteristics and scores on cognition, speech and language tests using the Student's $t$ test or Mann-Whitney $U$ test. To assess the influence of age, education, and disease duration on the results of assessments in the GCBS, we performed Pearson or Spearman correlation analysis. GCBS patients were subdivided into two groups, according to the PET-FDG result: CBS+ (suggestive of $A D$ as the underlying pathology, $n=7)$ and $C B S-(n=13)$. We made comparisons between sociodemographic and clinical characteristics, tests of cognitive 
screening, speech and language, and scales of functionality and severity of linguistic impairments. We calculated the proportion of patients in the GCBS, $\mathrm{CBS}+$, and CBS- who performed below the median of the CG in cognition, speech and language tests. Results: GCBS and CG differed in all cognition and language subtests, with lower scores for the GCBS. Among the patients, 57.9\% had speech apraxia and $21.05 \%$ was dysarthric. We found a positive correlation between disease duration and severity of speech disorders. A positive correlation was also found between schooling and total score on the cognitive screening test and a negative correlation between the same test and the disease duration. When comparing the CBS+ and CBS- groups in the cognitive screening test, there was a trend towards greater impairment of attention $(\mathrm{p}=0.057)$ and visuospatial abilities ( $p=0.051)$ in the CBS+ group. There was no statistical difference between groups in speech and language tests. Conclusions: Language impairments in patients with CBS are heterogeneous and cover all language networks. Regarding motor speech skills, patients also presented heterogeneous conditions. When comparing the CBS+ and CBS- groups, there was a trend towards greater impairment of attention and visuospatial abilities in the CBS+ group. In the language tests, there was no statistically significant difference between the groups.

Descriptors: Speech, Language, and Hearing Sciences. Language. Corticobasal syndrome. Aphasia. Apraxia of speech. Dysarthria. 


\section{INTRODUÇÃO}

A síndrome corticobasal é uma doença neurodegenerativa, progressiva, que provoca alterações motoras e cognitivas. Está classificada entre as síndromes parkinsonianas atípicas, isto é, síndromes em que há presença de parkinsonismo (bradicinesia associada a tremor de repouso, rigidez ou instabilidade postural), de evolução rápida e resposta pobre ou transiente à terapia dopaminérgica (Litvan, 2005). Uma característica típica da SCB é a apresentação dos sintomas motores, que costuma ser marcadamente assimétrica (Chahine et al., 2014). De modo geral, é uma síndrome de difícil diagnóstico por causa de sua heterogeneidade clínica, patológica, radiológica e neuropsicológica (Parmera et al., 2016).

Os termos "síndrome corticobasal" e "degeneração corticobasal" (DCB) representam diferentes entidades. A primeira refere-se ao fenótipo clínico, enquanto a DCB é uma entidade patológica, que afeta regiões corticais e subcorticais, cujo diagnóstico é dado unicamente por análise anatomopatológica post-mortem (Parmera et al., 2016). Estima-se que, dos pacientes com sintomas clínicos de SCB, 50\% tenham diagnóstico post-mortem de DCB. Nos demais pacientes, geralmente são encontradas taupatias, como paralisia supranuclear progressiva (PSP), demência frontotemporal (DFT), doença de Pick e demência com corpos de Lewy, ou patologia amiloide, como doença de Alzheimer (DA). Por outro lado, a DCB é frequentemente encontrada em pacientes com diagnóstico clínico de outras síndromes (Grijalvo-Perez; Litvan, 2014; Burrell; Hodges; Rowe, 2014; Parmera et al., 2016; Oliveira et al., 2017). Tendo em vista essa heterogeneidade clínico-patológica, há um crescente interesse na busca por biomarcadores que auxiliem no diagnóstico antemortem da patologia de base da SCB (Zalewski et al., 2014; Parmera et al., 2016; Beyer et al., 2018). Exames de neuroimagem funcional, como a tomografia por emissão de pósitrons com marcador fluorodeoxiglicose (PET-FDG), têm sido utilizados como potenciais biomarcadores (Ali; Josephs, 2018). Um estudo recente mostrou que pacientes com SCB e diagnóstico neuropatológico post-mortem de DCB, PSP e DA 
apresentavam diferentes padrões de hipometabolismo, verificados em exames de PET-FDG (Pardini et al., 2019).

Desde sua descrição inicial, muitos critérios diagnósticos têm sido empregados para a SCB. Os critérios de Armstrong et al. (2013), amplamente utilizados, determinam a "SCB provável" quando há pelo menos dois dos seguintes sintomas motores, com apresentação assimétrica: [a] rigidez ou acinesia de membros; [b] distonia de membros; [c] mioclonia de membros; em associação com ao menos dois dos seguintes sintomas cognitivos: [d] apraxia orobucolingual ou de membros; [e] déficits sensoriais corticais; [f] fenômeno da mão alienígena.

Diferentemente do que se acreditava à época das primeiras publicações, alterações de fala e linguagem, bem como déficits em outras funções cognitivas, são bastante frequentes na SCB, e podem contribuir com o diagnóstico clínico (Kertesz; McMonagle, 2010; Mathew; Bak; Hodges, 2012; Peterson; Patterson; Rowe, 2019). Entretanto, o perfil de linguagem desses pacientes ainda é inconclusivo. Estudos mostram uma grande variabilidade de perfis linguísticos: um tipo misto de afasia, abrangendo características da afasia progressiva primária logopênica (APP-L) e da afasia progressiva primária semântica (APPS) (Di Stefano et al., 2016), afasia progressiva primária não-fluente (APP-nf) (Graham et al., 2003; McMonagle; Blair; Kertesz, 2006; Josephs; Duffy, 2008; Shelley et al., 2009; Abe et al., 2016; Dodich et al., 2019), afasia de Broca, afasia anômica e afasia transcortical motora (Frattali et al., 2000).

Assim como ocorre com os exames de neuroimagem, também as características clínicas têm sido estudadas como possíveis biomarcadores, capazes de auxiliar no diagnóstico da patologia subjacente à SCB e, dentre essas características, está a linguagem. Um estudo associou a dificuldade na repetição de sentenças a pacientes com SCB decorrente de DA e a apraxia de fala a pacientes com SCB relacionada a taupatias (Burrell et al., 2013). Outro estudo identificou alterações de linguagem mais graves em pacientes sem DA, principalmente na nomeação de figuras e na compreensão de palavras (Di Stefano et al., 2016).

Não é de nosso conhecimento que tenham sido realizados estudos com a população brasileira que investiguem o perfil linguístico de pacientes com SCB. Desse modo, este estudo busca contribuir com o conhecimento sobre as 
manifestações clínicas da SCB, mais especificamente, com as alterações de fala e linguagem na população brasileira, colaborando assim com o diagnóstico clínico mais preciso.

Este estudo também buscou averiguar se fatores sociodemográficos (idade e escolaridade) e clínicos (tempo de duração da doença) impactam a fala e linguagem desses pacientes. Por fim, diante da heterogeneidade das patologias subjacentes à SCB, também se buscou investigar se há perfis distintos de alteração de fala e linguagem característicos de SCB decorrente de DA e SCB não decorrente de DA.

A hipótese do estudo é de que o perfil de fala e linguagem dos pacientes com SCB em geral seja heterogêneo, assim como as demais manifestações clínicas, e que pacientes com maior idade, menor escolaridade e maior tempo de doença apresentem manifestações mais graves. Quanto à diferenciação das alterações de fala e linguagem segundo a patologia subjacente, com base no estudo de Burrell et al. (2013), a hipótese é de que os pacientes com DA como doença de base apresentem mais dificuldade na repetição de sentenças, enquanto os pacientes com SCB não decorrente de DA apresentem mais alterações relativas à produção motora da fala. 
2. OBJETIVOS

\subsection{Objetivo primário}

Caracterizar a fala e a linguagem de pacientes com diagnóstico de SCB provável, em seus aspectos fonético-fonológicos, morfossintáticos, léxicosemânticos e de funcionalidade da comunicação, buscando um padrão sugestivo da síndrome corticobasal.

\subsection{Objetivos secundários}

1 - Verificar possíveis impactos de idade, escolaridade e duração da doença nas alterações de fala e linguagem nos pacientes com SCB.

2 - Caracterizar um possível padrão de alteração de fala e linguagem sugestivo da SCB decorrente da DA. 


\section{REVISÃO DE LITERATURA}

A seguir serão apresentados alguns dos trabalhos que serviram de fundamentação teórica para este estudo. Esses trabalhos serão apresentados priorizando o encadeamento de ideias e guardando, quando possível, a ordem cronológica.

\subsection{Histórico da SCB}

A síndrome corticobasal (SCB) é uma doença neurodegenerativa, progressiva, classificada entre as síndromes parkinsonianas atípicas. Foi descrita pela primeira vez em uma conferência da Associação Norte-Americana de Neurologia, em 1967, por Rebeiz, Kolodny e Richardson, que apresentaram três casos de pacientes com importantes alterações motoras e, em estágio final, cognitivas (Bak; Hodges, 2008). Os casos foram publicados no ano seguinte (Rebeiz; Kolodny; Richardson, 1968). Os autores consideraram que se tratava de uma doença predominantemente motora. Entretanto, a própria descrição inicial mostra alterações de comportamento, cálculo, memória, fala, linguagem e habilidades visuoespaciais nos três pacientes, ainda que menos graves que as alterações motoras (Rebeiz; Kolodny; Richardson, 1968; Bak; Hodges, 2008). A doença recebeu a denominação de "degeneração córtico-dentato-nigral com acromasia neuronal".

Novas séries de casos com as mesmas características só começaram a ser publicadas duas décadas depois. A ênfase nas alterações motoras predominou durante a década de 1980 e início da década seguinte, ainda que as séries com número maior de casos, publicadas nesse período, incluam pacientes com alterações cognitivas e comportamentais (Bak; Hodges, 2008). No final da década de 1990, um estudo (Grimes et al., 1999 apud Bak; Hodges, 2008) descreveu 13 pacientes com SCB, dentre os quais apenas um não apresentava demência. Outro estudo da mesma época (Bergeron et al., 1998 apud Bak; 
Hodges, 2008), realizado a partir de um grande banco de encéfalos de pacientes diagnosticados em vida com demência, mostrou que $22 \%$ desses pacientes tinham características patológicas da DCB. Com base nesses resultados, esses autores sugeriram que a demência deveria ser considerada parte da apresentação clínica da SCB. Estudos subsequentes procuraram detalhar quais aspectos da cognição eram afetados na SCB (Bak; Hodges, 2008).

Ao longo dos anos, diversas designações foram utilizadas para se referir à mesma síndrome: "degeneração córtico-dentato-nigral com acromasia neuronal", "degeneração corticonigral com acromasia neuronal", "degeneração gangliônica corticobasal" e "degeneração cortical-basal gangliônica" (Boeve, 2005; Armstrong; Litvan, 2015). O termo "degeneração corticobasal" (DCB) passou a ser utilizado após 1989 (Gibb; Luthert; Marsden, 1989). Diferentemente do que se imaginou à época das primeiras descrições da $\mathrm{DCB}$, hoje sabe-se que não se trata de uma única entidade clínico-patológica SCB-DCB. Portanto, atualmente utiliza-se a terminologia "degeneração corticobasal" para se referir à doença específica, cuja confirmação do diagnóstico só pode ser feita por análise anatomopatológica post-mortem, enquanto o termo "síndrome corticobasal" restringe-se ao fenótipo clínico, que pode ter diversas condições patológicas subjacentes. Este trabalho emprega essa nomenclatura.

\subsection{Epidemiologia da SCB}

O diagnóstico antemortem da DCB é bastante desafiador. Estudos mostram que $25 \%$ a $56 \%$ dos casos de DCB são diagnosticados corretamente em vida (Armstrong et al., 2013). É provável que a escassez de dados sobre a incidência e a prevalência da DCB deva-se a essa dificuldade (Mahapatra et al., 2004; Boeve, 2005; Bak; Hodges, 2008; Grijalvo-Perez; Litvan, 2014; Oliveira et al., 2017). Estima-se, no entanto, que a incidência seja de 0,6-0,9/100.000 habitantes ao ano, com prevalência de 4,9-7,3/100.000 habitantes e que a DCB corresponda a 4\%-6\% dos casos de parkinsonismo (Mahapatra et al., 2004; Bak; Hodges, 2008; Constantinides et al., 2019).

Com relação à epidemiologia da SCB, o número de estudos também é limitado e os resultados, muitas vezes, divergentes. Um estudo realizado em 
uma comunidade rural no Japão identificou a prevalência de 6/100.000 habitantes (Osaki et al., 2011) e um estudo conduzido no Reino Unido reportou a prevalência de 10,6/100.000 habitantes (Coyle-Gilchrist et al., 2016). Mais recentemente, um estudo conduzido em Genebra, na Suíça, encontrou a prevalência de $3 / 100.000$ habitantes (Fleury et al., 2018). Quanto à incidência da SCB, um estudo em um grande distrito de Moscou encontrou a incidência de 0,02/100.000 habitantes ao ano (Winter et al., 2010).

A SCB tem início entre a quinta e a sétima décadas de vida. A média de idade de acometimento é de 63 anos e a sobrevida é, em média, de 6 a 8 anos. Não há evidências de que a SCB afete de forma diferente um dos sexos (Wenning et al., 1998; Wadia; Lang, 2007; Kouri et al., 2011; Oliveira et al., 2017).

\subsection{Características clínicas e critérios diagnósticos da SCB}

Em relação às características clínicas, pacientes com SCB podem apresentar sintomas motores e cognitivos. Classicamente, os sintomas motores ocorrem de modo assimétrico e incluem parkinsonismo rígido-acinético, distonia e movimentos mioclônicos. Os sintomas cognitivos incluem apraxia, afasia, déficits sensoriais corticais e o fenômeno da mão alienígena (Kertesz; McMonagle, 2010; Chahine et al., 2014; Parmera et al., 2016).

O parkinsonismo tende a se manifestar no início da doença e apresenta-se como síndrome rígido-acinética em um dos membros superiores, embora possa ocorrer em membros inferiores também. Com a progressão da doença, pode afetar o membro superior contralateral ou o membro inferior ipsilateral e, no estágio final da SCB, os quatro membros podem estar afetados (Bak; Hodges, 2008). A distonia é uma manifestação frequente na SCB, presente em cerca de $40 \%$ dos pacientes. Afeta, inicialmente, um dos membros superiores (Stover; Walker; Watts, 2007; Parmera et al., 2016; Constantinides et al., 2019). Os movimentos mioclônicos, frequentemente, iniciam-se em segmentos distais de um dos membros superiores e podem apresentar-se como primeiro sintoma da SCB, afetando de $55 \%$ a $93 \%$ dos pacientes (Boeve, 2005; Stover; Walker; Watts, 2007; Parmera et al., 2016). A terapia com levodopa tem pouco efeito sobre esses sintomas (Boeve, 2005; Parmera et al., 2016; Constantinides et al., 2019). 
Quanto às manifestações cognitivas, a apraxia ideomotora é considerada um sintoma clássico, presente em $86 \%$ dos casos (Parmera et al., 2016), porém outros tipos de apraxia podem estar presentes, como a apraxia ideacional e a apraxia de fala (Stover; Walker; Watts, 2007). O fenômeno da mão alienígena refere-se a movimentos involuntários realizados, normalmente, por um dos membros superiores, embora possa ocorrer também em membros inferiores (Bak; Hodges, 2008). Os pacientes percebem o membro afetado como "incontrolável", como se não Ihes pertencesse (Boeve, 2005; Constantinides et al., 2019). Os déficits sensoriais corticais manifestam-se, na maioria dos casos, como agrafestesia, astereognosia e dificuldade na discriminação de dois pontos, na ausência de déficits sensoriais primários (Boeve, 2005). A presença da afasia e da apraxia de fala serão discutidas mais detalhadamente na seção 3.5.

Estudos mostram que nem as características motoras nem as cognitivas são suficientes para distinguir a doença de base (Parmera et al., 2016; Pardini et al., 2019).

Desde que foi descrita, muitos critérios têm sido publicados para 0 diagnóstico da SCB. O mais recente, proposto por Armstrong et al. (2013), determina a "SCB provável" quando há pelo menos dois dos seguintes sintomas motores, com apresentação assimétrica:

[a] rigidez ou acinesia de membros;

[b] distonia de membros;

[c] mioclonia de membros;

em associação com ao menos dois dos seguintes sintomas cognitivos:

[d] apraxia orobucolingual ou de membros;

[e] déficits sensoriais corticais;

[f] fenômeno da mão alienígena.

Para o diagnóstico de "SCB possível" não é necessário haver assimetria dos sintomas motores e é necessária a detecção de apenas um sintoma motor e um sintoma cognitivo dentre os sintomas mencionados acima (Armstrong et al., 2013).

Já em relação à detecção clínica da $\mathrm{DCB}$, os mesmos autores propõem que sejam aceitos três fenótipos para "DCB provável": SCB provável, APP-nf e síndrome frontal-comportamental, sendo que, nesses dois últimos fenótipos, deve haver ao menos um sintoma da SCB. Para "DCB possível", aceita-se também o 
fenótipo da síndrome de Steele-Richardson-Olszewski (ou PSP). Tanto para DCB provável quanto possível, é necessário haver início insidioso e progressão gradual e ao menos um ano de duração dos sintomas (Armstrong et al., 2013).

\subsection{Neuroimagem e biomarcadores da SCB}

As primeiras publicações sobre a DCB sugeriram que se tratava de uma entidade clínico-patológica única SCB-DCB. Entretanto, estudos subsequentes foram demonstrando que a SCB poderia ser a manifestação clínica de diversos processos patológicos, além da DCB, e, por sua vez, a DCB poderia ser a doença subjacente a outras síndromes (Boeve, 2005; Bak; Hodges, 2008).

Tendo em vista essa heterogeneidade clínico-patológica, há um crescente interesse na busca por biomarcadores que auxiliem no diagnóstico antemortem da patologia de base da SCB (Zalewski et al., 2014; Parmera et al., 2016; Beyer et al., 2018). Exames de neuroimagem estrutural e funcional, como a ressonância magnética e a tomografia por emissão de pósitrons com marcador fluorodeoxiglicose (PET-FDG) têm sido utilizados como potenciais biomarcadores (Ali; Josephs, 2018).

Estudos a partir de ressonância magnética investigaram os padrões de atrofia cortical em pacientes com SCB e diagnóstico post-mortem de DA, DCB, PSP e degeneração lobar frontotemporal associada à proteína TDP-43 (DLFTTDP-43). Todos os pacientes apresentavam atrofia nos córtices pré-motor, área motora suplementar e ínsula. Os pacientes com DA e DLFT-TDP-43 apresentavam um padrão mais difuso de atrofia cortical e, nos casos de DLFTTDP-43, havia maior acometimento das regiões pré-frontais e temporais posteriores. Nos pacientes com DA, as regiões mais acometidas foram parietais, temporais posteriores e occipitais (Parmera et al., 2016).

Albrecht e colaboradores (2017), em um estudo de revisão envolvendo ressonância magnética em pacientes com SCB-DCB, mostraram que a atrofia em áreas pré-motora/motora suplementar e no córtex frontal medial/giro do cíngulo médio posterior são possíveis biomarcadores para DCB.

A tomografia com emissão de pósitrons com fluorodeoxiglicose ${ }^{18} \mathrm{~F}$ é uma técnica de neuroimagem que quantifica o metabolismo de glicose no cérebro 
(Moghbel; Newberg; Alavi, 2016). Uma revisão sistemática sobre a utilização desse exame no diagnóstico de síndromes parkinsonianas atípicas mostrou que, na SCB, O PET-FDG resulta em hipometabolismo no córtex contralateral ao hemicorpo mais afetado, envolvendo córtex parietal, sensório-motor primário, áreas pré-motoras mediais e laterais, estriado e tálamo. Os autores concluem que o PET-FDG é um exame que traz contribuições importantes para a distinção das síndromes parkinsonianas atípicas, com boa acurácia (Niccolini; Politis, 2016).

Um estudo recente buscou associar o diagnóstico neuropatológico postmortem com o padrão de hipometabolismo em pacientes com SCB a partir do exame de PET-FDG. Foram incluídos 29 pacientes, sendo 14 SCB-DCB, 5 SCBPSP e 10 SCB-DA. O grupo com SCB-DCB apresentou um padrão assimétrico de hipometabolismo em região frontoparietal perisylviana, córtex de associação frontoparietal, tálamo e núcleo caudado e, no hemisfério menos afetado, córtex motor. Já nos pacientes com SCB-DA, observou-se um padrão de hipometabolismo assimétrico em região têmporo-parietal posterior, no giro do cíngulo posterior e no pré-cúneo. Quanto ao grupo com SCB-PSP, o hipometabolismo mais marcado abrangeu regiões mais anteriores: giro frontal médio, cíngulo médio e anterior e núcleo caudado. A única região de hipometabolismo comum aos três grupos foi o giro pré-central. Desse modo, os autores confirmaram que o exame de PET-FDG é uma ferramenta importante na distinção da patologia subjacente à SCB (Pardini et al., 2019).

\subsection{Fala e linguagem na SCB}

Parte dos estudos que se dedicaram a avaliar a fala e a linguagem de pacientes com SCB aponta para um quadro compatível com a APP-nf, ou seja, alterações no nível morfossintático, diminuição da fluência e apraxia de fala (Shelley et al., 2009; Abe et al., 2016; Dodich et al., 2019); outros mostram um padrão misto, que engloba características de mais de um tipo de APP (Burrell et al., 2013; Di Stefano et al., 2016).

Dentre os artigos consultados, parte teve como objetivo mostrar que há uma sobreposição entre a SCB e a DFT. Kertesz e colaboradores (2000) realizaram um estudo retrospectivo com 35 pacientes com SCB, dos quais 15 
iniciaram com sintomas extrapiramidais, desenvolvendo posteriormente os sintomas cognitivos e linguísticos, e 20 iniciaram com sintomas cognitivos (APP$\mathrm{nf}=13$ e DFT $=7$ ), apresentando posteriormente acometimento motor. Dos 35 pacientes, 21 foram avaliados quanto às habilidades de fala e linguagem, utilizando o teste Western Aphasia Battery (WAB). A maior parte dos pacientes apresentou alterações de linguagem, que se iniciavam com dificuldades do tipo "word finding", isto é, dificuldade no acesso lexical durante o discurso. Os autores não detalham a natureza das alterações no curso da doença.

Outros dois estudos trataram da sobreposição entre SCB e DFT. GornoTempini e colaboradores (2004) reportaram o caso de uma paciente diagnosticada inicialmente com APP-nf, por meio de avaliações de linguagem bastante detalhadas, que evoluiu gradativamente com sintomas motores, preenchendo critério para SCB.

McMonagle, Blair e Kertesz (2006) realizaram um estudo retrospectivo, com 55 pacientes com SCB, divididos em dois grupos, de acordo com o sintoma inicial (motor $=19$ ou cognitivo $=36$ ). Dezessete dos dezenove pacientes com acometimento motor inicial desenvolveram alterações linguísticas no decorrer da doença, e todos os pacientes com alterações cognitivas iniciais desenvolveram alterações motoras. Inicialmente, as alterações de linguagem indicavam um quadro de afasia anômica para a maior parte dos pacientes dos dois grupos. Nas avaliações subsequentes, o quadro evoluiu para afasia de Broca para a maior parte, mostrando um percurso semelhante ao das APP-nf.

Dois estudos do mesmo período tiveram como objetivo principal a caracterização da fala e da linguagem de pacientes com SCB. O primeiro contou com 15 pacientes com SCB e identificou alterações de linguagem em oito pacientes, sendo predominantes: diminuição da fluência na fala espontânea e alteração na fluência verbal semântica. A nomeação de objetos estava comprometida em seis pacientes. Nenhum paciente apresentou dificuldade de compreensão de linguagem oral. Os pacientes foram classificados como tendo afasia anômica, afasia de Broca e afasia transcortical motora (Frattali et al., 2000).

O segundo estudo, com 10 pacientes, avaliou habilidades de leitura, soletração, nomeação, compreensão de palavras, consciência fonológica, associação semântica e fluência verbal fonêmica e semântica. Os autores 
encontraram alterações de linguagem principalmente nas provas de consciência fonológica, soletração e fluência verbal, sugerindo comprometimentos linguísticos relacionados ao processamento fonológico (Graham et al., 2003).

Aspectos específicos da linguagem foram investigados por uma série de estudos que incluíram pacientes com SCB. Cotelli e colaboradores (2006) compararam o processamento de verbos em oposição ao de substantivos em pacientes com SCB, PSP, APP-nf, APP-S e DFT variante comportamental (DFTvc). A avaliação de linguagem foi restrita a testes de compreensão e nomeação de verbos e substantivos, não sendo testadas as habilidades de repetição, compreensão oral de sentenças, memória semântica, leitura e aspectos motores da fala. Os resultados mostraram maior comprometimento no processamento de verbos em comparação com o processamento de substantivos em todos os pacientes, sobretudo naqueles com APP-nf, PSP e SCB.

Outro estudo do mesmo grupo (Cotelli et al., 2007) investigou o processamento sintático em pacientes com DFT-vc, APP-S, PSP e SCB, por meio de uma tarefa de identificação de estruturas que violam princípios da Gramática Universal. Apenas o subgrupo com SCB apresentou déficit no conhecimento sintático.

Três trabalhos do mesmo grupo investigaram a compreensão e a expressão de quantificadores (vocábulos que antecedem os substantivos, trazendo informação sobre quantidade) em pacientes com SCB. McMillan e colaboradores (2006) avaliaram 16 pacientes com SCB comparados a pacientes com DFT (sem especificar o subtipo) e DA em uma tarefa de compreensão de quantificadores. Os pacientes com SCB mostraram comprometimento nessa habilidade.

Troiani, Clark e Grossman (2011) realizaram um estudo semelhante, porém, utilizando um material para testar a compreensão de quantificadores que minimizava a demanda por habilidades visuoespaciais, em 11 pacientes com SCB, comparados a controles saudáveis e com outras doenças (DA e DFT). Os pacientes com SCB apresentaram desempenho significativamente inferior na tarefa em comparação aos controles.

O estudo de Ash e colaboradores (2016) avaliou a produção de quantificadores e o uso de substantivos no discurso de pacientes com SCB, DFT- 
vc e APP-S. Os grupos com SCB e DFT-vc mostraram comprometimento na utilização de quantificadores, mas não na utilização de substantivos, e o grupo com APP-S apresentou padrão inverso. Nos três estudos sobre quantificadores, os pacientes não eram afásicos como critério de inclusão, e foram testados em relação a poucas habilidades linguísticas.

A relação entre as características clínicas da SCB e a doença de base tem sido explorada em uma série de estudos. No trabalho de Borroni e colaboradores (2011), 30 pacientes com SCB foram divididos em dois grupos, de acordo com os resultados do exame de líquor (sugestivo de DA e não sugestivo de DA). Os grupos foram comparados quanto a caraterísticas clínicas e neuropsicológicas. O grupo com DA provável apresentou maior comprometimento nos testes de memória e linguagem e o outro grupo apresentou alterações extrapiramidais mais graves. A avaliação de linguagem, no entanto, foi restrita a um teste de compreensão verbal (Token Test).

Outro estudo explorou a relação dos aspectos clínicos com a patologia de base a partir de tomografia com emissão de pósitrons utilizando marcador para amiloide (PET-PiB), com 14 pacientes diagnosticados com SCB. Os autores encontraram alterações linguísticas como sintoma inicial em $71,4 \%$ dos pacientes, sendo as mais frequentes, em ordem decrescente: repetição de palavras, disgrafia, trocas fonológicas em fala espontânea, repetição de sentenças e dificuldade do tipo "word finding". O grupo com PET-PiB positivo apresentou dificuldade mais acentuada na repetição de sentenças, o que é característico da APP-L, cuja patologia subjacente é tipicamente a DA. Com base nesses achados, os autores relacionaram a dificuldade na repetição de sentenças à maior probabilidade de a doença de base ser DA (Burrell et al., 2013).

As funções cognitivas e linguísticas e a presença da patologia da DA foram também investigadas em um estudo com 45 pacientes com SCB. Sintomas de linguagem constituíram a queixa inicial em $69 \%$ dos pacientes e, à época da avaliação, estavam presentes em $95 \%$. Alterações de linguagem foram encontradas com maior frequência nas tarefas de: fluência verbal fonêmica e semântica ( $85 \%$ e $69 \%$ dos pacientes), repetição de sentenças (73\%), compreensão de palavras (52\%) e nomeação de figuras (45\%). Na análise qualitativa, os autores identificaram parafasias fonêmicas (52\%) e agramatismo 
(41\%). Quanto aos aspectos motores da fala, foram identificadas: apraxia de fala $(50 \%)$, apraxia orobucofacial $(61 \%)$ e disartria $(37 \%)$. Os pacientes foram subdivididos em dois grupos, de acordo com a presença ou ausência da assinatura da patologia de DA pela análise liquórica, respectivamente $\mathrm{SCB}+\mathrm{e}$ SCB-. O grupo SCB+ apresentou correlação positiva com a síndrome de Gerstmann (disgrafia, acalculia, agnosia digital e confusão direita-esquerda) e o grupo SCB- apresentou alterações linguísticas mais graves, sobretudo em nomeação de figuras e compreensão de palavras, características essas indicativas de APP-S. Os autores consideraram a presença da síndrome de Gerstmann um bom preditor da patologia DA, com boa sensibilidade e especificidade. Os autores assumiram que a afasia deve ser considerada como um sintoma cognitivo prevalente na SCB, ainda que não haja clareza sobre o subtipo de afasia (Di Stefano et al., 2016).

Turaga, Mridula e Borgohain (2013) exploraram as características cognitivas e de neuroimagem em 17 pacientes com SCB. Os autores encontraram alterações principalmente em funções executivas. Entretanto, a avaliação de linguagem se restringiu ao subteste de nomeação de figuras do Addenbrooke's Cognitive Examination Revised (ACE-R).

Um estudo retrospectivo, com 38 pacientes com SCB, procurou correlacionar a presença de sintomas motores no hemicorpo direito com a presença de afasia e/ou disartria. Dezesseis pacientes apresentaram sintomas compatíveis com o diagnóstico de afasia e nenhum apresentou quadro característico de disartria. Dentre os 16 pacientes afásicos, apenas dois apresentavam acometimento motor predominante no hemicorpo esquerdo, sendo que, em um deles, os exames demonstraram atrofia predominante no hemisfério esquerdo e alterações metabólicas bilateralmente, com predomínio no hemisfério direito. $\mathrm{O}$ outro paciente afásico e com comprometimento motor à esquerda apresentava atrofia no hemisfério direito e alterações metabólicas bilateralmente, com predomínio no hemisfério direito. Em resumo, todos os pacientes afásicos possuíam acometimento do hemisfério esquerdo. Os autores encontraram correlação positiva entre afasia e acometimento motor do hemicorpo direito. Não foram verificadas as características das afasias (Levin et al., 2015). 
Abe e colaboradores (2016) estudaram a relação entre alterações de linguagem na SCB e o padrão de perfusão cerebral, por meio de tomografia computadorizada por emissão de fóton único (SPECT). Foram incluídos 26 pacientes com SCB, divididos em dois grupos, aqueles com alterações linguísticas $(n=9)$ e aqueles sem alterações linguísticas $(n=17)$. A avaliação de linguagem foi realizada por meio de um teste abrangente, que identificou as seguintes alterações: hesitações, distorções, trocas fonêmicas e dificuldades na escrita, caracterizando um quadro de APP-nf nos nove pacientes, não sendo mencionadas diferenças entre eles. Dos nove pacientes afásicos, oito tinham acometimento motor predominante à direita e hipoperfusão em regiões perisylvianas.

Um estudo recente (Dodich et al., 2019) investigou a correlação entre o padrão de hipometabolismo no PET-FDG e as alterações linguísticas, partindo da hipótese de que pacientes com fenótipo de APP-nf apresentariam um padrão metabólico semelhante. O estudo incluiu 33 pacientes com SCB e 37 com PSP. Após uma avaliação abrangente de linguagem, os pacientes foram classificados em três grupos: alterações linguísticas compatíveis com APP-nf (SCB $=12$ e PSP = 9), outras alterações linguísticas ( $S C B=12$ e PSP $=8)$ e sem alterações de linguagem. O grupo com outras alterações de linguagem, que não a APP-nf, apresentavam anomia, circunlóquios, déficit na compreensão verbal e dificuldade na repetição de sentenças. Os pacientes com APP-nf tinham um padrão comum de hipometabolismo, envolvendo o giro frontal inferior e o córtex motor suplementar no hemisfério esquerdo; os pacientes com outras alterações de linguagem tinham padrões metabólicos diversos e os pacientes sem alterações de linguagem tinham hipometabolismo predominante no hemisfério direito.

Dois relatos de caso ilustram a heterogeneidade clínico-patológica da SCB. Sakurai e colaboradores (2013) reportaram o caso de uma paciente com SCB, com agrafia apráxica e micrografia, inicialmente sem outras alterações de linguagem, verificadas após uma avaliação abrangente. O exame de PET-FDG foi sugestivo de DA como patologia de base.

Dois casos de pacientes que iniciaram o quadro com déficits progressivos de linguagem e evoluíram com sintomas clássicos de SCB foram reportados por Caso e colaboradores (2012). A primeira paciente, diagnosticada inicialmente 
com APP-L, apresentava discurso com pausas frequentes em decorrência da dificuldade de acesso lexical, trocas fonológicas em vocábulos polissílabos, repetição de sentenças prejudicada e estruturação gramatical e nomeação preservadas. Posteriormente, surgiram os sintomas motores e cognitivos, indicativos de SCB. A segunda paciente tinha um histórico de quatro anos de déficits de linguagem, com discurso não fluente, distorções e trocas fonêmicas e simplificação de estruturas sintáticas. Na evolução do quadro, sua fala tornou-se telegráfica e dificultosa, com impacto importante na prosódia. A compreensão de fala estava alterada para estruturas complexas e a paciente podia repetir apenas monossílabos de alta frequência. Ela foi diagnosticada com APP-nf e apraxia de fala, evoluindo com sintomas motores e cognitivos, sugestivos de SCB.

Essa breve revisão mostra que o perfil de fala e linguagem dos pacientes ainda é inconclusivo. Como mencionado, o fenótipo da APP-nf é encontrado com alguma frequência. Os déficits de repetição de sentenças vêm sendo associados à DA como doença de base. Há ainda casos em que os pacientes apresentam alterações compatíveis com a APP-S, como dificuldade na nomeação de figuras e na compreensão de palavras. Além disso, alguns dos estudos mencionados, não tão recentes (Frattali et al., 2000; Graham et al., 2003), avaliaram a linguagem sob a perspectiva sindrômica das afasias causadas por acidente vascular cerebral (AVC), nas quais a lesão é abrupta e focal. Nas doenças neurodegenerativas, por outro lado, determinadas regiões corticais são afetadas de forma parcial e gradual, de modo que parte dos neurônios continua atuando na rede de linguagem. Sendo assim, os pacientes com doenças neurodegenerativas dificilmente se encaixam nos padrões sindrômicos das afasias decorrentes de AVC (Mesulam et al., 2014a).

\subsection{Atenção, memória e funções executivas na SCB}

Atenção, memória e funções executivas são habilidades cognitivas relacionadas ao lobo frontal que têm forte interação com a linguagem (Radanovic et al., 2003; Helm-Estabrooks, 2011; Murray, 2012).

As funções executivas compreendem um conjunto de habilidades cognitivas que são requisitadas quando se está diante de uma situação nova, não rotineira (Meulemans, 2006). São habilidades necessárias para o planejamento de 
ações, resolução de problemas, tomada de decisões, avaliação da eficiência da ação, mudança de estratégia, entre outras (Malloy-Diniz et al., 2008). Essas habilidades atuam de forma integrada, e envolvem ao menos três conjuntos de habilidades centrais: controle inibitório, que é a capacidade de inibir respostas prepotentes, de controlar a atenção, o comportamento, os pensamentos e as emoções, suprimindo informações irrelevantes; a memória operacional, que permite o armazenamento temporário e a manipulação de informações visuais e/ou auditivas; e flexibilidade mental, que se refere à capacidade de se adaptar às exigências do ambiente, modificando o curso das ações (Malloy-Diniz et al., 2008; Diamond, 2013).

Estudos com afásicos pós-AVC mostram que prejuízos na memória operacional verbal e nos mecanismos de atenção podem ocasionar dificuldades de repetição e de compreensão de sentenças, principalmente sentenças sintaticamente complexas (Radanovic et al., 2003). Até mesmo a compreensão de palavras pode sofrer impacto de déficits de memória operacional e atenção, a depender do tipo de tarefa solicitada. Helm-Estabrooks (2011) demonstrou que pacientes com déficits graves de compreensão auditiva tinham pior desempenho na compreensão de palavras quando solicitados a apontar para um objeto na sala do que quando precisavam apontar para uma figura do mesmo objeto localizada à sua frente. A autora interpretou esses resultados, em parte, como reflexos de alterações na memória operacional e na atenção, uma vez que o paciente precisa da memória operacional para manter a palavra enquanto busca o objeto, e da atenção para encontrar o objeto entre diversos distratores.

Déficits em funções executivas e mecanismos de atenção, como dificuldades na definição da meta, no controle inibitório de respostas inadequadas e no automonitoramento, podem resultar em alterações em nível discursivo, com impacto em micro e macroestrutura (Kurland, 2011).

A literatura a respeito da SCB mostra déficits consistentes em funções cognitivas relacionadas ao lobo frontal (Pillon et al., 1995; Dubois et al., 2000; Graham; Bak; Hodges, 2003; Mathew; Bak; Hodges, 2011; Burrell; Hodges; Howe, 2014; Grijalvo-Perez; Litvan, 2014). Embora não se saiba a frequência exata, estima-se que ao menos $50 \%$ dos pacientes tenham alterações envolvendo funções executivas (Kertesz; McMonagle, 2010). Estudos que utilizaram testes 
para avaliar funções executivas, como Wisconsin Card Sorting Test e Trail-making Test, mostram resultados abaixo dos valores normativos. Testes de fluência verbal semântica e fonêmica, que avaliam tanto habilidades linguísticas quanto de funções executivas e atenção (Henry; Crawford, 2004; Peterson; Patterson; Rowe, 2019), têm o maior número de estudos evidenciando déficits nessa população (Graham; Bak; Hodges, 2003; Bak; Hodges, 2008). No entanto, não se sabe ao certo quais aspectos das funções executivas estão prejudicados em pacientes com SCB (Graham; Bak; Hodges, 2003).

Há poucos estudos que avaliaram a memória episódica em pacientes com SCB, e os resultados são ainda inconsistentes. Um estudo com 15 pacientes com DCB comprovada por análise anatomopatológica mostrou que a memória episódica se manteve relativamente preservada nesses pacientes ao longo de todo o percurso da doença. Curiosamente, os autores comentam que, apesar de os testes não apontarem para prejuízos importantes nessa habilidade, a memória constava como uma das queixas mais comuns entre pacientes e cuidadores (Murray et al., 2007).

Outro estudo comparou um grupo de pacientes com DFT-vc a um grupo com SCB em relação a funções executivas e memória. Ambos os grupos tiveram pior desempenho nas funções executivas em comparação com os testes de memória (Wechsler Memory Scale). O grupo com DFT-vc mostrou maior comprometimento das funções executivas do que o grupo com SCB, com exceção dos testes que demandavam habilidades motoras e/ou visuoespaciais. Também em relação aos testes de memória, os pacientes com DFT-vc tiveram pior desempenho do que o grupo com SCB, mostrando que essa habilidade pode estar preservada nesses pacientes (Huey et al., 2009).

Acredita-se que os déficits de memória episódica sejam leves e alguns autores sugerem que esses podem estar relacionados a uma dificuldade no uso de estratégias de codificação e acesso à informação (Graham; Bak; Hodges, 2003; Oliveira et al., 2017). 


\subsection{Relação entre habilidades linguísticas, idade e escolaridade}

Habilidades de linguagem e nível socioeducacional estão fortemente correlacionados. São observadas diferenças na estrutura sintática, que é simplificada em indivíduos de baixa escolaridade, e na fluência de fala, sendo que indivíduos de baixa escolaridade apresentam mais disfluências. Além disso, ao se comunicarem com crianças, pessoas de baixa escolaridade apoiam-se mais em estratégias não-verbais do que verbais (Ardila et al., 2010).

Estudos que compararam o desempenho de pessoas alfabetizadas e não alfabetizadas em testes de linguagem encontraram diferenças em fluência verbal semântica e, principalmente, fonêmica, tarefa em que os analfabetos apresentam muita dificuldade. A repetição, quando envolve apenas palavras de alta frequência, não diferencia os grupos. Porém, quando os estímulos são nãopalavras, pseudopalavras ou palavras de baixa frequência, os analfabetos têm desempenho inferior (Mansur; Radanovic, 2004; Ardila et al., 2010).

A escolaridade, ou o grau de letramento, influencia outras habilidades cognitivas, intrinsecamente relacionadas à linguagem, como memória operacional, consciência fonológica, funções executivas e habilidades visuoespaciais (Rosselli; Ardila, 2003; Mansur; Radanovic, 2004; Mousinho; Correa, 2009; Ardila et al., 2010).

Estudos com neuroimagem funcional mostram que a escolaridade pode ter influência sobre quais redes neurais são utilizadas em tarefas que envolvem funções executivas e linguagem. Exames de neuroimagem estrutural, por sua vez, apontam para diferenças morfológicas em determinadas áreas cerebrais, como o corpo caloso, na comparação entre pessoas de alta e baixa escolaridade (Ardila et al., 2010).

Portanto, de modo geral, o grau de escolaridade exerce influência em testes neuropsicológicos e deve sempre ser observado (Rosselli; Ardila, 2003).

No que diz respeito à influência da idade sobre aspectos da linguagem, são observadas diferenças sutis em algumas habilidades enquanto outras permanecem preservadas (Parente et al., 1999; Mansur; Radanovic, 2004; Obler; Pekkala, 2008). A fonologia é um aspecto da linguagem que permanece preservado ao longo da vida. Já as habilidades sintáticas podem declinar no envelhecimento. Estudos mostram que o discurso dos idosos pode conter um 
menor número de estruturas sintáticas complexas, em comparação a falantes jovens, o que estaria relacionado a alterações na memória operacional. Estruturas sintáticas complexas, com orações subordinadas, aumentam a demanda da memória operacional, pois é necessário armazenar uma grande quantidade de itens, como concordância verbal, escolha pronominal, ordenação linear de adjetivos. Sabe-se que há um declínio da memória operacional com o envelhecimento, que pode ocasionar uma simplificação das estruturas sintáticas (Brandão, 2006). Em relação às habilidades lexicais, o principal déficit é no resgate de palavras, dificuldade conhecida como "fenômeno da ponta da língua" (Parente et al., 1999; Mansur; Radanovic, 2004; Brandão, 2006; Obler; Pekkala, 2008). Estudos que utilizaram provas de nomeação de figuras com idosos saudáveis mostram que palavras menos frequentes são mais difíceis de serem resgatadas, e essa dificuldade estaria ligada a um déficit no acesso à informação fonológica, já que esses sujeitos se beneficiam da pista fonológica, e não da pista semântica (Brandão, 2006). Na produção discursiva, alguns idosos apresentam uma característica denominada "verbosidade fora de tópico", que se manifesta como uma fala excessiva, com mudanças súbitas e repentinas de tópico (Brandão, 2006). Em tarefas de recontagem de história, idosos tendem a ser mais concisos que os mais jovens, ao passo que, ao narrar uma história livremente, idosos são mais prolixos, menos objetivos e menos eficientes (Mansur; Radanovic, 2004; Obler; Pekkala, 2008).

A compreensão de palavras mantém-se preservada no idoso saudável, podendo haver, inclusive, um aumento do vocabulário decorrente da experiência linguística (Fonseca; Parente, 2006; Obler; Pekkala, 2008). Já a compreensão de sentenças longas e sintaticamente complexas declina em comparação aos jovens, assim como a compreensão de textos, sobretudo quando esses exigem inferências complexas. Essas dificuldades não são decorrentes de alterações puramente linguísticas, mas de mudanças em outras habilidades cognitivas, diretamente relacionadas à linguagem, como atenção, memória, velocidade do processamento e mudanças no processamento auditivo central (Mansur; Radanovic, 2004; Fonseca; Parente, 2006; Obler; Pekkala, 2008). 


\section{MÉTODOS}

\subsection{Aspectos éticos}

Esta pesquisa foi aprovada pela Comissão de Ética para Análise de Projetos de Pesquisa (CAPPesq) do Hospital das Clínicas da Faculdade de Medicina da Universidade de São Paulo (HCFMUSP), em 28 de novembro de 2018, CAEE: 02874318.9.0000.0068 (Anexo A).

\subsection{Casuística}

Foram constituídos dois grupos de sujeitos: o grupo de pacientes com SCB (GSCB) e o grupo-controle (GC), formado por sujeitos cognitivamente saudáveis.

O GSCB foi composto por pacientes com diagnóstico clínico prévio de SCB provável, sem restrição de idade ou escolaridade. Os pacientes foram provenientes de um estudo conduzido no Grupo de Neurologia Cognitiva e do Comportamento (GNCC) do Departamento de Neurologia da Faculdade de Medicina da Universidade de São Paulo, denominado "Síndrome corticobasal: estudo longitudinal dos perfis clínicos e fisiopatológicos". CAAE: 67195517.4.0000.0068.

O GC foi composto por sujeitos voluntários, cognitivamente saudáveis, pareados em idade e escolaridade com o GSCB, e recrutados entre familiares de pacientes e pessoas da comunidade em que está inserido o HCFMUSP.

\subsubsection{Critérios de inclusão e exclusão}

Foram definidos como critérios de inclusão para o GSCB: ter o diagnóstico de SCB provável, português como língua materna, visão e audição funcionais (dentro da normalidade ou corrigidas), e concordância quanto aos termos da pesquisa.

Para o GC, os critérios de inclusão foram: ter o português como língua materna, idade e escolaridade pareadas ao GSCB, visão e audição funcionais 
(dentro da normalidade ou corrigidas), atender aos critérios estabelecidos pelo questionário Estudos Normativos de Idosos Americanos (Mayo Older American Normative Studies, MOANS) (Smith; Ivnik, 2003) (Anexo D), pontuação dentro dos limites da normalidade no ACE-R (Mioshi et al., 2006; Carvalho, 2009; César et al., 2017) (Anexo E) e concordância quanto aos termos da pesquisa.

Definiu-se como critério de exclusão para o GSCB a presença de outras doenças neurológicas e/ou psiquiátricas. Para o GC, os critérios de exclusão foram alterações cognitivas e/ou psiquiátricas e alterações significativas de fala e/ou linguagem.

Foram incluídos 20 pacientes no GSCB, que obedeciam a esses critérios. Quanto ao GC, foram avaliados 21 sujeitos e um foi excluído por apresentar alterações importantes na fala. Desse modo, ambos os grupos contam com 20 sujeitos.

Todos os sujeitos do GSCB e do GC assinaram o termo de consentimento livre e esclarecido (TCLE) (Anexo B) ${ }^{1}$.

\subsection{Materiais}

Os testes utilizados nas avaliações dos grupos estão listados no Quadro 1:

Quadro 1 - Testes que compõem as avaliações do GSCB e do GC

\begin{tabular}{|l|c|c|}
\hline \multicolumn{1}{|c|}{ Testes } & GSCB & GC \\
\hline $\begin{array}{l}\text { Estudos Normativos de Idosos Americanos (Mayo Older American Normative } \\
\text { Studies - MOANS) (Smith; Ivnik, 2003) (Anexo D) }\end{array}$ & & $\mathrm{x}$ \\
\hline $\begin{array}{l}\text { Exame Cognitivo de Addenbrooke - versão revisada (Addenbrooke's Cognitive } \\
\text { Examination-Revised - ACE-R) (Mioshi et al., 2006; Carvalho, 2009; César et al., } \\
\text { 2017) (Anexo E) }\end{array}$ & $\mathrm{x}$ & $\mathrm{x}$ \\
\hline $\begin{array}{l}\text { Bateria de Avaliação das Afasias de Western - versão revisada (Western Aphasia } \\
\text { Battery-Revised - WAB-R) (Kertesz, 2007) (Anexo F) }\end{array}$ & $\mathrm{x}$ & $\mathrm{x}$ \\
\hline $\begin{array}{l}\text { Base unificada de dados versão 3.0 - Bateria Neuropsicológica (NACC Uniform } \\
\text { Data Set - UDS Neuropsychological Battery) (Weintraub et al., 2018) (Anexo G) }\end{array}$ & $\mathrm{x}$ & $\mathrm{x}$ \\
\hline Avaliação Clínica da Disartria (Auzou et al., 2006) (Anexo H) & $\mathrm{x}$ & $\mathrm{x}$ \\
\hline
\end{tabular}

\footnotetext{
${ }^{1}$ Nove pacientes incluídos no GSCB foram avaliados entre maio de 2017 e outubro de 2018, portanto, antes da aprovação no Comitê de Ética em Pesquisa do HCFMUSP. Essas avaliações foram realizadas com respaldo do TCLE da pesquisa "Síndrome corticobasal: estudo longitudinal dos perfis clínicos e fisiopatológicos”, da Dra. Jacy Parmera, no qual está descrita uma avaliação fonoaudiológica (ANEXO C).
} 


\begin{tabular}{|l|c|c|}
\hline Avaliação da Apraxia de Fala (Wertz; LaPointe; Rosenbeck, 1984) (Anexo I) & $\mathrm{x}$ & $\mathrm{x}$ \\
\hline $\begin{array}{l}\text { Escala de apraxia de fala (Apraxia of Speech Rating Scale) (Strand et al., 2014) } \\
\text { (Anexo J) }\end{array}$ & $\mathrm{x}$ & $\mathrm{x}$ \\
\hline $\begin{array}{l}\text { Escala de Avaliação Funcional das Habilidades de Comunicação (American } \\
\text { Speech-Language-Hearing Association Functional Assessment of Communication } \\
\text { Skills for Adults - ASHA-FACS) (Carvalho; Mansur, 2008) (Anexo K) }\end{array}$ & $\mathrm{x}$ & $\mathrm{x}$ \\
\hline $\begin{array}{l}\text { Escala de Gravidade da Afasia Progressiva Primária (Progressive Aphasia } \\
\text { Severity Scale-PASS) (Sapolsky; Domoto-Reilly; Dickerson, 2014) (Anexo L) }\end{array}$ & $\mathrm{x}$ & \\
\hline
\end{tabular}

\subsubsection{Estudos Normativos de Idosos Americanos (Mayo Older American Normative Studies - MOANS)}

O MOANS (Smith; Ivnik, 2003) é um questionário semiestruturado, que visa determinar a saúde cognitiva de indivíduos com idade acima de 55 anos. É composto por seis itens, relacionados a doenças psiquiátricas e neurológicas, uso de medicações psicotrópicas, queixas de dificuldades cognitivas, entre outros (Anexo D).

\subsubsection{Exame Cognitivo de Addenbrooke - versão revisada (Addenbrooke's Cognitive Examination-Revised - ACE-R)}

O ACE-R (Mioshi et al., 2006; Carvalho, 2009; César et al., 2017) foi utilizado como rastreio de aspectos cognitivos. Esse teste é composto por cinco seções: atenção e orientação (18 pontos), memória (26 pontos), fluência verbal fonêmica e semântica (14 pontos), linguagem (26 pontos) e habilidades visuoespaciais (16 pontos), totalizando 100 pontos (Anexo E). O ACE-R possui normas de referência para a população brasileira de diferentes escolaridades (César et al., 2017).

\subsubsection{Bateria de Avaliação das Afasias de Western - versão revisada (Western Aphasia Battery-Revised - WAB-R)}

O WAB-R (Kertesz, 2007) é uma bateria de testes de linguagem, composta por duas seções. Na primeira seção são avaliadas as seguintes habilidades: fala espontânea; compreensão verbal auditiva; repetição; e nomeação e word finding. A segunda seção avalia: leitura; escrita; apraxia; e tarefas construtivas, visuoespaciais e de cálculo. Além da pontuação de cada seção, a bateria fornece três valores: o quociente de afasia, o quociente de linguagem e o quociente cortical 
(máximo de 100 pontos cada um). O quociente de afasia é obtido a partir das pontuações de fala espontânea, compreensão verbal auditiva, repetição e nomeação e word finding. O quociente de linguagem é calculado com as pontuações dos quatro domínios que compõem o quociente de afasia, somadas às pontuações de leitura e escrita. $O$ quociente cortical é calculado a partir de todas as seções do WAB-R (Anexo F). Esse teste ainda está em processo de validação no Brasil. Nessa pesquisa, utilizamos uma versão-piloto e, para as normas de referência, contamos com o GC.

\subsubsection{Base Unificada de Dados versão 3.0 Bateria Neuropsicológica (NACC Uniform Data Set - UDS Neuropsychological Battery)}

A UDS Neuropsychological Battery (Weintraub et al., 2018) é uma bateria de testes para avaliação abrangente de linguagem, com foco na identificação de alterações linguísticas relacionadas às redes neurais subjacentes aos processos fonológico, sintático e semântico. A bateria é composta pelos seguintes testes: cópia imediata e reprodução posterior de uma figura complexa; fluência verbal semântica e fonêmica; compreensão de palavras; associação entre figuras semanticamente relacionadas; construção de sentenças em ordem canônica e não-canônica a partir de anagramas; nomeação de figuras (substantivos e verbos); leitura de palavras (regulares e irregulares); leitura de sentenças; e repetição de sentenças (Anexo G). Essa bateria também está em processo de validação no Brasil. Utilizamos uma versão-piloto e, para as normas de referência, contamos com o GC.

\subsubsection{Avaliação Clínica da Disartria}

O protocolo de avaliação clínica da disartria contém questões relacionadas às bases motoras da fala: respiração, fonação, ressonância, articulação e prosódia. É composto por oito seções, nas quais são avaliados: reflexos (tosse e deglutição), controle da saliva, respiração, tônus e mobilidade dos órgãos fonoarticulatórios (língua, lábios, mandíbula, véu palatino e laringe) e a inteligibilidade de fala, por meio de leitura de frases. Esse protocolo baseia-se na Batterie d'Evaluation Clinique de la Dysarthrie (Auzou et al., 2006) (Anexo H). Para as normas de referência, utilizamos os dados do GC. 


\subsubsection{Avaliação da Apraxia de Fala}

Para avaliar a apraxia de fala, utilizamos um protocolo baseado em Wertz, LaPointe e Rosenbeck (1984). As provas que compõem o protocolo são: fala espontânea, diadococinesia oral, repetição de polissílabos, múltiplas repetições do mesmo polissílabo, repetição de palavras que aumentam em extensão por derivação sufixal e prefixal, repetição de dissílabos e dissociação entre produção automática e voluntária (Anexo I).

A diadococinesia oral tem sido descrita como um teste sensível para alterações motoras da fala por não sofrer influência de habilidades linguísticas (Padovani; Gielow; Behlau, 2009). Nesse teste, o paciente deve produzir a sílaba /pa/ repetidamente, o mais rápido que puder. A mesma tarefa é feita com as sílabas /ta/ e $/ \mathrm{ka} /$ e com a sequência /pataka/. Em seguida, calcula-se o número de sílabas que o paciente consegue produzir em um segundo. Há normas de referência dessas tarefas para a população brasileira (Padovani; Gielow; Behlau, 2009).

Com base no desempenho obtido nessas tarefas, bem como em todas as provas realizadas que envolvem produção de fala (provas do WAB-R: conversa espontânea, narrativa oral, repetição de palavras e sentenças, nomeação de objetos), pontuamos a escala de apraxia de fala (Strand et al., 2014). Trata-se de um instrumento adaptado de Strand et al. (2014), clínico e perceptivo, contendo 15 características da apraxia de fala, pontuadas por uma escala de 0 a 4 , sendo 0 = ausente; 1 = detectável mas não frequente; 2 = frequente mas não constante; 3 = quase sempre evidente mas não chama a atenção pela gravidade; e 4 = quase sempre evidente e chama a atenção pela gravidade (Anexo J). A escala fornece uma pontuação final, indicativa da gravidade do quadro.

Essa escala foi desenvolvida para ser uma ferramenta descritiva, e está em processo de validação. Os itens que devem ser pontuados são características aceitas na literatura como indicativas de apraxia de fala, e são organizadas de acordo com quatro categorias:

1. Características distintivas da apraxia de fala (não há sobreposição com disartria e/ou afasia);

2. Características distintivas, a menos que a disartria esteja presente;

3. Características distintivas, a menos que a afasia esteja presente; 
4. Características distintivas, a menos que a disartria e/ou a afasia estejam presentes.

Para as normas de referência, utilizamos os dados do GC.

4.3.7 Avaliação Funcional das Habilidades de Comunicação (American Speech-Language-Hearing Association Functional Assessment of Communication Skills for Adults - ASHA-FACS)

A ASHA-FACS é uma escala que verifica a funcionalidade da comunicação e avalia o continuum em relação ao nível de assistência que o paciente necessita para comunicar-se de forma efetiva. Abrange quatro domínios: comunicação social; comunicação de necessidades básicas; leitura, escrita e conceitos numéricos; e planejamento diário. As questões da escala são direcionadas a um cuidador do paciente (Carvalho; Mansur, 2008) (Anexo K).

\subsubsection{Escala de Gravidade da Afasia Progressiva Primária (Progressive Aphasia Severity Scale - PASS)}

A PASS é uma escala estruturada, utilizada para avaliar a presença e a gravidade de alterações nos seguintes domínios da fala e da linguagem: articulação, fluência, sintaxe e gramática, recuperação de palavras e expressões, repetição, compreensão auditiva, compreensão de palavras isoladas, leitura, escrita, comunicação funcional, iniciativa de comunicação, trocas de turno e geração de linguagem. Cada domínio é pontuado da seguinte forma: 0 = normal, 0,5 = muito leve/questionável, 1 = leve; 2 = moderado e 3 = grave. A escala é construída a partir de um questionário, que deve ser respondido por um cuidador, com auxílio de um terapeuta (Sapolsky; DomotoReilly; Dickerson, 2014) (Anexo L).

\subsection{Procedimentos}

O diagnóstico clínico de SCB provável, de acordo com os critérios de Armstrong et al. (2013), foi realizado por uma equipe de médicos neurologistas do GNCC do HCFMUSP, por meio dos seguintes instrumentos: ACE-R, Bateria breve de rastreio cognitivo (BBRC), Escore clínico de demência (CDR), 
Questionário de atividades funcionais (Pfeffer), Escala de Hoehn\&Yahr modificada e exame neurológico.

\subsubsection{Avaliação cognitiva, de fala e de linguagem - GSCB}

Os sujeitos do GSCB foram avaliados individualmente, entre junho de 2017 e agosto de 2019, nas dependências do ambulatório da Divisão de Clínica Neurológica do HCFMUSP (16 pacientes) ou em suas residências (quatro pacientes), quando provindos de consultórios particulares de médicos neurologistas. A avaliação foi realizada em uma ou duas sessões de aproximadamente uma hora e meia, com intervalo não superior a duas semanas (quando em duas sessões). As tarefas que implicam produção de fala foram registradas em vídeo e, posteriormente, analisadas pela pesquisadora executante e pela pesquisadora responsável.

As sessões eram iniciadas com uma anamnese e seguidas pelas provas anteriormente mencionadas. Com exceção do ACE-R, que foi aplicado por um médico neurologista do GNCC HCFMUSP, as demais provas foram aplicadas pela autora deste trabalho.

Todas as modalidades de linguagem foram testadas em todos os sujeitos, mesmo quando o acompanhante afirmava que o paciente já não era capaz de executar alguma tarefa, como escrever ou ler. No entanto, se o paciente deixava de responder após cinco tentativas, o teste era interrompido.

A presença de características da apraxia de fala foi julgada após a avaliação, com base nos vídeos das tarefas do protocolo de Avaliação da Apraxia de Fala e de todas as produções de fala dos pacientes (fala espontânea, repetição, nomeação de objetos). A pontuação para cada característica da escala de apraxia de fala (de 0 a 4; 0 = ausente) foi dada por três juízes, fonoaudiólogos, com ampla experiência na área, de forma independente. As divergências nas pontuações foram resolvidas posteriormente pelos três juízes, após discussão embasada nos vídeos dos pacientes.

$\mathrm{Na}$ análise da diadococinesia oral, foi utilizado o software Audacity®, que possibilita maior precisão na contagem de sílabas e na marcação da duração da tarefa, uma vez que é possível visualizar as sílabas pela forma da onda, facilitando 
sua contagem. Outro recurso do Audacity®, redução de ruído, também foi utilizado em alguns casos em que a qualidade do áudio não estava satisfatória.

Tendo em vista o fato de a escala de apraxia de fala ser uma ferramenta descritiva, e não diagnóstica (Strand et al., 2014), o diagnóstico de apraxia de fala foi dado com base na impressão clínica da pesquisadora executante e da pesquisadora responsável, e não unicamente na pontuação da escala.

A disartria foi avaliada utilizando-se o protocolo mencionado anteriormente e, a partir dos resultados, foram identificadas as bases motoras alteradas.

Com base em todas as produções orais e escritas, foram identificados os pacientes que possuíam alterações morfossintáticas, tais como: alteração na organização das palavras na sentença, omissão ou substituição de palavras funcionais e/ou morfemas gramaticais.

\subsubsection{Avaliação cognitiva, de fala e de linguagem - GC}

Os sujeitos do GC foram avaliados entre setembro de 2018 e agosto de 2019, em suas residências, em uma ou duas sessões de aproximadamente uma hora e meia cada, realizadas com intervalos que não excedessem sete dias. Foram aplicadas todas as provas propostas.

Quanto aos aspectos motores da fala, os mesmos procedimentos utilizados no GSCB foram adotados no GC.

\subsubsection{Exame de tomografia com emissão de pósitrons com fluorodeoxiglicose18F (PET-FDG)}

Todos os indivíduos do GSCB realizaram o exame de PET-FDG, acompanhados por um médico neurologista do GNCC HCFMUSP, no Instituto de Radiologia (InRad) do HCFMUSP. Após jejum de quatro horas, os sujeitos receberam a injeção intravenosa de fluorodeoxiglicose ${ }^{18} \mathrm{~F}$. A aquisição das imagens iniciou-se 60 minutos após a administração do traçador. As imagens de PET foram adquiridas sequencialmente com protocolo 3D padronizado para 0 cérebro.

Com base nos resultados desse exame, os pacientes foram divididos em dois grupos: SCB+ e SCB-. O grupo SCB+ foi composto pelos sujeitos cujo resultado do exame de PET-FDG mostra um padrão de hipometabolismo 
sugestivo de DA; o grupo SCB- foi composto pelos sujeitos cujo resulto do exame não sugeria a DA.

\subsection{Análise estatística}

Os dados gerais do GSCB e do GC foram descritos por meio de médias, desvios-padrão, medianas, valores mínimos e máximos e frequências.

A distribuição das variáveis quantitativas foi avaliada em cada grupo por meio do teste de normalidade de Shapiro-Wilk. Para os dados que violaram o pressuposto de normalidade em pelo menos um grupo $(p<0,05)$, foram utilizados testes não-paramétricos, ao passo que, para os dados que não violaram o pressuposto de normalidade para todos os grupos $(p>0,05)$, as comparações foram feitas por meio de testes paramétricos.

Os valores dos testes ACE-R, WAB-R, UDS, escala de apraxia de fala e diadococinesia oral foram descritos por meio de médias, desvios-padrão, medianas e valores mínimos e máximos. Os grupos foram comparados quanto a esses valores, utilizando-se um teste paramétrico (t de Student para amostras independentes) ou um teste não-paramétrico (U de Mann-Whitney), conforme o critério exposto acima. O tamanho do efeito da diferença entre os grupos para cada medida de desempenho foi medido por meio do cálculo do coeficiente $d$ (Cohen, 1992) ou r (Rosenthal, 1991).

Os dados da escala ASHA-FACS foram descritos por meio de médias, desvios-padrão, medianas e valores mínimo e máximo, e, da escala PASS, por meio de medianas e quartis.

A presença de disartria e alteração morfossintática foi descrita em termos de frequências absoluta e relativa.

A fim de investigar os possíveis impactos da escolaridade, da idade e da duração da doença nos resultados das avaliações cognitiva, de fala e de linguagem, foi feito o cálculo do coeficiente de correlação e do valor de p por meio do teste de correlação de Pearson (paramétrico, para dados com distribuição normal) ou Spearman (não-paramétrico).

Os dados gerais dos grupos SCB+ e SCB- foram descritos por meio de médias, desvios-padrão, medianas e valores mínimo e máximo, e comparados 
entre si e ao total de pacientes (GSCB) em relação ao desempenho nos testes de cognição (ACE-R), fala (escala de apraxia de fala e diadococinesia oral), linguagem (WAB-R e UDS) e nas escalas funcionais (ASHA-FACS e PASS). Devido ao baixo número amostral, todas as comparações entre os grupos SCB+ e SCB- foram realizadas por meio de teste não-paramétrico ( $U$ de MannWhitney), e não foram calculados os valores de intervalo de confiança. $O$ tamanho do efeito da diferença entre os grupos para cada valor de desempenho foi medido por meio do cálculo do coeficiente $r$ (Rosenthal, 1991).

A presença de disartria, apraxia de fala e de alteração morfossintática nos grupos SCB+, SCB- e GSCB foi comparada utilizando-se o teste exato de Fisher.

Foi calculada a proporção de pacientes que tiveram desempenho abaixo do GC nas seguintes variáveis: pontuação total do $A C E-R$, quociente de afasia (WAB-R), fala espontânea (conteúdo da informação e fluência - WAB-R), repetição (WAB-R), compreensão auditiva - questões sim/não (WAB-R), compreensão auditiva - reconhecimento auditivo da palavra (WAB-R), compreensão auditiva - comandos sequenciais (WAB-R), nomeação de objetos (WAB-R), fluência verbal semântica (WAB-R), completar sentenças (WAB-R), fluência verbal fonêmica (UDS), denominação responsiva (WAB-R), associação semântica (UDS), leitura de palavras (UDS), leitura de sentenças (UDS) e pontuação total da escala de apraxia de fala. Foi, também, calculada a proporção de pacientes com alteração morfossintática. Os cálculos das proporções foram feitos com base nas medianas do GC referentes a cada variável. Todas essas variáveis foram agrupadas com base no tipo de processamento linguístico que avaliam: fonético-fonológico, morfossintático, léxico-semântico e de leitura.

O valor de significância estatística adotado foi igual a $5 \%(p \leq 0,05)$. Utilizouse o software SPSS Statistics, versão 25.0 (IBM Corp., Armonk, NY, EUA). Para o cálculo dos intervalos de confiança de $95 \%$ foi utilizado o método de viés corrigido e acelerado com base em 2000 amostras bootstrap. Os valores entre colchetes nas tabelas indicam os limites superior e inferior dos intervalos de confiança de $95 \%$. 


\section{RESULTADOS}

\subsection{Caracterização sociodemográfica e clínica dos grupos}

A Tabela 1 descreve as características gerais do GSCB e do GC e apresenta a comparação entre eles.

Tabela 1 - Características sociodemográficas e clínicas dos grupos

\begin{tabular}{|c|c|c|c|c|}
\hline Variáveis & $\begin{array}{c}\text { GSCB }(n=20) \\
n(\%)\end{array}$ & $\begin{array}{c}G C(n=20) \\
n(\%)\end{array}$ & $P$ & T.E. \\
\hline \multicolumn{5}{|l|}{ Sexo* } \\
\hline Masculino & $8(40)$ & $5(25)$ & 0,501 & \\
\hline Feminino & $12(60)$ & $15(75)$ & & -- \\
\hline \multicolumn{5}{|l|}{ Idade (anos) ${ }^{\star *}$} \\
\hline Média $(D P)$ & $67,35(8,88)$ & $68,90(8,44)$ & & \\
\hline Mediana & 70,00 & 68,50 & 0,575 & 0,184 \\
\hline Min-Max & $53-83$ & $57-84$ & & \\
\hline \multicolumn{5}{|l|}{ Dominância manual* } \\
\hline Destro & $18(90)$ & $17(85)$ & $>0,999$ & \\
\hline Canhoto & $2(10)$ & $3(15)$ & & -- \\
\hline \multicolumn{5}{|l|}{ Escolaridade (anos) ${ }^{\star *}$} \\
\hline Média (DP) & $8,50(5,18)$ & $8,45(4,33)$ & & \\
\hline Mediana & 8,00 & 9,00 & 0,974 & 0,012 \\
\hline Min-Max & $2-20$ & $1-15$ & & \\
\hline \multicolumn{5}{|l|}{ Duração da doença (anos) } \\
\hline Média (DP) & $5,60(2,93)$ & -- & & \\
\hline Mediana & 5,00 & & & \\
\hline Min-Max & $2-13$ & -- & & \\
\hline \multicolumn{5}{|l|}{ Idade de início dos sintomas } \\
\hline Média (DP) & $61,65(9,21)$ & -- & & \\
\hline Mediana & 64,50 & & & \\
\hline Min-Max & $45-78$ & -- & & \\
\hline \multicolumn{5}{|l|}{ Sintoma inicial } \\
\hline Memória & $8(40)$ & -- & & \\
\hline Alteração motora & $5(25)$ & -- & & \\
\hline Fala/Linguagem & $3(15)$ & -- & & \\
\hline Disfunção executiva & $1(5)$ & -- & & \\
\hline Alteração comportamental & $1(5)$ & -- & & \\
\hline Agnosia & $1(5)$ & -- & & \\
\hline Apraxia & $1(5)$ & -- & & \\
\hline
\end{tabular}


As comparações mostram que os dois grupos não diferem entre si quanto às variáveis sociodemográficas e de dominância manual. Há maior predomínio de indivíduos do sexo feminino e destros. A média de idade foi um pouco abaixo de 70 anos, com média de escolaridade de 8 anos, em ambos os grupos. No GSCB, o tempo médio de doença foi de 5 anos e a média de idade de início dos sintomas, aos 61 anos. O sintoma inicial mais frequente foi relacionado a memória (40\%), seguido de alterações motoras (25\%) e alterações de fala/linguagem (15\%).

\subsection{Avaliação cognitiva e de linguagem}

Dos 20 pacientes que compuseram o GSCB, três (sujeitos 10, 12 e 16) não foram avaliados em relação à cognição, com o teste ACE-R, devido ao grau de comprometimento cognitivo.

Quanto à avaliação de linguagem com o WAB-R, a segunda parte do teste, que inclui leitura, escrita, praxias e tarefas construtivas, visuoespaciais e de cálculo, só pôde ser aplicada em seis pacientes. Nos demais, esses testes não foram aplicados pelas seguintes razões: analfabetismo (sujeito 1), agnosia visual importante (sujeitos 2 e 17) e alterações cognitivas e motoras graves (sujeitos 3, 4, $5,6,9,10,11,12,13,15,16)$. Tendo em vista o baixo número amostral na segunda parte do WAB-R, optou-se por não incluir esses resultados nas análises.

Ainda em relação ao WAB-R, em três pacientes (sujeitos 4, 5 e 6) não foram aplicados dois subtestes de compreensão auditiva que demandam movimentação com o membro superior, em decorrência de comprometimento motor importante. Desse modo, não foi possível calcular o quociente de afasia para esses pacientes.

Após análise das produções orais e escritas do WAB-R para verificação do processamento morfossintático, foi encontrada alteração em um paciente (sujeito 4). Essa alteração caracterizou-se como "fala telegráfica", manifestada por palavras isoladas, omissão de palavras funcionais e diminuição da quantidade de verbos em comparação aos substantivos.

Quanto ao outro teste que avalia a linguagem, a bateria UDS, três pacientes (sujeitos 4, 5 e 6) não realizaram a cópia da figura complexa (alteração motora grave) e um paciente (sujeito 1) não realizou as provas de fluência verbal fonêmica, leitura de palavras e sentenças e o Northwestern Anagram Test, que 
avalia habilidades sintáticas por meio da formação de sentenças a partir de palavras recortadas (analfabetismo).

Em decorrência dessas questões, nas diferentes provas de cognição e linguagem, o número amostral varia.

A Tabela 2 apresenta a comparação dos grupos nos subtestes do ACE-R.

Tabela 2 - Valores descritivos e análise comparativa dos grupos em relação ao desempenho no ACE-R

\begin{tabular}{|c|c|c|c|c|c|c|c|c|c|}
\hline Variável & Grupo & $\mathbf{n}$ & Média & DP & Mediana & Mín. & Máx. & $p$ & T.E. \\
\hline \multirow{2}{*}{ Total } & GSCB & 17 & $\begin{array}{r}38,00 \\
{[27,63,} \\
49,42]\end{array}$ & 21,53 & $\begin{array}{r}34,00 \\
{[32,00} \\
34,00]\end{array}$ & 0,00 & 83,00 & \multirow{2}{*}{$<0,001^{\star a}$} & \multirow{2}{*}{5,093} \\
\hline & GC & 20 & $\begin{array}{r}84,30 \\
{[80,35,} \\
88,05]\end{array}$ & 9,09 & $\begin{array}{r}86,50 \\
{[81,50,} \\
89,00]\end{array}$ & 63,00 & 99,00 & & \\
\hline \multirow{2}{*}{ Atenção } & GSCB & 17 & $\begin{array}{c}8,94 \\
{[6,88,} \\
11,12]\end{array}$ & 4,60 & $\begin{array}{l}9,00 \\
{[7,00,} \\
11,00]\end{array}$ & 0,00 & 18,00 & \multirow{2}{*}{$<0,001^{\star b}$} & \multirow{2}{*}{0,695} \\
\hline & GC & 20 & $\begin{array}{r}16,45 \\
{[15,75,} \\
17,10]\end{array}$ & 1,61 & $\begin{array}{r}17,00 \\
{[17,00,} \\
17,00]\end{array}$ & 13,00 & 18,00 & & \\
\hline \multirow{2}{*}{ Memória } & GSCB & 17 & $\begin{array}{c}8,82 \\
{[5,64,} \\
12,47]\end{array}$ & 7,03 & $\begin{array}{c}7,00 \\
{[4,00,} \\
14,00]\end{array}$ & 0,00 & 23,00 & \multirow{2}{*}{$<0,001^{\star a}$} & \multirow{2}{*}{2,192} \\
\hline & GC & 20 & $\begin{array}{r}20,00 \\
{[17,80,} \\
22,20]\end{array}$ & 5,10 & $\begin{array}{r}20,50 \\
{[17,00,} \\
24,00]\end{array}$ & 10,00 & 26,00 & & \\
\hline \multirow{2}{*}{$\begin{array}{c}\text { Fluência } \\
\text { verbal }\end{array}$} & GSCB & 17 & $\begin{array}{r}2,18 \\
{[1,06,} \\
3,37]\end{array}$ & 2,51 & $\begin{array}{r}1,00 \\
{[0,00} \\
2,00]\end{array}$ & 0,00 & 7,00 & \multirow{2}{*}{$<0,001^{\star b}$} & \multirow{2}{*}{0,807} \\
\hline & GC & 20 & $\begin{array}{c}9,85 \\
{[8,90,} \\
10,80]\end{array}$ & 2,13 & $\begin{array}{r}10,00 \\
{[10,00,} \\
10,00]\end{array}$ & 6,00 & 14,00 & & \\
\hline \multirow{2}{*}{ Linguagem } & GSCB & 17 & $\begin{array}{r}13,65 \\
{[10,12,} \\
17,33]\end{array}$ & 7,22 & $\begin{array}{l}13,00 \\
{[9,00,} \\
16,00]\end{array}$ & 0,00 & 26,00 & \multirow{2}{*}{$<0,001^{\star b}$} & \multirow{2}{*}{0,647} \\
\hline & GC & 20 & $\begin{array}{r}24,10 \\
{[23,05} \\
25,00]\end{array}$ & 2,40 & $\begin{array}{r}25,00 \\
{[25,00,} \\
25,00]\end{array}$ & 17,00 & 26,00 & & \\
\hline \multirow{3}{*}{$\begin{array}{l}\text { Habilidades } \\
\text { visuo- } \\
\text { espaciais }\end{array}$} & GSCB & 17 & $\begin{array}{r}4,41 \\
{[2,59,} \\
6,28]\end{array}$ & 3,91 & $\begin{array}{r}4,00 \\
{[4,00} \\
4,00]\end{array}$ & 0,00 & 12,00 & \multirow{3}{*}{$<0,001^{* \mathrm{~b}}$} & \multirow{3}{*}{0,795} \\
\hline & & & 13,90 & & 14,00 & & & & \\
\hline & GC & 20 & $\begin{array}{r}{[12,95,} \\
14,75]\end{array}$ & 2,10 & $\begin{array}{c}{[13,00} \\
16,00]\end{array}$ & 9,00 & 16,00 & & \\
\hline
\end{tabular}

Teste $t$ de Student para amostras independentes $\left({ }^{a}\right)$ e teste $U$ de Mann-Whitney $\left({ }^{b}\right)$. Legenda: DP: Desvio padrão; Mín.: Mínimo; Máx.: Máximo; *: Valor estatisticamente significante no nível de $5 \%(p \leq 0,05)$; T.E.: Tamanho do efeito. 
Houve diferença entre os grupos em todos os subtestes do ACE-R, sendo que o GSCB teve desempenho inferior. $O$ tamanho do efeito da diferença entre os grupos foi grande (TE) em todos os subtestes (Cohen, 1992; Rosenthal, 1991).

A Tabela 3 apresenta a comparação dos grupos nos subtestes do WAB-R.

Tabela 3 - Valores descritivos e análise comparativa dos grupos em relação ao desempenho no WAB-R

\begin{tabular}{|c|c|c|c|c|c|c|c|c|c|}
\hline Variável & Grupo & $\mathbf{n}$ & Média & DP & Mediana & Mín. & Máx. & $p$ & T.E. \\
\hline \multirow{2}{*}{$\begin{array}{c}\text { Quociente de } \\
\text { afasia }\end{array}$} & GSCB & 17 & $\begin{array}{r}60,55 \\
{[44,06} \\
77,03]\end{array}$ & 34,97 & $\begin{array}{r}74,60 \\
{[38,50} \\
82,92]\end{array}$ & 1,20 & 97,50 & \multirow{2}{*}{$<0,001^{\star}$} & \multirow{2}{*}{0,762} \\
\hline & $\mathrm{GC}$ & 20 & $\begin{array}{r}97,51 \\
{[96,40} \\
98,37]\end{array}$ & 2,27 & $\begin{array}{r}97,80 \\
{[97,10} \\
98,65]\end{array}$ & 90,00 & 100,00 & & \\
\hline \multirow{2}{*}{$\begin{array}{l}\text { Fala espontânea - } \\
\text { conteúdo da } \\
\text { informação }\end{array}$} & GSCB & 20 & $\begin{array}{r}6,30 \\
{[4,85} \\
7,55]\end{array}$ & 3,21 & $\begin{array}{r}8,00 \\
{[8,00} \\
8,00]\end{array}$ & 0,00 & 10,00 & \multirow{2}{*}{$<0,001^{*}$} & \multirow{2}{*}{0,753} \\
\hline & $\mathrm{GC}$ & 20 & $\begin{array}{r}9,85 \\
{[9,65} \\
10,00]\end{array}$ & 0,49 & $\begin{array}{r}10,00 \\
{[10,00} \\
10,00]\end{array}$ & 8,00 & 10,00 & & \\
\hline \multirow{2}{*}{$\begin{array}{l}\text { Fala espontânea - } \\
\text { pontuação fluência }\end{array}$} & GSCB & 20 & $\begin{array}{r}5,85 \\
{[4,20} \\
7,40]\end{array}$ & 3,69 & $\begin{array}{r}7,00 \\
{[3,50} \\
9,00]\end{array}$ & 0,00 & 10,00 & \multirow{2}{*}{$<0,001^{*}$} & \multirow{2}{*}{0,846} \\
\hline & $\mathrm{GC}$ & 20 & $\begin{array}{r}10,00 \\
{[10,00} \\
10,00] \\
\end{array}$ & 0,00 & $\begin{array}{r}10,00 \\
{[10,00} \\
10,00] \\
\end{array}$ & 10,00 & 10,00 & & \\
\hline \multirow{2}{*}{$\begin{array}{c}\text { Compreensão } \\
\text { auditiva - questões } \\
\text { sim/não }\end{array}$} & GSCB & 20 & $\begin{array}{r}44,30 \\
{[34,35} \\
53,05]\end{array}$ & 21,24 & $\begin{array}{r}55,50 \\
{[45,00} \\
58,50]\end{array}$ & 0,00 & 60,00 & \multirow{2}{*}{$<0,001^{*}$} & \multirow{2}{*}{0,619} \\
\hline & $\mathrm{GC}$ & 20 & $\begin{array}{c}59,70 \\
{[59,40} \\
6,00]\end{array}$ & 0,92 & $\begin{array}{r}60,00 \\
{[60,00} \\
60,00]\end{array}$ & 57,00 & 60,00 & & \\
\hline \multirow{2}{*}{$\begin{array}{l}\text { Compreensão } \\
\text { auditiva - } \\
\text { reconhecimento } \\
\text { auditivo da palavra }\end{array}$} & GSCB & 17 & $\begin{array}{r}35,71 \\
{[24,82} \\
46,41]\end{array}$ & 23,44 & $\begin{array}{r}46,00 \\
{[19,00} \\
56,00]\end{array}$ & 2,00 & 60,00 & \multirow{2}{*}{$<0,001^{*}$} & \multirow{2}{*}{0,730} \\
\hline & $\mathrm{GC}$ & 20 & $\begin{array}{r}59,15 \\
{[58,70} \\
59,55] \\
\end{array}$ & 1,18 & $\begin{array}{r}60,00 \\
{[60,00} \\
60,00] \\
\end{array}$ & 56,00 & 60,00 & & \\
\hline \multirow{2}{*}{$\begin{array}{l}\text { Compreensão } \\
\text { auditiva - } \\
\text { comandos } \\
\text { sequenciais }\end{array}$} & GSCB & 17 & $\begin{array}{r}46,00 \\
{[32,19,} \\
59,86]\end{array}$ & 29,33 & $\begin{array}{l}48,00 \\
{[32,00} \\
68,00]\end{array}$ & 2,00 & 80,00 & \multirow{2}{*}{$<0,001^{\star}$} & \multirow{2}{*}{0,736} \\
\hline & $\mathrm{GC}$ & 20 & $\begin{array}{c}79,75 \\
{[79,50} \\
80,00\end{array}$ & 1,12 & $\begin{array}{r}80,00 \\
{[80,00} \\
80,00]\end{array}$ & 75,00 & 80,00 & & \\
\hline \multirow{3}{*}{ Repetição } & GSCB & 20 & $\begin{array}{r}64,20 \\
{[49,03} \\
79,10]\end{array}$ & 35,12 & $\begin{array}{r}78,00 \\
{[66,00} \\
90,00]\end{array}$ & 0,00 & 96,00 & \multirow{2}{*}{$<0,001^{*}$} & \multirow{2}{*}{0,645} \\
\hline & $\mathrm{GC}$ & 20 & $\begin{array}{r}95,70 \\
{[94,30} \\
97,20] \\
\end{array}$ & 3,51 & $\begin{array}{r}96,00 \\
{[96,00} \\
96,00] \\
\end{array}$ & 90,00 & 100,00 & & \\
\hline & GSCB & 20 & 35,60 & 23,15 & 40,50 & 0,00 & 60,00 & $<0,001^{*}$ & 0,620 \\
\hline
\end{tabular}




\begin{tabular}{|c|c|c|c|c|c|c|c|c|c|}
\hline \multirow{3}{*}{$\begin{array}{l}\text { Nomeação - } \\
\text { objetos }\end{array}$} & \multicolumn{4}{|c|}{$\begin{array}{l}25,42, \\
45,41]\end{array}$} & \multicolumn{5}{|l|}{$\begin{array}{l}{[22,50,} \\
56,50]\end{array}$} \\
\hline & & & 59,20 & & 60,00 & & & & \\
\hline & $\mathrm{GC}$ & 20 & $\begin{array}{l}{[58,30} \\
59,90]\end{array}$ & 2,02 & $\begin{array}{l}{[60,00,} \\
60,00]\end{array}$ & 53,00 & 60,00 & & \\
\hline \multirow{2}{*}{$\begin{array}{l}\text { Nomeação - } \\
\text { fluência verbal } \\
\text { semântica }\end{array}$} & GSCB & 20 & $\begin{array}{r}4,40 \\
{[2,30} \\
6,82]\end{array}$ & 5,63 & $\begin{array}{r}1,50 \\
{[0,00} \\
7,00]\end{array}$ & 0,00 & 20,00 & \multirow{2}{*}{$<0,001^{*}$} & \multirow{2}{*}{0,731} \\
\hline & GC & 20 & $\begin{array}{r}15,25 \\
{[13,35} \\
17,00]\end{array}$ & 3,95 & $\begin{array}{r}15,50 \\
{[14,00} \\
18,00]\end{array}$ & 6,00 & 20,00 & & \\
\hline \multirow{2}{*}{$\begin{array}{l}\text { Nomeação - } \\
\text { completar } \\
\text { sentenças }\end{array}$} & GSCB & 20 & $\begin{array}{r}5,40 \\
{[3,50} \\
7,25]\end{array}$ & 4,13 & $\begin{array}{c}7,50 \\
{[3,50} \\
8,00]\end{array}$ & 0,00 & 10,00 & \multirow{2}{*}{$<0,001^{*}$} & \multirow{2}{*}{0,681} \\
\hline & $\mathrm{GC}$ & 20 & $\begin{array}{c}9,70 \\
{[9,30} \\
10,00]\end{array}$ & 0,98 & $\begin{array}{r}10,00 \\
{[10,00} \\
10,00]\end{array}$ & 6,00 & 10,00 & & \\
\hline \multirow{2}{*}{$\begin{array}{c}\text { Nomeação - } \\
\text { denominação } \\
\text { responsiva }\end{array}$} & GSCB & 20 & $\begin{array}{r}5,45 \\
{[3,80,} \\
7,15]\end{array}$ & 4,06 & $\begin{array}{r}6,50 \\
{[2,00} \\
8,50]\end{array}$ & 0,00 & 10,00 & \multirow{2}{*}{$<0,001^{*}$} & \multirow{2}{*}{0,699} \\
\hline & $\mathrm{GC}$ & 20 & $\begin{array}{r}9,90 \\
{[9,80,} \\
10,00]\end{array}$ & 0,45 & $\begin{array}{r}10,00 \\
{[10,00} \\
10,00]\end{array}$ & 8,00 & 10,00 & & \\
\hline
\end{tabular}

Teste U de Mann-Whitney. Legenda: DP: Desvio padrão; Mín.: Mínimo; Máx.: Máximo; *: Valor estatisticamente significante no nivel de $5 \%(p \leq 0,05)$; T.E.: Tamanho do efeito.

Houve diferença entre os grupos para todos os subtestes do WAB-R, sendo que o GSCB apresentou desempenho inferior. $O$ tamanho do efeito da diferença entre os grupos foi grande (TE) para todos os valores (Rosenthal, 1991).

A Tabela 4 apresenta a comparação dos grupos nos subtestes da UDS.

Tabela 4 - Valores descritivos e análise comparativa dos grupos em relação ao desempenho na UDS

\begin{tabular}{|c|c|c|c|c|c|c|c|c|c|}
\hline Variável & Grupo & $\mathbf{N}$ & Média & DP & Mediana & Mín. & Máx. & $p$ & T.E. \\
\hline \multirow{2}{*}{$\begin{array}{c}\text { Cópia imediata da } \\
\text { figura complexa de } \\
\text { Benson }\end{array}$} & GSCB & 17 & $\begin{array}{r}2,47 \\
{[0,71} \\
4,41]\end{array}$ & 5,54 & $\begin{array}{c}0,00 \\
{[0,00,0,00]}\end{array}$ & 0,00 & 15,00 & \multirow{2}{*}{$\stackrel{<}{0,001^{*}}$} & \multirow{2}{*}{0,791} \\
\hline & $\mathrm{GC}$ & 20 & $\begin{array}{r}15,25 \\
{[14,45} \\
16,00]\end{array}$ & 1,77 & $\begin{array}{r}15,50 \\
{[15,00} \\
16,50]\end{array}$ & 12,00 & 17,00 & & \\
\hline \multirow{2}{*}{$\begin{array}{l}\text { Fluência verbal } \\
\text { fonêmica "p" }\end{array}$} & GSCB & 19 & $\begin{array}{r}1,79 \\
{[0,79} \\
2,95]\end{array}$ & 2,90 & $\begin{array}{c}0,00 \\
{[0,00,0,00]}\end{array}$ & 0,00 & 10,00 & \multirow{2}{*}{$\underset{0,001^{*}}{<}$} & \multirow{2}{*}{0,829} \\
\hline & $\mathrm{GC}$ & 20 & $\begin{array}{r}11,90 \\
{[10,25} \\
13,66]\end{array}$ & 4,15 & $\begin{array}{l}10,50 \\
{[9,00} \\
14,00]\end{array}$ & 7,00 & 21,00 & & \\
\hline $\begin{array}{l}\text { Fluência verbal } \\
\text { fonêmica "a" }\end{array}$ & GSCB & 19 & $\begin{array}{r}1,53 \\
{[0,58} \\
2,53]\end{array}$ & 2,57 & $\begin{array}{c}0,00 \\
{[0,00,0,00]}\end{array}$ & 0,00 & 7,00 & $\underset{0,001^{*}}{<}$ & 0,815 \\
\hline
\end{tabular}




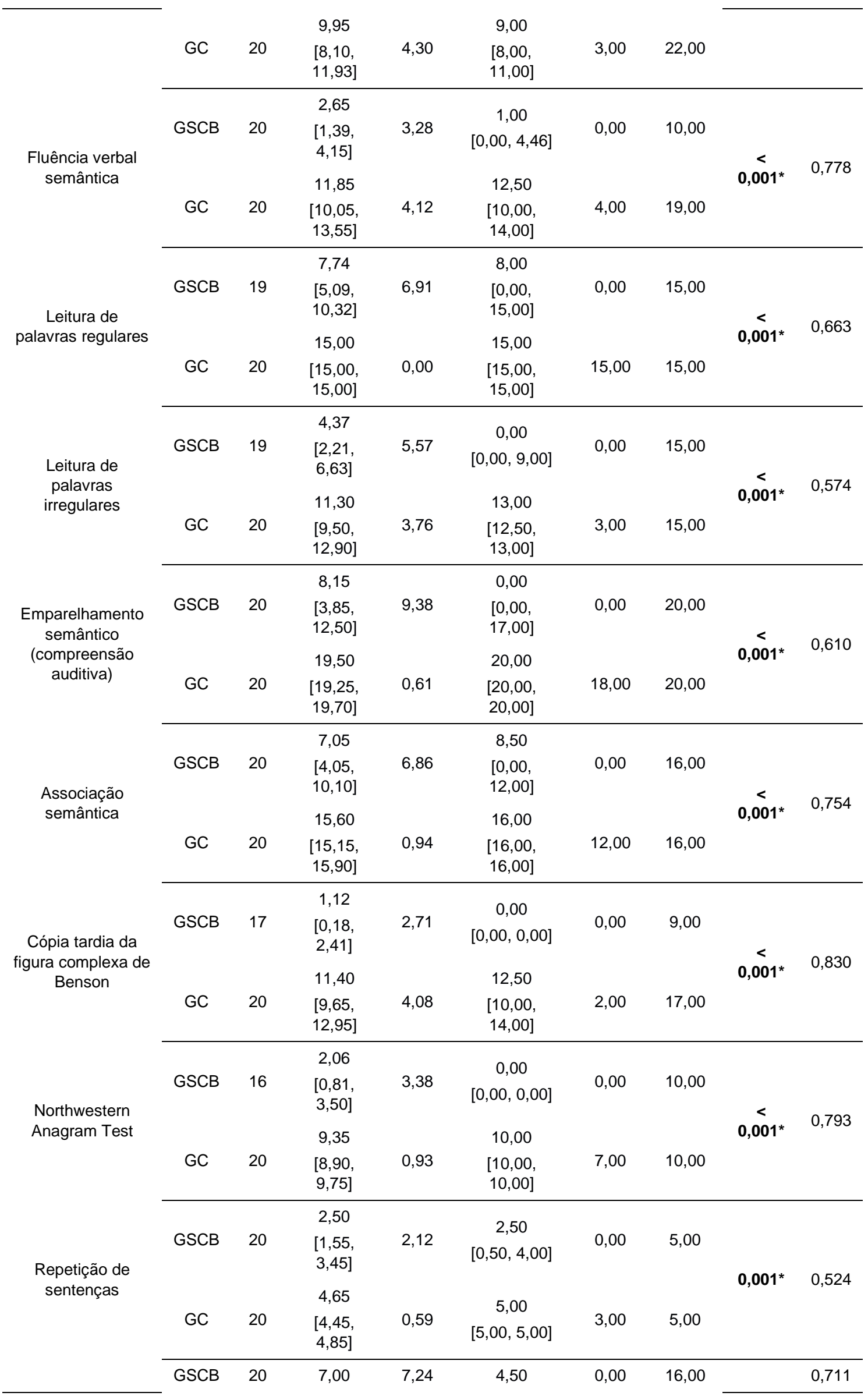




\begin{tabular}{|c|c|c|c|c|c|c|c|c|c|}
\hline \multirow{3}{*}{$\begin{array}{l}\text { Nomeação de } \\
\text { substantivos }\end{array}$} & \multirow[b]{3}{*}{ GC } & \multirow[b]{3}{*}{20} & \multicolumn{2}{|l|}{$\begin{array}{l}{[4,15,} \\
10,00]\end{array}$} & \multicolumn{2}{|l|}{$\begin{array}{l}{[0,00,} \\
14,00]\end{array}$} & \multirow[b]{3}{*}{16,00} & \multirow{3}{*}{$\stackrel{<}{<, 001^{*}}$} & \\
\hline & & & 15,70 & & 16,00 & & & & \\
\hline & & & $\begin{array}{r}{[15,45,} \\
15,90]\end{array}$ & 0,66 & $\begin{array}{l}{[16,00} \\
16,00]\end{array}$ & 14,00 & & & \\
\hline \multirow{4}{*}{$\begin{array}{l}\text { Nomeação de } \\
\text { verbos }\end{array}$} & & & 5,70 & & 3,00 & & & \multirow{4}{*}{$\underset{0,001^{*}}{<}$} & \multirow{4}{*}{0,762} \\
\hline & GSCB & 20 & $\begin{array}{l}{[3,20,} \\
8,40]\end{array}$ & 6,28 & $\begin{array}{l}{[0,00} \\
10,84]\end{array}$ & 0,00 & 16,00 & & \\
\hline & & & 15,20 & & 16,00 & & & & \\
\hline & GC & 20 & $\begin{array}{l}{[14,80,} \\
15,60]\end{array}$ & 1,11 & $\begin{array}{l}{[16,00,} \\
16,00]\end{array}$ & 13,00 & 16,00 & & \\
\hline \multirow{3}{*}{ Leitura } & GSCB & 19 & $\begin{array}{r}2,16 \\
{[1,32} \\
3,16]\end{array}$ & 2,50 & $\begin{array}{c}0,00 \\
{[0,00,5,00]}\end{array}$ & 0,00 & 5,00 & \multirow{3}{*}{$\stackrel{<}{<, 001^{*}}$} & \multirow{3}{*}{0,632} \\
\hline & & & 5,00 & & 500 & & & & \\
\hline & GC & 20 & $\begin{array}{l}{[5,00,} \\
5,00]\end{array}$ & 0,00 & {$\left[\begin{array}{c}5,00 \\
{[5,00,5,00]}\end{array}\right.$} & 5,00 & 5,00 & & \\
\hline
\end{tabular}

Teste U de Mann-Whitney. Legenda: DP: Desvio padrão; Mín.: Mínimo; Máx.: Máximo; *: Valor estatisticamente significante no nivel de $5 \%(p \leq 0,05)$; T.E.: Tamanho do efeito.

Houve diferença entre os grupos para todos os subtestes referentes à UDS, sendo que o GSCB apresentou desempenho inferior ao GC. O tamanho do efeito da diferença entre os grupos foi grande (TE) (Rosenthal, 1991).

\subsection{Avaliação da fala}

Para a avaliação de fala, foram incluídos 19 pacientes do GSCB, pois um deles (sujeito 12) estava em mutismo. Na avaliação da diadococinesia oral, seis pacientes (sujeitos 2, 3, 4, 5, 10 e 12) não obedeceram ao comando da prova, em decorrência de grave alteração cognitiva e/ou de linguagem. Sendo assim, o número total de sujeitos do GSCB varia em algumas análises.

Como mencionado anteriormente, a escala de apraxia de fala foi utilizada como instrumento descritivo, e o diagnóstico de apraxia de fala foi dado a partir da avaliação clínica. Onze pacientes $(57,9 \%)$ foram diagnosticados com apraxia de fala (sujeitos 2, 3, 4, 7, 8, 11, 13, 14, 17, 18 e 19).

Quanto à presença da disartria, quatro pacientes $(21,05 \%)$ apresentaram alterações indicativas desse quadro (sujeitos 5, 13, 14 e 18). O Quadro 2 apresenta as bases motoras da fala que estavam alteradas em cada pacientes e as respectivas manifestações. 
Quadro 2 - Descrição das alterações encontradas nos pacientes com disartria

\begin{tabular}{|c|c|c|c|c|}
\hline Base motora & Suj. 5 & Suj. 13 & $\begin{array}{c}\text { Suj. } 14 \\
\end{array}$ & Suj. 18 \\
\hline Respiração & - Diminuição do TMF & - & - Diminuição do TMF & - \\
\hline Fonação & $\begin{array}{l}\text { - Loudness reduzida } \\
\text { - Pitch elevado }\end{array}$ & $\begin{array}{l}\text { - Instabilidade vocal } \\
\text { - Loudness } \\
\text { reduzida }\end{array}$ & $\begin{array}{l}\text { - Loudness reduzida } \\
\text { - Soprosidade }\end{array}$ & $\begin{array}{l}\text { - Loudness } \\
\text { reduzida } \\
\text { - Rouquidão } \\
\text { - Soprosidade } \\
\text { - Instabilidade } \\
\text { vocal }\end{array}$ \\
\hline Ressonância & - & - & - Hipernasalidade & - \\
\hline Articulação & $\begin{array}{l}\text { - Consoantes } \\
\text { imprecisas }\end{array}$ & $\begin{array}{l}\text { - Consoantes } \\
\text { imprecisas }\end{array}$ & $\begin{array}{l}\text { - Consoantes } \\
\text { imprecisas }\end{array}$ & $\begin{array}{l}\text { - Consoantes } \\
\text { imprecisas }\end{array}$ \\
\hline Prosódia & $\begin{array}{l}\text { - Pausas inapropriadas } \\
\text { - Ausência de } \\
\text { acentuação } \\
\text { - Diminuição da taxa de } \\
\text { fala } \\
\text { - Segmentação silábica }\end{array}$ & $\begin{array}{l}\text { - Ausência de } \\
\text { acentuação } \\
\text { - Aumento da taxa } \\
\text { de fala }\end{array}$ & $\begin{array}{l}\text { - Ausência de } \\
\text { acentuação } \\
\text { - Diminuição da taxa de } \\
\text { fala } \\
\text { - Segmentação silábica }\end{array}$ & $\begin{array}{l}\text { - Diminuição da } \\
\text { taxa de fala }\end{array}$ \\
\hline
\end{tabular}

Suj. = sujeito; TMF = tempo máximo de fonação.

A Tabela 5 apresenta a comparação dos grupos nos testes da escala de apraxia de fala.

Tabela 5 - Valores descritivos e análise comparativa dos grupos em relação ao desempenho na escala de apraxia de fala

\begin{tabular}{|c|c|c|c|c|c|c|c|c|c|}
\hline Variável & Grupo & $\mathbf{n}$ & Média & DP & Mediana & Mín. & Máx. & $p$ & T.E. \\
\hline \multirow{2}{*}{$\begin{array}{l}\text { 1.1 Substituições } \\
\text { distorcidas }\end{array}$} & GSCB & 19 & 1,32 & 1,11 & 1,00 & 0,00 & 4,00 & \multirow{2}{*}{$<0,001^{*}$} & \multirow{2}{*}{0,777} \\
\hline & GC & 20 & 0,00 & 0,00 & 0,00 & 0,00 & 0,00 & & \\
\hline \multirow{2}{*}{$\begin{array}{l}\text { 1.2 Adição de som } \\
\text { distorcido }\end{array}$} & GSCB & 19 & 0,68 & 1,00 & 0,00 & 0,00 & 4,00 & \multirow{2}{*}{$<0,001^{*}$} & \multirow{2}{*}{0,551} \\
\hline & $\mathrm{GC}$ & 20 & 0,00 & 0,00 & 0,00 & 0,00 & 0,00 & & \\
\hline $\begin{array}{l}\text { 1.3 Aumento das } \\
\text { distorções ou } \\
\text { substituições } \\
\text { distorcidas na }\end{array}$ & GSCB & 19 & 2,21 & 1,13 & 2,00 & 0,00 & 4,00 & & \\
\hline $\begin{array}{l}\text { aumenta o } \\
\text { enunciado ou a } \\
\text { complexidade } \\
\text { articulatória das } \\
\text { sílabas/palavras }\end{array}$ & GC & 20 & 0,45 & 0,60 & 0,00 & 0,00 & 2,00 & $<0,001^{*}$ & 0,698 \\
\hline \multirow{3}{*}{$\begin{array}{l}\text { 1.4 Aumento das } \\
\text { distorções de som } \\
\text { ou substituições } \\
\text { distorcidas com o } \\
\text { aumento da taxa } \\
\text { de fala }\end{array}$} & GSCB & 19 & 1,37 & 1,16 & 1,00 & 0,00 & 3,00 & & \\
\hline & $\mathrm{GC}$ & 20 & 0,00 & 0,00 & 0,00 & 0,00 & 0,00 & $<0,001^{*}$ & 0,699 \\
\hline & GSCB & 14 & 0,42 & 0,51 & 0,00 & 0,00 & 1,00 & 0,065 & 0,765 \\
\hline
\end{tabular}




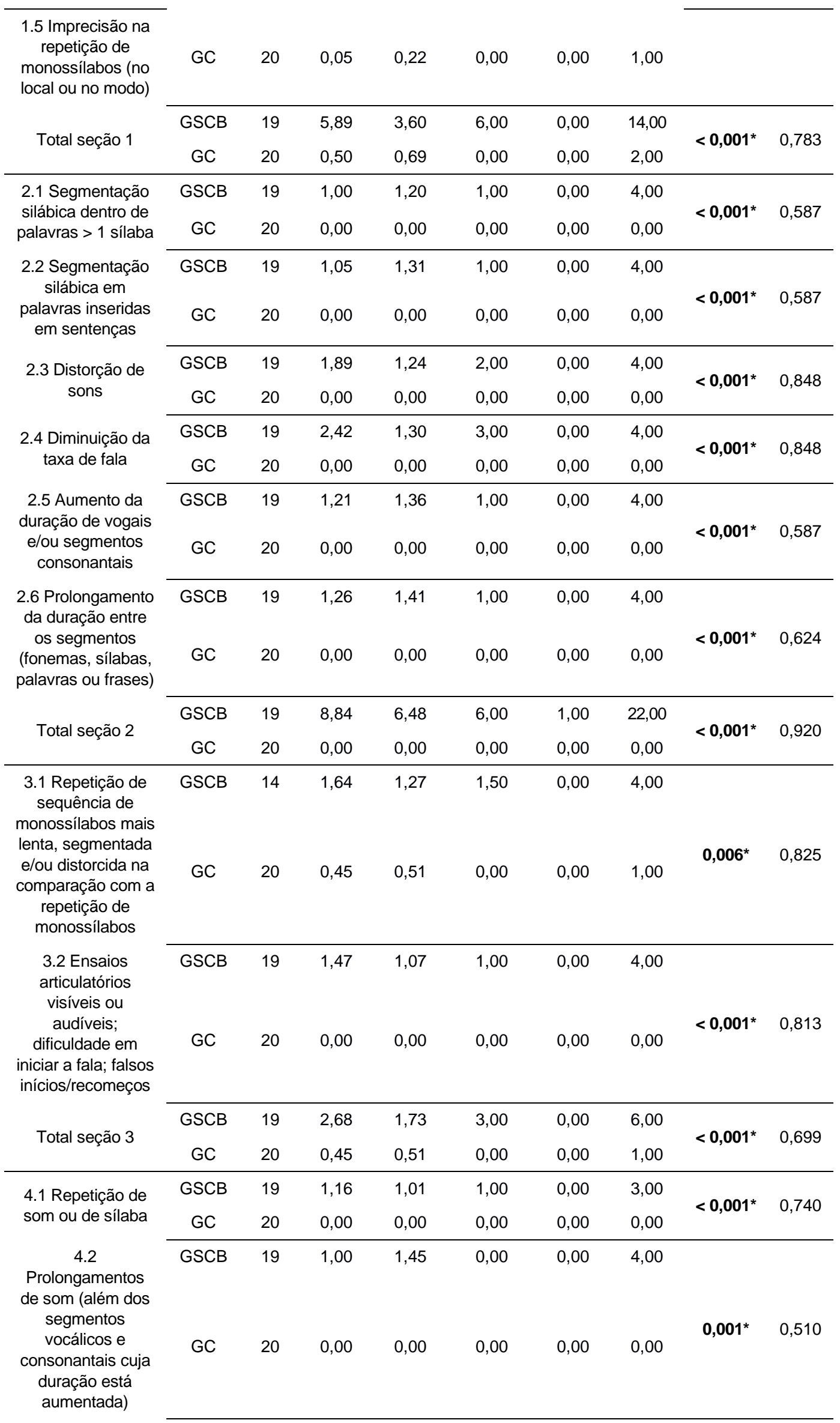




\begin{tabular}{|c|c|c|c|c|c|c|c|c|c|}
\hline \multirow{2}{*}{ Total seção 4} & GSCB & 19 & 2,16 & 2,27 & 1,00 & 0,00 & 7,00 & \multirow{2}{*}{$<0,001^{*}$} & \multirow{2}{*}{0,773} \\
\hline & $\mathrm{GC}$ & 20 & 0,00 & 0,00 & 0,00 & 0,00 & 0,00 & & \\
\hline \multirow{2}{*}{ Total geral } & GSCB & 19 & 19,63 & 11,72 & 16,00 & 1,00 & 47,00 & \multirow{2}{*}{$<0,001^{*}$} & \multirow{2}{*}{0,824} \\
\hline & GC & 20 & 0,95 & 1,00 & 1,00 & 0,00 & 3,00 & & \\
\hline
\end{tabular}

Teste U de Mann-Whitney. Legenda: DP: Desvio padrão; Mín.: Mínimo; Máx.: Máximo; *: Valor estatisticamente significante no nível de $5 \%(p \leq 0,05)$; T.E.: Tamanho do efeito.

Houve diferença entre os grupos para todos os itens da escala de apraxia de fala, com maiores valores para o GSCB, exceto no item 1.5 "Imprecisão na repetição de monossílabos (no local ou no modo)", no qual os dois grupos tiveram desempenho similar. Sendo assim, os sujeitos do GSCB apresentaram mais características da apraxia de fala e com maior gravidade do que o GC. O tamanho do efeito da diferença entre os grupos foi grande (TE) para todos os itens (Rosenthal, 1991).

A Tabela 6 apresenta a comparação dos grupos nas provas de diadococinesia oral.

Tabela 6 - Valores descritivos e análise comparativa dos grupos em relação ao desempenho na diadococinesia oral

\begin{tabular}{|c|c|c|c|c|c|c|c|c|c|}
\hline Variável & Grupo & $\mathbf{n}$ & Média & DP & Mediana & Mín. & Máx. & p & T.E. \\
\hline \multirow{2}{*}{$/ p a /$} & GSCB & 14 & $\begin{array}{c}5,19 \\
{[4,08,6,32]}\end{array}$ & 2,53 & $\begin{array}{c}4,38 \\
{[3,45,6,60]}\end{array}$ & 1,20 & 10,00 & \multirow{2}{*}{$0,155^{a}$} & \multirow{2}{*}{$0,970^{d}$} \\
\hline & $\mathrm{GC}$ & 20 & $\begin{array}{c}6,26 \\
{[5,76,6,72]}\end{array}$ & 1,11 & $\begin{array}{c}6,55 \\
{[6,20,6,80]}\end{array}$ & 4,10 & 7,80 & & \\
\hline \multirow{2}{*}{$/ \mathrm{ta} /$} & GSCB & 14 & $\begin{array}{c}5,08 \\
{[4,05,6,12]}\end{array}$ & 2,47 & $\begin{array}{c}4,85 \\
{[3,50,6,50]}\end{array}$ & 1,00 & 10,00 & \multirow{2}{*}{$0,304^{\mathrm{a}}$} & \multirow{2}{*}{$0,789^{\circ}$} \\
\hline & GC & 20 & $\begin{array}{c}5,82 \\
{[5,45,6,18]}\end{array}$ & ,93 & $\begin{array}{c}5,78 \\
{[5,25,6,25]}\end{array}$ & 4,16 & 7,30 & & \\
\hline \multirow{2}{*}{$/ \mathrm{ka} /$} & GSCB & 14 & $\begin{array}{c}4,74 \\
{[3,69,5,87]}\end{array}$ & 2,56 & $\begin{array}{c}3,65 \\
{[3,00,6,15]}\end{array}$ & 1,10 & 10,00 & \multirow{2}{*}{$0,189^{b}$} & \multirow{2}{*}{0,228} \\
\hline & $\mathrm{GC}$ & 20 & $\begin{array}{c}5,48 \\
{[5,01,6,00]}\end{array}$ & 1,31 & $\begin{array}{c}5,00 \\
{[4,78,6,05]}\end{array}$ & 3,40 & 9,50 & & \\
\hline \multirow{2}{*}{ /pataka/ } & GSCB & 14 & $\begin{array}{c}4,43 \\
{[3,36,5,55]}\end{array}$ & 2,55 & $\begin{array}{c}4,02 \\
{[3,20,4,50]}\end{array}$ & 1,20 & 9,00 & \multirow{2}{*}{$0,007^{\star b}$} & \multirow{2}{*}{$0,457^{r}$} \\
\hline & GC & 20 & $\begin{array}{c}6,18 \\
{[5,60,6,77]}\end{array}$ & 1,30 & $\begin{array}{c}6,00 \\
{[5,55,6,80]}\end{array}$ & 3,80 & 9,13 & & \\
\hline
\end{tabular}

Teste t de Student para amostras independentes $\left({ }^{a}\right)$ e Teste U de Mann-Whitney $\left({ }^{b}\right)$. Legenda: DP: Desvio padrão; Mín.: Mínimo; Máx.: Máximo; *: Valor estatisticamente significante no nível de $5 \%(p \leq 0,05)$; T.E.: Tamanho do efeito. 
Houve diferença entre os grupos apenas para a repetição da sequência de monossílabos /pataka/, sendo que o GSCB apresentou valores inferiores ao GC. Para as demais provas, não houve diferença estatisticamente significante entre os grupos. O tamanho do efeito da diferença entre os grupos na repetição de sequência de monossílabos foi médio (TE) (Rosenthal, 1991).

\subsection{Escalas de funcionalidade da comunicação e gravidade das alterações de linguagem (ASHA-FACS e Escala PASS)}

$\mathrm{Na}$ escala de funcionalidade da comunicação ASHA-FACS não foram obtidos os dados de um paciente, que perdeu o seguimento (sujeito 2). A escala PASS, foi aplicada em todos os sujeitos do GSCB.

A Tabela 7 apresenta a comparação dos grupos na escala ASHA-FACS. Quanto mais próximo do número 7, maior a independência comunicativa.

Tabela 7 - Caracterização do GSCB em relação ao desempenho na escala ASHA-FACS

\begin{tabular}{|c|c|c|c|c|c|c|}
\hline Variável & $\mathbf{n}$ & Média & DP & Mediana & Mín. & Máx. \\
\hline Comunicação social & 19 & $\begin{array}{c}4,08 \\
{[3,11,5,07]}\end{array}$ & 2,09 & $\begin{array}{c}4,42 \\
{[2,61,5,10]}\end{array}$ & 1,00 & 7,00 \\
\hline Necessidades básicas & 19 & $\begin{array}{c}5,04 \\
{[4,09,5,94]}\end{array}$ & 1,88 & $\begin{array}{c}5,80 \\
{[4,28,6,14]}\end{array}$ & 1,14 & 7,00 \\
\hline $\begin{array}{l}\text { Leitura, escrita e conceitos } \\
\text { numéricos }\end{array}$ & 19 & $\begin{array}{c}2,66 \\
{[1,79,3,62]}\end{array}$ & 2,03 & $\begin{array}{c}2,00 \\
{[1,00,2,70]}\end{array}$ & 1,00 & 7,00 \\
\hline Planejamento diário & 19 & $\begin{array}{c}2,97 \\
{[2,18,3,91]}\end{array}$ & 2,00 & $\begin{array}{c}2,20 \\
{[2,20,3,40]}\end{array}$ & 1,00 & 7,00 \\
\hline $\begin{array}{c}\text { Independência comunicativa - } \\
\text { Total }\end{array}$ & 19 & $\begin{array}{c}3,69 \\
{[2,88,4,59]}\end{array}$ & 1,83 & $\begin{array}{c}3,41 \\
{[2,52,4,88]}\end{array}$ & 1,04 & 7,00 \\
\hline
\end{tabular}

Legenda: DP: Desvio padrão; Mín.: Mínimo; Máx.: Máximo.

Os domínios em que os sujeitos do GSCB apresentaram maior dependência comunicativa foram "Leitura, escrita e conceitos numéricos", seguido do "Planejamento diário". O domínio em que os pacientes apresentaram maior independência comunicativa foi na comunicação das necessidades básicas.

A Tabela 8 apresenta a comparação dos grupos na escala PASS. Devido ao fato de as subescalas da PASS se tratarem de variáveis qualitativas ordinais, as medidas de tendência central e de dispersão foram calculadas em termos de 
medianas e quartis, bem como não foram incluídos os valores de média e desviopadrão.

Tabela 8 - Caracterização do GSCB em relação ao desempenho na escala PASS

\begin{tabular}{|c|c|c|c|c|c|c|}
\hline Variável & $\mathbf{n}$ & Mediana & Mín. & Q1 & Q3 & Máx. \\
\hline Articulação & 19 & $\begin{array}{c}0,50 \\
{[0,50,1,00]}\end{array}$ & 0,00 & 0,00 & 1,00 & 3,00 \\
\hline Fluência & 20 & $\begin{array}{c}1,00 \\
{[0,50,2,00]}\end{array}$ & 0,00 & 0,50 & 2,00 & 3,00 \\
\hline Sintaxe e gramática & 20 & $\begin{array}{c}0,50 \\
{[0,00,0,50]}\end{array}$ & 0,00 & 0,00 & 1,00 & 3,00 \\
\hline $\begin{array}{c}\text { Recuperação de palavras e } \\
\text { expressões }\end{array}$ & 20 & $\begin{array}{c}1,00 \\
{[0,50,2,50]}\end{array}$ & 0,00 & 0,50 & 3,00 & 3,00 \\
\hline Repetição & 20 & $\begin{array}{c}0,50 \\
{[0,50,0,75]}\end{array}$ & 0,00 & 0,12 & 1,75 & 3,00 \\
\hline Compreensão auditiva & 20 & $\begin{array}{c}0,75 \\
{[0,00,1,00]}\end{array}$ & 0,00 & 0,00 & 1,75 & 3,00 \\
\hline Compreensão de palavras isoladas & 20 & $\begin{array}{c}0,00 \\
{[0,00,1,00]}\end{array}$ & 0,00 & 0,00 & 1,00 & 3,00 \\
\hline Leitura & 19 & $\begin{array}{c}3,00 \\
{[3,00,3,00]}\end{array}$ & 0,00 & 1,00 & 3,00 & 3,00 \\
\hline Escrita & 16 & $\begin{array}{c}3,00 \\
{[3,00,3,00]}\end{array}$ & 0,00 & 3,00 & 3,00 & 3,00 \\
\hline Comunicação funcional & 20 & $\begin{array}{c}2,00 \\
{[1,50,2,00]}\end{array}$ & 0,00 & 0,62 & 3,00 & 3,00 \\
\hline
\end{tabular}

Legenda: DP: Desvio padrão; Mín.: Mínimo; Máx.: Máximo.

Os domínios linguísticos mais alterados no GSCB, de acordo com a escala PASS, foram: "leitura" e "escrita" (alteração grave) e "comunicação funcional" (alteração moderada). O domínio "compreensão de palavras isoladas" estava preservado e nos domínios "articulação", "sintaxe e gramática" e "repetição" a alteração é questionável/muito leve. Na "compreensão auditiva", o déficit está entre questionável/muito leve e leve. "Fluência" e "recuperação de palavras e expressões" têm déficit leve. 


\subsection{Correlação entre habilidades cognitivas, de linguagem e fala $e$ idade, escolaridade e duração da doença}

A Tabela 9 apresenta a análise de correlação entre pontuação total no ACE- $R$, quociente de afasia do WAB- $R$, a pontuação total da escala de apraxia de fala e idade, escolaridade e duração da doença para o GSCB.

Tabela 9 - Análise de correlação entre pontuação total no ACE-R, quociente de afasia, pontuação total da escala de apraxia de fala e idade, escolaridade e duração da doença para o GSCB

\begin{tabular}{|c|c|c|c|c|}
\hline Variável & & Idade & Escolaridade & Duração da doença \\
\hline \multirow[t]{2}{*}{ ACE-R - Total } & Coef. & $-0,177[-0,517,0,109]$ & $0,650[0,185,0,879]$ & $-0,560[-0,0857,0,056]$ \\
\hline & $p$ & $0,496^{a}$ & $0,005^{\star a}$ & $0,037^{\star \mathrm{b}}$ \\
\hline \multirow[t]{2}{*}{$\begin{array}{c}\text { WAB-R - Quociente de } \\
\text { afasia }\end{array}$} & Coef. & $-0,035[-0,492,0,373]$ & $0,420[-0,186,0,835]$ & $-0,479[-0,854,0,026]$ \\
\hline & $p$ & $0,905^{b}$ & $0,135^{b}$ & $0,083^{b}$ \\
\hline \multirow[t]{2}{*}{$\begin{array}{l}\text { Escala de apraxia de fala - } \\
\text { Total }\end{array}$} & Coef. & $0,016[-0,377,0,389]$ & $-0,320[-0,800,0,148]$ & $0,626[-0,040,0,954]$ \\
\hline & $p$ & $0,953^{\mathrm{a}}$ & $0,211^{a}$ & $0,017^{* \mathrm{~b}}$ \\
\hline
\end{tabular}

Teste de correlação de Pearson (a) e Spearman ${ }^{(b)}$. Legenda: Coef.: Coeficiente; *: Valor estatisticamente significante no nível de $5 \%(p \leq 0,05)$.

Entre as seguintes duplas de variáveis observou-se correlação estatisticamente significante e positiva:

- $\quad$ Duração da doença e escala de apraxia de fala - Total;

- $\quad$ Escolaridade e ACE-R - Total.

Entre a seguinte dupla de variáveis observou-se correlação estatisticamente significante e negativa:

- $\quad$ Duração da doença e ACE-R - Total.

Para as demais duplas de variáveis, não foram observadas correlações estatisticamente significantes na amostra.

\subsection{Comparação dos grupos SCB+ e SCB-}

Os grupos SCB+ e SCB- foram constituídos com base nos resultados do exame de PET-FDG, sendo que no grupo SCB+ se encontram os indivíduos com resultados indicativos de DA e no SCB- aqueles cujo exame não aponta para a DA como doença de base. O grupo SCB+ é composto por sete pacientes 
(sujeitos 3, 6, 7, 9, 10, 11 e 19) e o grupo SCB-, por 13 pacientes (sujeitos 1, 2, $4,5,8,12,13,14,15,16,17,18$ e 20).

Devido ao baixo número amostral, todas as comparações entre os grupos SCB + e SCB- foram realizadas por meio de testes não-paramétricos, e não foram calculados os valores de intervalo de confiança.

\subsubsection{Características sociodemográficas e clínicas}

A Tabela 10 descreve as características gerais dos grupos SCB+ e SCBe apresenta a comparação entre eles.

Tabela 10 - Características sociodemográficas e clínicas dos grupos SCB+ e SCB-

\begin{tabular}{|c|c|c|c|}
\hline Variáveis & $\begin{array}{c}\text { SCB- }(n=13) \\
n(\%)\end{array}$ & $\begin{array}{c}\mathrm{SCB}+(\mathrm{n}=7) \\
\mathrm{n}(\%)\end{array}$ & $P$ \\
\hline \multicolumn{4}{|l|}{ Sexo* } \\
\hline Masculino & $7(53,84)$ & $1(14,28)$ & 0,157 \\
\hline Feminino & $6(46,15)$ & $6(85,71)$ & \\
\hline \multicolumn{4}{|l|}{ Idade $(\text { anos })^{\star *}$} \\
\hline Média $(D P)$ & $65,84(9,69)$ & $70,14(6,91)$ & \\
\hline Mediana & 68,00 & 71,00 & 0,314 \\
\hline Min-Max & $53-83$ & $60-78$ & \\
\hline \multicolumn{4}{|l|}{ Dominância manual* ${ }^{*}$} \\
\hline Destro & $11(84,61)$ & $7(100)$ & $>0,999$ \\
\hline Canhoto & $2(15,38)$ & $0(0)$ & \\
\hline \multicolumn{4}{|l|}{ Escolaridade $(\text { anos })^{\star \star}$} \\
\hline Média (DP) & $8,92(5,61)$ & $7,71(4,53)$ & \\
\hline Mediana & 8,00 & 7,00 & 0,630 \\
\hline Min-Max & $2-20$ & $3-16$ & \\
\hline \multicolumn{4}{|l|}{ Duração da doença (anos) ${ }^{\star *}$} \\
\hline Média (DP) & $5,15(3,26)$ & $6,42(2,14)$ & \\
\hline Mediana & 5,00 & 8,00 & 0,368 \\
\hline Min-Max & $2-13$ & $3-8$ & \\
\hline \multicolumn{4}{|l|}{ Idade de início dos sintomas** } \\
\hline Média (DP) & $60,61(10,42)$ & $63,57(6,70)$ & \\
\hline Mediana & 60,00 & 65,00 & 0,507 \\
\hline Min-Max & $45-78$ & $52-70$ & \\
\hline
\end{tabular}

*Teste Exato de Fisher; **teste t de Student.

Os grupos SCB+ e SCB- não diferem entre si em relação às características sociodemográficas e clínicas.

\subsubsection{Avaliação cognitiva e de linguagem}

A Tabela 11 apresenta a comparação dos grupos SCB+ e SCB- nos testes do ACE-R. 
Tabela 11 - Valores descritivos e análise comparativa dos grupos $\mathrm{SCB}+\mathrm{e}$ SCB- em relação ao desempenho no ACE- $R$

\begin{tabular}{|c|c|c|c|c|c|c|c|c|c|}
\hline Variável & Grupo & $\mathbf{n}$ & Média & DP & Mediana & Mín. & Máx. & $p$ & T.E. \\
\hline \multirow{2}{*}{ Total } & SCB- & 11 & 44,82 & 19,54 & 35,00 & 25,00 & 83,00 & \multirow{2}{*}{0,078} & \multirow{2}{*}{0,428} \\
\hline & $\mathrm{SCB}+$ & 6 & 25,50 & 20,75 & 23,50 & 0,00 & 59,00 & & \\
\hline \multirow{2}{*}{ Atenção } & SCB- & 11 & 10,55 & 4,08 & 10,00 & 5,00 & 18,00 & \multirow{2}{*}{0,057} & \multirow{2}{*}{0,466} \\
\hline & $\mathrm{SCB}+$ & 6 & 6,00 & 4,29 & 6,50 & 0,00 & 11,00 & & \\
\hline \multirow{2}{*}{ Memória } & SCB- & 11 & 10,55 & 7,15 & 8,00 & 2,00 & 23,00 & \multirow{2}{*}{0,114} & \multirow{2}{*}{0,391} \\
\hline & $\mathrm{SCB}+$ & 6 & 5,67 & 6,12 & 4,00 & 0,00 & 14,00 & & \\
\hline \multirow{2}{*}{ Fluência verbal } & SCB- & 11 & 2,45 & 2,70 & 2,00 & ,00 & 7,00 & \multirow{2}{*}{0,627} & \multirow{2}{*}{0,126} \\
\hline & $\mathrm{SCB}+$ & 6 & 1,67 & 2,25 & 1,00 & 0,00 & 6,00 & & \\
\hline \multirow{2}{*}{ Linguagem } & SCB- & 11 & 15,45 & 5,82 & 15,00 & 8,00 & 25,00 & \multirow{2}{*}{0,104} & \multirow{2}{*}{0,403} \\
\hline & $\mathrm{SCB}+$ & 6 & 10,33 & 8,87 & 7,50 & 0,00 & 26,00 & & \\
\hline \multirow{2}{*}{$\begin{array}{c}\text { Habilidades visuo- } \\
\text { espaciais }\end{array}$} & SCB- & 11 & 5,82 & 4,02 & 6,00 & 0,00 & 12,00 & \multirow{2}{*}{0,051} & \multirow{2}{*}{0,486} \\
\hline & $\mathrm{SCB}+$ & 6 & 1,83 & 2,04 & 1,50 & 0,00 & 4,00 & & \\
\hline
\end{tabular}

Teste U de Mann-Whitney. Legenda: DP: Desvio padrão; Mín.: Mínimo; Máx.: Máximo; T.E.: Tamanho do efeito.

Não houve diferença entre os grupos para todos os subtestes do ACE-R. Sendo assim, indivíduos com DA provável tiveram desempenho semelhante a indivíduos sem DA em relação ao desempenho no ACE-R. Houve uma tendência à significância nos testes de atenção e habilidades visuoespaciais, sendo que os pacientes com biomarcador de DA apresentaram desempenho inferior.

A Tabela 12 apresenta a comparação dos grupos SCB+ e SCB- nos testes do WAB-R.

Tabela 12 - Valores descritivos e análise comparativa dos grupos SCB+e SCB- em relação ao desempenho no WAB-R

\begin{tabular}{|c|c|c|c|c|c|c|c|c|c|}
\hline Variável & Grupo & $\mathbf{n}$ & Média & DP & Mediana & Mín. & Máx. & $p$ & T.E. \\
\hline \multirow{2}{*}{ Quociente de afasia } & SCB - & 11 & 68,06 & 32,53 & 82,70 & 1,20 & 97,50 & \multirow{2}{*}{0,256} & \multirow{2}{*}{0,292} \\
\hline & $\mathrm{SCB}+$ & 6 & 46,77 & 38,00 & 47,85 & 6,20 & 97,20 & & \\
\hline \multirow{2}{*}{$\begin{array}{l}\text { Fala espontânea - conteúdo } \\
\text { da informação }\end{array}$} & SCB- & 13 & 7,00 & 2,86 & 8,00 & 0,00 & 10,00 & \multirow{2}{*}{0,192} & \multirow{2}{*}{0,299} \\
\hline & $\mathrm{SCB}+$ & 7 & 5,00 & 3,65 & 5,00 & 0,00 & 10,00 & & \\
\hline \multirow{2}{*}{$\begin{array}{l}\text { Fala espontânea - pontuação } \\
\text { fluência }\end{array}$} & SCB- & 13 & 6,38 & 3,78 & 9,00 & 0,00 & 10,00 & \multirow{2}{*}{0,327} & \multirow{2}{*}{0,227} \\
\hline & $\mathrm{SCB}+$ & 7 & 4,86 & 3,58 & 5,00 & 0,00 & 10,00 & & \\
\hline \multirow{3}{*}{$\begin{array}{l}\text { Compreensão auditiva - } \\
\text { questões sim/não }\end{array}$} & SCB- & 13 & 46,31 & 21,55 & 57,00 & 0,00 & 60,00 & \multirow{2}{*}{0,492} & \multirow{2}{*}{0,162} \\
\hline & SCB+ & 7 & 40,57 & 21,81 & 51,00 & 5,00 & 60,00 & & \\
\hline & SCB- & 11 & 38,55 & 22,73 & 53,00 & 2,00 & 60,00 & 0,419 & 0,208 \\
\hline
\end{tabular}




\begin{tabular}{|c|c|c|c|c|c|c|c|c|c|}
\hline $\begin{array}{l}\text { Compreensão auditiva - } \\
\text { reconhecimento auditivo da } \\
\text { palavra }\end{array}$ & $\mathrm{SCB}+$ & 6 & 30,50 & 25,97 & 32,00 & 2,00 & 58,00 & & \\
\hline Compreensão auditiva - & SCB- & 11 & 51,27 & 29,48 & 63,00 & 2,00 & 80,00 & 0115 & 0106 \\
\hline Comandos sequenciais & $\mathrm{SCB}+$ & 6 & 36,33 & 29,03 & 37,50 & 4,00 & 80,00 & טדוד, & , \\
\hline Donotioño & SCB- & 13 & 72,31 & 31,20 & 90,00 & 0,00 & 96,00 & 107 & 200 \\
\hline & $\mathrm{SCB}+$ & 7 & 49,14 & 39,41 & 66,00 & 4,00 & 96,00 & 0,108 & $0,00<$ \\
\hline Nomoneñ & SCB- & 13 & 42,62 & 19,93 & 54,00 & 1,00 & 60,00 & & \\
\hline 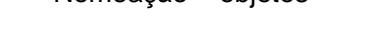 & $\mathrm{SCB}+$ & 7 & 22,57 & 24,46 & 9,00 & 0,00 & 60,00 & & \\
\hline Nomeação - fluência verbal & SCB- & 13 & 5,77 & 6,02 & 5,00 & 0,00 & 20,00 & 138 & 0339 \\
\hline semântica & $\mathrm{SCB}+$ & 7 & 1,86 & 4,06 & 0,00 & 0,00 & 11,00 & 0,100 & , \\
\hline Nomeação - completar & SCB- & 13 & 6,31 & 4,03 & 8,00 & 0,00 & 10,00 & 0236 & 0272 \\
\hline sentenças & SCB+ & 7 & 3,71 & 4,07 & 4,00 & 0,00 & 10,00 & & \\
\hline Nomeação - denominação & SCB- & 13 & 6,38 & 3,97 & 8,00 & 0,00 & 10,00 & 5 & \\
\hline & $\mathrm{SCB}+$ & 7 & 3,71 & 3,90 & 2,00 & 0,00 & 10,00 & & \\
\hline
\end{tabular}

Teste U de Mann-Whitney. Legenda: DP: Desvio padrão; Mín.: Mínimo; Máx.: Máximo; T.E.: Tamanho do efeito.

Não houve diferença entre os grupos para todos os subtestes do WAB-R. Sendo assim, indivíduos com DA provável tiveram desempenho semelhante a indivíduos sem DA.

A Tabela 13 apresenta a comparação dos grupos SCB+ e SCB- nos testes da UDS.

Tabela 13 - Valores descritivos e análise comparativa dos grupos SCB+e SCB- em relação ao desempenho na UDS

\begin{tabular}{|c|c|c|c|c|c|c|c|c|c|}
\hline Variável & Grupo & $\mathbf{n}$ & Média & DP & Mediana & Mín. & Máx. & $p$ & T.E. \\
\hline \multirow{2}{*}{$\begin{array}{l}\text { Cópia imediata da figura } \\
\text { complexa de Benson }\end{array}$} & SCB- & 11 & 3,82 & 6,59 & 0,00 & 0,00 & 15,00 & \multirow{2}{*}{0,353} & \multirow{2}{*}{0,330} \\
\hline & $\mathrm{SCB}+$ & 6 & 0,00 & 0,00 & 0,00 & 0,00 & 0,00 & & \\
\hline \multirow{2}{*}{ Fluência verbal fonêmica "p" } & SCB- & 12 & 1,92 & 2,47 & 0,50 & 0,00 & 6,00 & \multirow{2}{*}{0,466} & \multirow{2}{*}{0,184} \\
\hline & $\mathrm{SCB}+$ & 7 & 1,57 & 3,74 & 0,00 & 0,00 & 10,00 & & \\
\hline \multirow{2}{*}{ Fluência verbal fonêmica "a" } & SCB- & 12 & 1,83 & 2,59 & 0,00 & 0,00 & 7,00 & \multirow{2}{*}{0,404} & \multirow{2}{*}{0,223} \\
\hline & $\mathrm{SCB}+$ & 7 & 1,00 & 2,65 & 0,00 & 0,00 & 7,00 & & \\
\hline \multirow{2}{*}{ Fluência verbal semântica } & SCB- & 13 & 3,46 & 3,53 & 3,00 & 0,00 & 10,00 & \multirow{2}{*}{0,136} & \multirow{2}{*}{0,342} \\
\hline & $\mathrm{SCB}+$ & 7 & 1,14 & 2,27 & 0,00 & 0,00 & 6,00 & & \\
\hline \multirow{2}{*}{ Leitura de palavras regulares } & SCB- & 12 & 8,00 & 7,05 & 9,50 & 0,00 & 15,00 & \multirow{2}{*}{0,740} & \multirow{2}{*}{0,092} \\
\hline & $\mathrm{SCB}+$ & 7 & 7,29 & 7,20 & 8,00 & 0,00 & 15,00 & & \\
\hline \multirow{3}{*}{ Leitura de palavras irregulares } & SCB- & 12 & 4,75 & 6,36 & 0,00 & 0,00 & 15,00 & \multirow{2}{*}{0,944} & \multirow{2}{*}{0,021} \\
\hline & $\mathrm{SCB}+$ & 7 & 3,71 & 4,27 & 3,00 & 0,00 & 10,00 & & \\
\hline & SCB- & 13 & 8,69 & 9,83 & 0,00 & 0,00 & 20,00 & 0,687 & 0,097 \\
\hline
\end{tabular}




\begin{tabular}{|c|c|c|c|c|c|c|c|c|c|}
\hline \multirow[b]{2}{*}{$\begin{array}{l}\text { Emparelhamento semântico } \\
\text { (compreensão auditiva) }\end{array}$} & \multirow[b]{2}{*}{$\mathrm{SCB}+$} & \multirow[b]{2}{*}{7} & \multirow[b]{2}{*}{7,14} & \multirow[b]{2}{*}{9,14} & \multirow[b]{2}{*}{0,00} & \multirow[b]{2}{*}{0,00} & \multirow[b]{2}{*}{20,00} & & \\
\hline & & & & & & & & & \\
\hline \multirow{2}{*}{ Associação semântica } & SCB- & 13 & 8,15 & 6,91 & 12,00 & 0,00 & 16,00 & \multirow{2}{*}{0,366} & \multirow{2}{*}{0,205} \\
\hline & $\mathrm{SCB}+$ & 7 & 5,00 & 6,76 & 0,00 & 0,00 & 16,00 & & \\
\hline \multirow{2}{*}{$\begin{array}{l}\text { Cópia tardia da figura complexa } \\
\text { de Benson }\end{array}$} & SCB- & 11 & 1,73 & 3,26 & 0,00 & 0,00 & 9,00 & \multirow{2}{*}{0,353} & \multirow{2}{*}{0,330} \\
\hline & $\mathrm{SCB}+$ & 6 & 0,00 & 0,00 & 0,00 & 0,00 & 0,00 & & \\
\hline \multirow{2}{*}{ Northwestern Anagram Test } & SCB- & 10 & 2,80 & 3,88 & 0,00 & 0,00 & 10,00 & \multirow{2}{*}{0,452} & \multirow{2}{*}{0,265} \\
\hline & $\mathrm{SCB}+$ & 6 & 0,83 & 2,04 & 0,00 & 0,00 & 5,00 & & \\
\hline \multirow{2}{*}{ Repetição de sentenças } & SCB- & 13 & 3,08 & 2,02 & 4,00 & 0,00 & 5,00 & \multirow{2}{*}{0,108} & \multirow{2}{*}{0,383} \\
\hline & SCB+ & 7 & 1,43 & 1,99 & 0,00 & 0,00 & 5,00 & & \\
\hline \multirow{2}{*}{ Nomeação de substantivos } & SCB- & 13 & 7,77 & 7,54 & 7,00 & 0,00 & 16,00 & \multirow{2}{*}{0,261} & \multirow{2}{*}{0,261} \\
\hline & $\mathrm{SCB}+$ & 7 & 5,57 & 6,97 & 0,00 & 0,00 & 14,00 & & \\
\hline \multirow{2}{*}{ Nomeação de verbos } & SCB- & 13 & 6,85 & 6,84 & 9,00 & 0,00 & 16,00 & \multirow{2}{*}{0,291} & \multirow{2}{*}{0,246} \\
\hline & $\mathrm{SCB}+$ & 7 & 3,57 & 4,83 & 0,00 & 0,00 & 12,00 & & \\
\hline \multirow{2}{*}{ Leitura } & SCB- & 12 & 2,17 & 2,52 & 0,50 & 0,00 & 5,00 & \multirow{2}{*}{$\stackrel{>}{0,999}$} & \multirow{2}{*}{0,033} \\
\hline & SCB+ & 7 & 2,14 & 2,67 & 0,00 & 0,00 & 5,00 & & \\
\hline
\end{tabular}

Teste U de Mann-Whitney. Legenda: DP: Desvio padrão; Mín.: Mínimo; Máx:: Máximo; T.E.: Tamanho do efeito.

Não houve diferença entre os grupos para todos os testes da UDS. Sendo assim, indivíduos com DA provável tiveram desempenho semelhante a indivíduos sem DA.

\subsubsection{Avaliação da fala}

A Tabela 14 apresenta a comparação dos grupos SCB+ e SCB- nos parâmetros da escala de apraxia de fala.

Tabela 14 - Valores descritivos e análise comparativa dos grupos SCB+e SCB- em relação ao desempenho na escala de apraxia de fala

\begin{tabular}{|c|c|c|c|c|c|c|c|c|c|}
\hline Variável & Grupo & $\mathbf{n}$ & Média & DP & Mediana & Mín. & Máx. & $p$ & T.E. \\
\hline \multirow{2}{*}{ 1.1 Substituições distorcidas } & SCB- & 12 & 1,33 & 1,23 & 1,00 & 0,00 & 4,00 & \multirow{2}{*}{0,973} & \multirow{2}{*}{0,021} \\
\hline & $\mathrm{SCB}+$ & 7 & 1,29 & 0,95 & 1,00 & 0,00 & 3,00 & & \\
\hline \multirow{2}{*}{ 1.2 Adição de som distorcido } & SCB- & 12 & 0,75 & 1,22 & 0,00 & 0,00 & 4,00 & \multirow{2}{*}{0,825} & \multirow{2}{*}{0,054} \\
\hline & $\mathrm{SCB}+$ & 7 & 0,57 & 0,53 & 1,00 & 0,00 & 1,00 & & \\
\hline \multirow{3}{*}{$\begin{array}{l}\text { 1.3 Aumento das distorções } \\
\text { ou substituições distorcidas } \\
\text { na medida em que aumenta } \\
\text { o enunciado ou a } \\
\text { complexidade articulatória } \\
\text { das sílabas/palavras }\end{array}$} & SCB- & 12 & 2,08 & 1,31 & 2,00 & 0,00 & 4,00 & & \\
\hline & $\mathrm{SCB}+$ & 7 & 2,43 & 0,79 & 3,00 & 1,00 & 3,00 & 0,548 & 0,152 \\
\hline & SCB- & 12 & 1,25 & 1,29 & 1,00 & 0,00 & 3,00 & 0,595 & 0,140 \\
\hline
\end{tabular}




\begin{tabular}{|c|c|c|c|c|c|c|c|c|c|}
\hline \multirow[b]{2}{*}{$\begin{array}{l}\text { 1.4 Aumento das distorções } \\
\text { de som ou substituições } \\
\text { distorcidas com o aumento } \\
\text { da taxa de fala }\end{array}$} & \multirow[b]{2}{*}{$\mathrm{SCB}+$} & \multirow[b]{2}{*}{7} & \multirow[b]{2}{*}{1,57} & \multirow[b]{2}{*}{0,98} & \multirow[b]{2}{*}{2,00} & \multirow[b]{2}{*}{0,00} & \multirow[b]{2}{*}{3,00} & \\
\hline & & & & & & & & & \\
\hline \multirow{2}{*}{$\begin{array}{c}1.5 \text { Imprecisão na repetição } \\
\text { de monossílabos (no local } \\
\text { ou no modo) }\end{array}$} & SCB- & 9 & 0,55 & 0,52 & 1,00 & 0,00 & 1,00 & \multirow{2}{*}{0,317} & \multirow{2}{*}{0,277} \\
\hline & $\mathrm{SCB}+$ & 5 & 0,20 & 0,44 & 0,00 & 0,00 & 1,00 & & \\
\hline \multirow{2}{*}{ Total seção 1} & SCB- & 12 & 5,83 & 4,34 & 6,00 & 0,00 & 14,00 & \multirow{2}{*}{0,754} & \multirow{2}{*}{0,078} \\
\hline & $\mathrm{SCB}+$ & 7 & 6,00 & 2,08 & 6,00 & 3,00 & 8,00 & & \\
\hline \multirow{2}{*}{$\begin{array}{l}\text { 2.1 Segmentação silábica } \\
\text { dentro de palavras > } 1 \text { sílaba }\end{array}$} & SCB- & 12 & 1,25 & 1,36 & 1,00 & 0,00 & 4,00 & \multirow{2}{*}{0,356} & \multirow{2}{*}{0,238} \\
\hline & $\mathrm{SCB}+$ & 7 & 0,57 & 0,79 & 0,00 & 0,00 & 2,00 & & \\
\hline \multirow{2}{*}{$\begin{array}{l}\text { 2.2 Segmentação silábica } \\
\text { em palavras inseridas em } \\
\text { sentenças }\end{array}$} & SCB- & 12 & 1,33 & 1,50 & 1,00 & 0,00 & 4,00 & \multirow{2}{*}{0,346} & \multirow{2}{*}{0,238} \\
\hline & $\mathrm{SCB}+$ & 7 & 0,57 & 0,79 & 0,00 & 0,00 & 2,00 & & \\
\hline \multirow{2}{*}{ 2.3 Distorção de sons } & SCB- & 12 & 2,17 & 1,40 & 2,00 & 0,00 & 4,00 & \multirow{2}{*}{0,337} & \multirow{2}{*}{0,231} \\
\hline & $\mathrm{SCB}+$ & 7 & 1,43 & 0,79 & 2,00 & 0,00 & 2,00 & & \\
\hline \multirow{2}{*}{$\begin{array}{l}\text { 2.4 Diminuição da taxa de } \\
\text { fala }\end{array}$} & SCB- & 12 & 2,33 & 1,23 & 2,50 & 0,00 & 4,00 & \multirow{2}{*}{0,643} & \multirow{2}{*}{0,130} \\
\hline & $\mathrm{SCB}+$ & 7 & 2,57 & 1,51 & 3,00 & 0,00 & 4,00 & & \\
\hline 2.5 Aumento da duração de & SCB- & 12 & 1,50 & 1,51 & 1,50 & 0,00 & 4,00 & & \\
\hline $\begin{array}{l}\text { Vogals e/ou segmentos } \\
\text { consonantais }\end{array}$ & $\mathrm{SCB}+$ & 7 & 0,71 & 0,95 & 0,00 & 0,00 & 2,00 & 0,286 & 0,258 \\
\hline 2.6 Prolongamento da & SCB- & 12 & 1,50 & 1,62 & 1,00 & 0,00 & 4,00 & & \\
\hline $\begin{array}{c}\text { duração entre os segmentos } \\
\text { (fonemas, sílabas, palavras } \\
\text { ou frases) }\end{array}$ & $\mathrm{SCB}+$ & 7 & 0,86 & 0,90 & 1,00 & 0,00 & 2,00 & 0,533 & 0,152 \\
\hline Total secão 2 & SCB- & 12 & 10,08 & 7,39 & 9,00 & 1,00 & 22,00 & 0.518 & 0,156 \\
\hline & $\mathrm{SCB}+$ & 7 & 6,71 & 4,19 & 5,00 & 3,00 & 14,00 & & \\
\hline $\begin{array}{l}\text { 3.1 Repetição de sequência } \\
\text { de monossílabos mais lenta. }\end{array}$ & SCB- & 9 & 1,00 & 1,00 & 1,00 & 0,00 & 3,00 & & \\
\hline $\begin{array}{l}\text { segmentada e/ou distorcida } \\
\text { na comparação com a } \\
\text { repetição de monossílabos }\end{array}$ & $\mathrm{SCB}+$ & 5 & 2,80 & 0,83 & 3,00 & 2,00 & 4,00 & $0,016^{*}$ & 0,406 \\
\hline 3.2 Ensaios articulatórios & SCB- & 12 & 1,33 & 1,07 & 1,00 & 0,00 & 3,00 & & \\
\hline $\begin{array}{l}\text { dificuldade em iniciar a fala; } \\
\text { falsos inícios/recomeços }\end{array}$ & $\mathrm{SCB}+$ & 7 & 1,71 & 1,11 & 1,00 & 1,00 & 4,00 & 0,516 & 0,143 \\
\hline & SCB- & 12 & 2,08 & 1,68 & 1,50 & 0,00 & 6,00 & $0000 *$ & P \\
\hline & $\mathrm{SCB}+$ & 7 & 3,71 & 1,38 & 4,00 & 1,00 & 5,00 & & \\
\hline 4.1 Repetição de som ou de & SCB- & 12 & 1,25 & 1,22 & 1,00 & 0,00 & 3,00 & 0.51 & 0021 \\
\hline sílaba & $\mathrm{SCB}+$ & 7 & 1,00 & 0,58 & 1,00 & 0,00 & 2,00 & & \\
\hline $\begin{array}{l}\text { 4.2 Prolongamentos de som } \\
\text { (além dos segmentos }\end{array}$ & SCB- & 12 & 1,33 & 1,67 & 0,50 & 0,00 & 4,00 & & \\
\hline $\begin{array}{l}\text { vocálicos e consonantais } \\
\text { cuja duração está } \\
\text { aumentada) }\end{array}$ & $\mathrm{SCB}+$ & 7 & 0,43 & 0,79 & 0,00 & 0,00 & 2,00 & 0,268 & 0,260 \\
\hline & SCB- & 12 & 2,58 & 2,64 & 2,00 & 0,00 & 7,00 & $\operatorname{mins}$ & 0170 \\
\hline IVtal ડల̧̧au 4 & $\mathrm{SCB}+$ & 7 & 1,43 & 1,27 & 1,00 & 0,00 & 4,00 & 0,461 & $0,1 / 9$ \\
\hline Totolo & SCB- & 12 & 20,58 & 13,96 & 16,50 & 1,00 & 47,00 & 0010 & ل \\
\hline Tular yerai & $\mathrm{SCB}+$ & 7 & 18,00 & 7,05 & 16,00 & 9,00 & 30,00 & & \\
\hline
\end{tabular}

Teste U de Mann-Whitney. Legenda: DP: Desvio padrão; Mín.: Mínimo; Máx.: Máximo; *: Valor estatisticamente significante no nível de $5 \%$ ( $p \leq 0,05)$; T.E.: Tamanho do efeito. 
Houve diferença entre os grupos para o item 3.1 "Repetição de sequência de monossílabos mais lenta, segmentada e/ou distorcida na comparação com a repetição de monossílabos" e para a pontuação total da seção 3, com maiores valores para o grupo SCB+ nos dois casos. Para os demais parâmetros, não houve diferença estatisticamente significante entre os grupos. $O$ tamanho do efeito da diferença entre os grupos no item 3.1 e na seção 3 foi médio (Rosenthal, 1991).

A Tabela 15 apresenta a comparação dos grupos SCB+ e SCB- nas provas de diadococinesia oral.

Tabela 15 - Valores descritivos e análise comparativa dos grupos SCB+e SCB- em relação ao desempenho na diadococinesia oral

\begin{tabular}{|c|c|c|c|c|c|c|c|c|c|}
\hline Variável & Grupo & $\mathbf{n}$ & Média & DP & Mediana & Mín. & Máx. & $p$ & T.E. \\
\hline \multirow{2}{*}{$/ p a /$} & SCB- & 9 & 5,39 & 3,05 & 4,00 & 1,20 & 10,00 & \multirow{2}{*}{0,898} & \multirow{2}{*}{0,053} \\
\hline & $\mathrm{SCB}+$ & 5 & 4,83 & 1,40 & 4,75 & 3,40 & 6,30 & & \\
\hline \multirow{2}{*}{$/ \mathrm{ta} /$} & SCB- & 9 & 5,05 & 2,83 & 4,50 & 1,00 & 10,00 & \multirow{2}{*}{0,868} & \multirow{2}{*}{0,054} \\
\hline & $\mathrm{SCB}+$ & 5 & 5,14 & 1,96 & 5,20 & 2,50 & 7,75 & & \\
\hline \multirow{2}{*}{$/ \mathrm{ka} /$} & SCB- & 9 & 4,97 & 3,00 & 3,80 & 1,10 & 10,00 & \multirow{2}{*}{0,774} & \multirow{2}{*}{0,089} \\
\hline & $\mathrm{SCB}+$ & 5 & 4,34 & 1,73 & 3,50 & 2,50 & 6,80 & & \\
\hline \multirow{2}{*}{ /pataka/ } & SCB- & 9 & 4,96 & 3,04 & 4,50 & 1,20 & 9,00 & \multirow{2}{*}{0,415} & \multirow{2}{*}{0,233} \\
\hline & $\mathrm{SCB}+$ & 5 & 3,49 & 0,95 & 3,82 & 2,00 & 4,50 & & \\
\hline
\end{tabular}

Teste U de Mann-Whitney. Legenda: DP: Desvio padrão; Mín.: Mínimo; Máx.: Máximo; T.E.: Tamanho do efeito.

Não houve diferença entre os grupos para todos os parâmetros da diadococinesia oral.

\subsubsection{Alteração morfossintática, disartria e apraxia de fala}

A Tabela 16 apresenta a distribuição dos indivíduos SCB+ e SCB- e do grupo GSCB inteiro em relação à presença de alteração morfossintática, disartria e apraxia de fala. Um paciente foi excluído dessa análise (sujeito 12) pois se encontrava em mutismo. 
Tabela 16 - Comparação dos grupos SCB+, SCB- e GSCB em relação à presença de alteração morfossintática, disartria e apraxia de fala

\begin{tabular}{|c|c|c|c|c|c|}
\hline \multirow[t]{3}{*}{ Variável } & \multirow[t]{3}{*}{ Categorias } & \multicolumn{3}{|c|}{ Grupo } & \multirow[t]{3}{*}{$p$} \\
\hline & & SCB- & $\mathrm{SCB}+$ & GSCB & \\
\hline & & $\mathrm{n}(\%)$ & $\mathrm{n}(\%)$ & $\mathrm{n}(\%)$ & \\
\hline \multirow{2}{*}{ Alteração morfossintática } & Sim & $1(8,33)$ & $0(0,00)$ & $1(5,26)$ & \multirow{2}{*}{$>0,999$} \\
\hline & Não & $11(91,67)$ & $7(100)$ & $18(94,74)$ & \\
\hline \multirow{2}{*}{ Disartria } & Sim & $4(33,33)$ & $0(0,00)$ & $4(21,05)$ & \multirow{2}{*}{0,245} \\
\hline & Não & $8(66,66)$ & $7(100)$ & $15(78,94)$ & \\
\hline \multirow{2}{*}{ Apraxia de fala } & Sim & $7(58,33)$ & $4(57,14)$ & $11(57,89)$ & \multirow{2}{*}{$>0,99$} \\
\hline & Não & $5(41,66)$ & $3(42,85)$ & $8(42,10)$ & \\
\hline
\end{tabular}

Teste exato de Fisher.

Não houve diferença estatisticamente significante entre os grupos em relação à presença de alteração morfossintática, disartria e apraxia de fala. Sendo assim, a proporção de indivíduos com alteração morfossintática, disartria e apraxia de fala foi semelhante nos grupos com e sem DA provável.

\subsubsection{Escalas de funcionalidade da comunicação e de gravidade das alterações linguísticas}

A Tabela 17 apresenta a comparação dos grupos SCB+ e SCB- na escala de funcionalidade da comunicação ASHA-FACS.

Tabela 17 - Valores descritivos e análise comparativa dos grupos $\mathrm{SCB}+\mathrm{e}$ SCB- em relação ao desempenho na ASHA-FACS

\begin{tabular}{|c|c|c|c|c|c|c|c|c|c|}
\hline Variável & Grupo & $\mathbf{n}$ & Média & DP & Mediana & Mín. & Máx. & $p$ & T.E. \\
\hline \multirow{2}{*}{$\begin{array}{l}\text { Comunicação } \\
\text { social }\end{array}$} & SCB- & 12 & 4,44 & 2,15 & 4,81 & 1,19 & 7,00 & \multirow{2}{*}{0,299} & \multirow{2}{*}{0,252} \\
\hline & $\mathrm{SCB}+$ & 7 & 3,47 & 1,99 & 3,42 & 1,00 & 6,50 & & \\
\hline \multirow{2}{*}{$\begin{array}{l}\text { Necessidades } \\
\text { básicas }\end{array}$} & SCB- & 12 & 5,37 & 1,69 & 6,05 & 2,42 & 7,00 & \multirow{2}{*}{0,307} & \multirow{2}{*}{0,244} \\
\hline & $\mathrm{SCB}+$ & 7 & 4,49 & 2,18 & 5,50 & 1,14 & 6,70 & & \\
\hline \multirow{2}{*}{$\begin{array}{l}\text { Leitura, escrita } \\
\text { e conceitos } \\
\text { numéricos }\end{array}$} & SCB- & 12 & 3,24 & 2,23 & 2,50 & 1,00 & 7,00 & \multirow{2}{*}{0,145} & \multirow{2}{*}{0,343} \\
\hline & $\mathrm{SCB}+$ & 7 & 1,67 & 1,21 & 1,00 & 1,00 & 4,11 & & \\
\hline \multirow{2}{*}{$\begin{array}{l}\text { Planejamento } \\
\text { diário }\end{array}$} & SCB- & 12 & 3,53 & 2,12 & 3,50 & 1,00 & 7,00 & \multirow{2}{*}{0,131} & \multirow{2}{*}{0,357} \\
\hline & $\mathrm{SCB}+$ & 7 & 2,00 & 1,43 & 1,60 & 1,00 & 5,00 & & \\
\hline \multirow{2}{*}{$\begin{array}{c}\text { Total - } \\
\text { Independência } \\
\text { comunicativa }\end{array}$} & SCB- & 12 & 4,14 & 1,90 & 4,29 & 1,55 & 7,00 & \multirow{2}{*}{0,142} & \multirow{2}{*}{0,349} \\
\hline & $\mathrm{SCB}+$ & 7 & 2,91 & 1,52 & 3,14 & 1,04 & 5,58 & & \\
\hline
\end{tabular}

Teste U de Mann-Whitney. Legenda: DP: Desvio padrão; Mín.: Mínimo; Máx.: Máximo; T.E.: Tamanho do efeito. 
Não houve diferença entre os grupos para todos os domínios da ASHAFACS. Sendo assim, indivíduos com DA provável tiveram desempenho semelhante a indivíduos sem DA em relação à funcionalidade da comunicação.

A Tabela 18 apresenta a comparação dos grupos SCB+ e SCB- na escala PASS.

Tabela 18 - Valores descritivos e análise comparativa dos grupos SCB+e SCB- em relação ao desempenho na escala PASS

\begin{tabular}{|c|c|c|c|c|c|c|c|c|c|}
\hline Variável & Grupo & $\mathbf{n}$ & Mediana & Mín. & Q1 & Q3 & Máx. & p & T.E. \\
\hline \multirow{2}{*}{ Articulação } & SCB- & 12 & 1,00 & 0,00 & 0,25 & 1,00 & 2,00 & \multirow{2}{*}{0,277} & \multirow{2}{*}{0,271} \\
\hline & $\mathrm{SCB}+$ & 7 & 0,50 & 0,00 & 0,00 & 0,50 & 3,00 & & \\
\hline \multirow{2}{*}{ Fluência } & SCB- & 13 & 1,00 & 0,00 & 0,50 & 2,00 & 3,00 & \multirow{2}{*}{$>0,999$} & \multirow{2}{*}{0,000} \\
\hline & SCB+ & 7 & 1,00 & 0,00 & 0,50 & 3,00 & 3,00 & & \\
\hline \multirow{2}{*}{ Sintaxe e gramática } & SCB- & 13 & 0,50 & 0,00 & 0,00 & 1,00 & 3,00 & \multirow{2}{*}{0,721} & \multirow{2}{*}{0,085} \\
\hline & $\mathrm{SCB}+$ & 7 & 0,00 & 0,00 & 0,00 & 3,00 & 3,00 & & \\
\hline \multirow{2}{*}{$\begin{array}{l}\text { Recuperação de palavras e } \\
\text { expressões }\end{array}$} & SCB- & 13 & 0,50 & 0,00 & 0,00 & 1,00 & 3,00 & \multirow{2}{*}{$0,004^{\star}$} & \multirow{2}{*}{0,619} \\
\hline & $\mathrm{SCB}+$ & 7 & 3,00 & 0,50 & 2,00 & 3,00 & 3,00 & & \\
\hline \multirow{2}{*}{ Repetição } & SCB- & 13 & 0,50 & 0,00 & 0,00 & 1,00 & 3,00 & \multirow{2}{*}{0,085} & \multirow{2}{*}{0,385} \\
\hline & SCB+ & 7 & 1,00 & 0,50 & 0,50 & 2,00 & 3,00 & & \\
\hline \multirow{2}{*}{ Compreensão auditiva } & SCB- & 13 & 0,00 & 0,00 & 0,00 & 1,00 & 3,00 & \multirow{2}{*}{0,217} & \multirow{2}{*}{0,282} \\
\hline & $\mathrm{SCB}+$ & 7 & 1,00 & 0,00 & 0,00 & 2,00 & 2,00 & & \\
\hline \multirow{2}{*}{$\begin{array}{l}\text { Compreensão de palavras } \\
\text { isoladas }\end{array}$} & SCB- & 13 & 0,00 & 0,00 & 0,00 & 1,00 & 3,00 & \multirow{2}{*}{0,209} & \multirow{2}{*}{0,282} \\
\hline & $\mathrm{SCB}+$ & 7 & 0,50 & 0,00 & 0,00 & 2,00 & 2,00 & & \\
\hline \multirow{2}{*}{ Leitura } & SCB- & 12 & 2,00 & 0,00 & 0,75 & 3,00 & 3,00 & \multirow{2}{*}{0,458} & \multirow{2}{*}{0,191} \\
\hline & $\mathrm{SCB}+$ & 7 & 3,00 & 1,00 & 1,00 & 3,00 & 3,00 & & \\
\hline \multirow{2}{*}{ Escrita } & SCB- & 10 & 3,00 & 0,00 & 0,50 & 3,00 & 3,00 & \multirow{2}{*}{0,250} & \multirow{2}{*}{0,359} \\
\hline & $\mathrm{SCB}+$ & 6 & 3,00 & 3,00 & 3,00 & 3,00 & 3,00 & & \\
\hline \multirow{2}{*}{ Comunicação } & SCB- & 13 & 1,00 & 0,00 & 0,50 & 3,00 & 3,00 & \multirow{2}{*}{0,397} & \multirow{2}{*}{0,211} \\
\hline & $\mathrm{SCB}+$ & 7 & 2,00 & 0,50 & 1,00 & 3,00 & 3,00 & & \\
\hline
\end{tabular}

Teste U de Mann-Whitney. Legenda: DP: Desvio padrão; Mín.: Mínimo; Máx.: Máximo; *: Valor estatisticamente significante no nível de $5 \%(p \leq 0,05)$; T.E.: Tamanho do efeito.

Houve diferença entre os grupos apenas para a pontuação total da subescala "Recuperação de palavras e expressões", com maiores valores para o grupo SCB+. Para as demais subescalas, não houve diferença estatisticamente significante entre os grupos. Sendo assim, cuidadores/familiares de indivíduos com DA provável referiram pior desempenho no acesso lexical, medido pela Escala PASS, quando comparados a indivíduos sem DA. 


\subsection{Proporção de pacientes com desempenho abaixo do GC em relação a cognição, linguagem e fala}

Para o cálculo da proporção de pacientes que teve desempenho abaixo do GC nos testes de cognição, fala e linguagem foram utilizadas as medianas do GC referentes a cada variável.

O Gráfico 1 apresenta a porcentagem de pacientes dos grupos SCB-, $\mathrm{SCB}+$ e GSCB cujo desempenho foi abaixo do GC em subtestes selecionados de cognição, fala e linguagem. Os subtestes foram agrupados por cores, que representam o principal processamento linguístico envolvido.

Gráfico 1 - Porcentagem de pacientes com desempenho abaixo do GC em provas de cognição, fala e linguagem

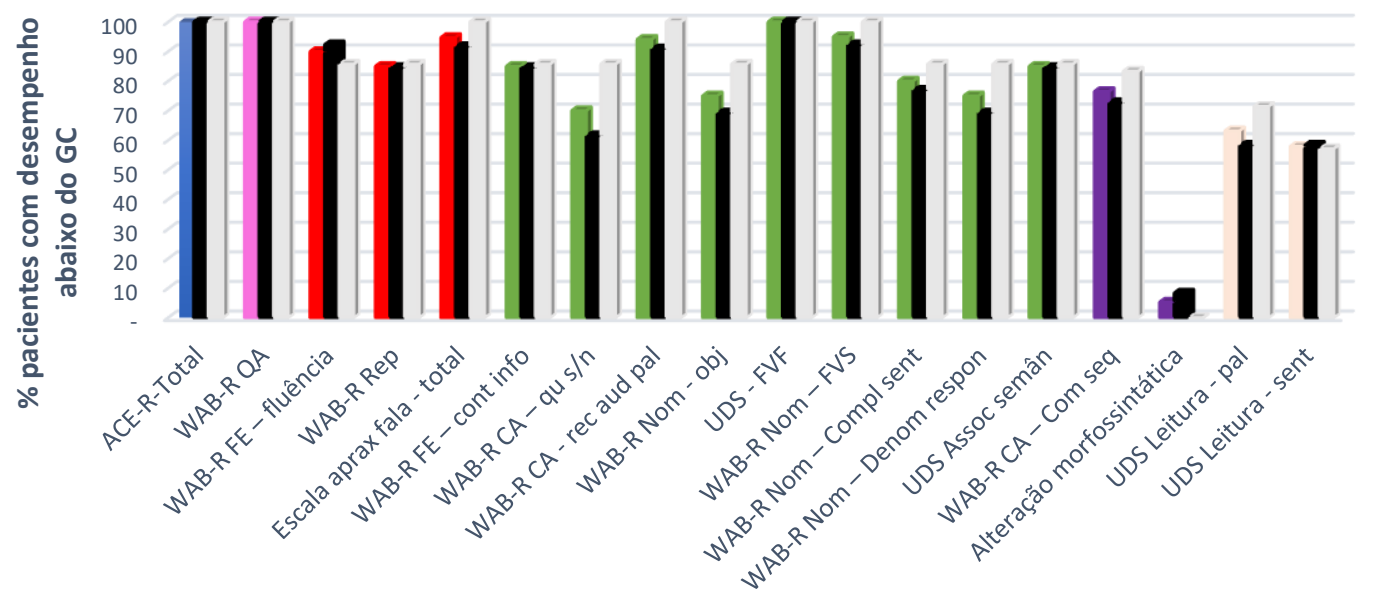

Colunas coloridas $=$ GSCB; colunas pretas $=$ SCB - ; colunas cinzas $=$ SCB +

\section{Abreviações:}

ACE-R-Total = pontuação total do ACE-R;

Escala aprax fala - total = pontuação total da escala de apraxia de fala;

UDS - FVF = prova de fluência verbal fonêmica "p" da bateria UDS;

UDS Assoc semân = prova de associação semântica da bateria UDS;

UDS Leitura - pal = prova de leitura de palavras da bateria UDS;

UDS Leitura - sent = prova de leitura de sentenças da bateria UDS;

WAB-R CA - Com seq = prova de compreensão auditiva (comandos sequenciais) do WAB-R;

WAB-R $C A$ - qu s/n = prova de compreensão auditiva (questões sim/não) do WAB-R;

WAB-R CA - rec aud pal = prova de compreensão auditiva (reconhecimento auditivo da palavra) do WAB-R;

WAB-R FE - cont info = prova de fala espontânea (conteúdo da informação) do WAB-R;

WAB-R FE - fluência = prova de fala espontânea (fluência) do WAB-R;

WAB-R Nom - Compl sent = prova de completar sentenças do WAB-R;

WAB-R Nom - Denom respon = prova de denominação responsiva do WAB-R;

WAB-R Nom - FVS = prova de fluência verbal semântica ("animais") do WAB-R;

WAB-R Nom - obj = prova de nomeação de objetos do WAB-R;

WAB-R $Q A$ = quociente de afasia do teste WAB-R;

WAB-R Rep = prova de repetição de palavras e sentenças do WAB-R.

Índice de gravidade das alterações cognitivas

Índice de gravidade da afasia

Processamento fonético-fonológico
Processamento léxico-semântico

Processamento morfossintático

Processamento de leitura 
Todos os pacientes obtiveram valores abaixo do GC na pontuação total do ACE-R e no quociente de afasia. O Gráfico 1 mostra que as alterações de linguagem afetam todos os processamentos linguísticos no GSCB. As provas em que houve a maior porcentagem de pacientes do GSCB com comprometimento foram: fluência verbal fonêmica (100\%), fluência verbal semântica $(95 \%)$, reconhecimento auditivo da palavra (94\%), fala espontânea - fluência (90\%), repetição (85\%), fala espontânea - conteúdo da informação (85\%) e associação semântica (85\%).

Na comparação entre os grupos SCB+ e SCB- (respectivamente, colunas cinzas e pretas), a porcentagem de pacientes com alterações no processamento léxico-semântico é maior no grupo SCB+ do que no SCB-, em todas as provas. Quanto aos déficits no processamento morfossintático, há uma desproporcionalidade importante em relação à porcentagem de pacientes com alterações de compreensão verbal de estruturas sintaticamente complexas (prova do WAB-R - comandos sequenciais) na comparação com as manifestações na expressão (alteração na organização das palavras na sentença, omissão ou substituição de palavras funcionais e/ou morfemas gramaticais). 


\section{DISCUSSÃO}

Este estudo teve como objetivo primário caracterizar a fala e a linguagem de pacientes com síndrome corticobasal. Foi verificado o impacto da idade, da escolaridade e da duração da doença no desempenho em testes de rastreio cognitivo, fala e linguagem. Por fim, constituiu também um objetivo desta pesquisa buscar um padrão de fala e linguagem sugestivo de SCB decorrente de DA, a partir da presença de biomarcador para DA (PET-FDG).

\subsection{Caracterização sociodemográfica e clínica dos grupos}

A amostra de pacientes com SCB é majoritariamente feminina e destra, com média de idade de 67 anos (DP 8,8) e escolaridade média de 8,5 anos (DP 5,18) (Tabela 1). A média de idade de início dos sintomas é de 61,6 anos (DP 9,21), o que está próximo da idade encontrada em outros estudos. Kertesz e colaboradores (2000) analisaram uma amostra de 35 pacientes, com média de idade de início dos sintomas aos 62 anos. McMonagle, Blair e Kertesz (2006) estudaram uma amostra de 55 pacientes, divididos entre aqueles com alteração motora inicial e aqueles com alteração cognitiva inicial, e encontrou a média de idade de início dos sintomas de 64,6 (DP 8) e 62 anos (DP 8,8), respectivamente. Di Stefano e colaboradores (2016) avaliaram 45 pacientes, com média de idade de início dos sintomas aos 65,9 anos (DP 7,4).

O sintoma inicial mais frequente na amostra estudada foi relacionado à memória (40\%), seguido de alterações motoras (25\%) (Tabela 1). As alterações no domínio de fala/linguagem configuraram o sintoma inicial em 15\% da amostra, frequência inferior ao que mostram outros estudos. Di Stefano e colaboradores (2016) e Burrell e colaboradores (2013) encontraram alterações de linguagem como sintoma inicial mais frequente em, respectivamente, $69 \%$ e $71,4 \%$ de suas amostras. É possível que a baixa frequência na referência a alterações de fala/linguagem como sintoma inicial neste estudo esteja relacionada a uma dificuldade na percepção dos sintomas por parte dos pacientes. Sintomas como 
anomia podem ter sido ignorados ou percebidos como decorrentes do envelhecimento normal, ao passo que sintomas relacionados a memória (como esquecimento de compromissos de trabalho, por exemplo) e alterações motoras são mais facilmente percebidos. Outra questão refere-se à escolaridade e à ocupação dos pacientes. A média de escolaridade dos pacientes desta pesquisa é inferior à dos dois estudos mencionados, e muitos deles tinham ocupações com pouca demanda de linguagem. Isso pode ter contribuído com uma dificuldade na percepção dos sintomas de fala/linguagem.

\subsection{Desempenho nos testes de rastreio cognitivo e de linguagem}

No teste de rastreio cognitivo (ACE-R) (Tabela 2), o GSCB teve desempenho inferior ao GC em todas as funções cognitivas. Mathew, Bak e Hodges (2011) investigaram a aplicabilidade do ACE-R em 21 pacientes com SCB e 23 com APP-nf, comparados a 47 sujeitos saudáveis. Os dois grupos de pacientes apresentaram prejuízo em todos os subtestes do ACE-R em comparação aos controles. $O$ único parâmetro que diferenciou os dois grupos de pacientes foram as habilidades visuoespaciais, com desempenho inferior no grupo com SCB. O domínio mais impactado tanto no grupo com SCB quanto no grupo com APP-nf foi a fluência verbal. Frattali e colegas (2000) utilizaram o MiniExame do Estado Mental (MEEM) como teste de rastreio cognitivo em 15 pacientes com SCB. A média do escore total do teste estava abaixo dos valores normativos. Assim, também, no estudo de Graham e colegas (2003), com 10 sujeitos com SCB, no qual todos obtiveram uma pontuação total no MEEM abaixo do grupo-controle. No estudo de Burrell e colaboradores (2013), foi utilizado o ACE-R na avaliação de 14 sujeitos com SCB. Com exceção do subteste de "atenção", os pacientes obtiveram pontuação abaixo do grupocontrole em todos os outros domínios. Di Stefano e colegas (2016) avaliaram 45 pacientes, utilizando o MEEM. A média do valor total do MEEM estava abaixo dos valores normativos. Sendo assim, os resultados desta pesquisa estão em consonância com a literatura, que mostra que pacientes com SCB têm alterações cognitivas em diversos domínios, que podem ser detectadas em testes de rastreio, como ACE-R e MEEM. 
Com relação à avaliação de linguagem por meio dos testes WAB-R e UDS (Tabelas 3 e 4), o grupo de pacientes teve desempenho inferior ao GC em todos os subtestes de ambas as baterias. Sendo assim, os pacientes avaliados apresentaram comprometimento em todas as habilidades linguísticas, não sendo possível identificar processamentos linguísticos mais ou menos alterados nesse grupo, por meio dessa análise. Esse resultado foi semelhante ao encontrado por Di Stefano e colegas (2016), que compararam as médias dos valores dos testes de linguagem com os valores normativos e encontraram alteração em todos os domínios linguísticos.

Todos os pacientes do GSCB tiveram desempenho abaixo da mediana do GC no valor total do ACE-R e no quociente de afasia (Gráfico 1). Esses dados mostram que, mesmo que em graus variados, todos os pacientes têm alterações linguístico-cognitivas. Assim como no estudo de Di Stefano e colegas (2016), o teste com a maior porcentagem de pacientes abaixo da normativa é a fluência verbal fonêmica, seguido de fluência verbal semântica. Essas são provas que demandam, além do processamento linguístico, funções executivas, sobretudo a fluência verbal fonêmica. Gerar uma lista de palavras a partir de um critério ortográfico, como na fluência verbal fonêmica, é uma tarefa não usual no dia a dia e, portanto, exige a criação de estratégias de busca, organização, automonitoramento e inibição das respostas já fornecidas. Já a fluência verbal semântica demanda uma organização a partir do significado, consequentemente, com maior demanda da memória semântica (Henry; Crawford, 2004). Portanto, é provável que esse resultado seja reflexo tanto de alterações de funções executivas quanto de habilidades léxico-semânticas.

$\mathrm{Na}$ compreensão de palavras ("reconhecimento auditivo da palavra") também houve uma frequência alta de pacientes com comprometimento (Gráfico 1), assim como no estudo de Di Stefano e colegas (2016). Essa é uma característica indicativa de APP-S (Mesulam et al., 2014a), porém, no presente estudo, os pacientes também apresentaram, em alta frequência, alterações de repetição e apraxia de fala, que não são característicos dessa variante da APP. Além do mais, esse dado deve ser visto com cautela, pois muitos pacientes tiveram dificuldades importantes em canalizar a atenção na tarefa, sendo 
necessário fornecer instruções diversas vezes e chamar sua atenção constantemente, o que pode ter impactado os resultados.

Diferentemente do que descreve grande parte das pesquisas (Peterson; Patterson; Rowe, 2019), a incidência de alterações no processamento morfossintático nos pacientes deste estudo foi baixa. Essa discrepância pode estar relacionada ao fato de ter-se restringido o entendimento de alteração morfossintática a uma definição clássica de agramatismo, que pressupõe erros na organização das palavras na sentença, omissão ou substituição de palavras funcionais e/ou morfemas gramaticais (Thompson; Bastiaanse, 2012; Mesulam, 2014a). Apenas um paciente apresentou erros compatíveis com essa definição. Entretanto, outros pacientes tinham diminuição da taxa de fala e simplificação de estruturas sintáticas na produção oral. Além disso, na comparação do desempenho dos pacientes no subteste do WAB-R "comandos sequenciais", que avalia a compreensão de estruturas sintáticas mais complexas, com a porcentagem de pacientes com alterações no processamento morfossintático (Gráfico 1), vê-se que há uma desproporção importante. Sabe-se que o agramatismo inclui dificuldade não só na expressão como na compreensão sintática (Thompson; Bastiaanse, 2012). Ademais, o agramatismo pode manifestar-se primeiramente na escrita antes de aparecer na fala (Mesulam, 2014a). Porém, em decorrência das alterações motoras e cognitivas, poucos pacientes de nossa amostra realizaram uma produção escrita.

Um estudo com pacientes diagnosticados com APP-nf mostrou que a maior parte da amostra, incluindo pacientes em estágios avançados da doença, não apresentou agramatismo clássico ("franck agrammatism") (Graham et al., 2016). Sendo assim, é possível que o número de pacientes com alterações morfossintáticas no presente estudo seja maior do que o reportado, sendo necessária uma análise mais aprofundada das produções orais e, quando possível, escritas, à luz de critérios mais atuais e específicos para doenças neurodegenerativas.

As alterações de linguagem nos pacientes deste estudo abrangem todos os processamentos linguísticos, e não são passíveis de classificação em um único tipo de APP. Outros estudos identificaram diversos perfis de linguagem: um tipo misto de afasia, abrangendo características da APP-L e da APP-S (Di Stefano et 
al., 2016), APP-nf (Josephs; Duffy, 2008; Shelley et al., 2009; Abe et al., 2016; Dodich et al., 2019), afasia de Broca, afasia anômica e afasia transcortical motora (Frattali et al., 2000). Essa heterogeneidade pode decorrer do estágio da doença no momento da avaliação, das diferentes patologias subjacentes à SCB (Peterson; Patterson; Rowe, 2019) ou, ainda, de avaliações de linguagem restritas. Gorno-Tempini e colaboradores (2011) recomendam que a avaliação de linguagem nas APP abranja os seguintes domínios: nomeação, compreensão de palavras e de sentenças, repetição de palavras e sentenças, processamento sintático, memória semântica, leitura e os aspectos motores da fala.

Alguns dos estudos que avaliaram fala e linguagem na SCB não incluíram todas as habilidades recomendadas. O estudo de Frattali e colaboradores (2000), que identificou quadros de afasia de Broca, afasia anômica e afasia transcortical motora, não menciona avaliação dos aspectos motores da fala nem de leitura. Graham e colegas (2003), cujo estudo identificou comprometimento linguístico relacionado ao processamento fonológico, não avaliaram as habilidades de compreensão oral e repetição. Há, também, estudos que não mencionam os testes aplicados nem as habilidades linguísticas avaliadas (Shelley et al., 2009; Dopper et al., 2011; Marshall et al., 2015). Há, ainda, uma série de estudos que empregaram uma avaliação restrita de linguagem mas cujo objetivo era analisar aspectos específicos de linguagem na SCB, como habilidades narrativas, produção e compreensão de quantificadores e processamento de verbos (McMillan et al., 2006; Cotelli et al., 2006; Gross et al., 2010; Troiani; Clark; Grossman, 2011). Dentre os estudos consultados que realizaram uma avaliação completa, conforme preconizado por Gorno-Tempini e colegas (2011), são mencionados os fenótipos da APP-nf (Abe et al., 2016; Dodich et al., 2019) e um tipo de afasia mista, com características da APP-L e da APP-S (Di Stefano et al., 2016). Desse modo, vêse que, mesmo os estudos que realizaram uma avaliação abrangente, encontraram características da APP-L, da APP-S e da APP-nf.

Por fim, é importante considerar, também, a influência das funções executivas na avaliação de linguagem no presente estudo. Apesar de essas funções não terem sido formalmente avaliadas, foram notadas dificuldades atencionais importantes, que podem ter impactado os resultados. Durante a avaliação, as instruções das tarefas precisaram ser repetidas diversas vezes e, 
ainda assim, alguns pacientes tiveram dificuldade em canalizar a atenção na tarefa, levantando-se da cadeira durante os testes ou permanecendo em silêncio, parecendo não escutar as instruções.

\subsection{Caracterização da fala}

\subsubsection{Apraxia de fala}

Dos 19 pacientes avaliados em relação à apraxia de fala, 11 (57,9\%) apresentaram alterações compatíveis com esse quadro. A apraxia de fala é descrita na literatura como uma alteração frequente na SCB, podendo ocorrer inclusive na ausência de alterações de linguagem (Grijalvo-Perez; Litvan, 2014; Peterson; Patterson; Rowe, 2019). No entanto, poucos estudos mencionam a proporção de pacientes com essa alteração. Di Stefano et al. (2016) encontraram uma proporção de pacientes com apraxia de fala próxima à encontrada no presente estudo, de 50\%. Dodich et al. (2019) encontraram alterações motoras da fala, sem fazer distinção entre apraxia de fala e disartria, em 33\% da amostra de pacientes com SCB.

Com o objetivo de descrever a natureza das alterações encontradas na apraxia de fala, foi utilizada a escala de apraxia de fala. Quando se comparou o GSCB ao GC em relação aos valores dessa escala, foi encontrada diferença em todos os itens, com exceção do item 1.5 "imprecisão na repetição de monossílabos (no local ou no modo)" (Tabela 5). Idosos saudáveis podem apresentar imprecisões articulatórias decorrentes da ausência de dentes, da utilização de próteses dentárias mal adaptadas e da redução de tonicidade muscular (Cardoso, 2010). Esse fato pode explicar a ausência de diferenciação entre os grupos no item 1.5, uma vez o GC é composto por idosos saudáveis.

A diferença significativa entre os grupos em todos os demais itens da escala de apraxia de fala mostra que pacientes com SCB têm alterações na fala que não são encontradas em indivíduos saudáveis de mesma idade e escolaridade. Entretanto, não foi observado um padrão de alterações motoras no GSCB. Assim como ocorre com outros sintomas da SCB, há uma grande heterogeneidade nas manifestações motoras que impactam a fala dos pacientes. Não foram 
encontrados na literatura outros estudos que tenham se aprofundado na questão da natureza da apraxia de fala em pacientes com SCB.

Em relação à diadococinesia oral (Tabela 6), o único parâmetro em que houve diferença significante entre os grupos foi a taxa de repetição de sequência de monossílabos /pataka/, em que o GSCB teve desempenho abaixo do GC. A literatura aponta como característico da apraxia de fala um pior desempenho na repetição de sequência de monossílabos na comparação com a repetição de monossílabos, que costuma estar preservada nesses pacientes (Ziegler, 2002; Duffy, 2013). Portanto, esse resultado pode decorrer do fato de que mais da metade do GSCB têm apraxia de fala.

Assim como em outros estudos que utilizaram a tarefa de diadococinesia oral (Ziegler, 2002; Padovani; Gielow; Behlau, 2009), a média da taxa de repetição de monossílabos diminui, tanto no GC quanto no GSCB, conforme o ponto articulatório torna-se mais posterior na cavidade oral (/pa/ $\rightarrow / \mathrm{ta} / \rightarrow / \mathrm{ka} /$ ). Isso se deve à complexidade da ação necessária para a execução dos fonemas. Para a produção de fonemas bilabiais surdos, apenas a musculatura orbicular é recrutada, ao passo que, para fonemas velares, como $\circ / \mathrm{k} /$, são necessários diversos músculos atuando em conjunto (Padovani; Gielow; Behlau, 2009).

\subsubsection{Disartria}

Quatro pacientes de nossa amostra $(21,05 \%)$ foram diagnosticados com disartria. A frequência da disartria na SCB relatada na literatura é bastante ampla, entre 29\% e 93\% (Frattali; Duffy, 2005). Em um estudo retrospectivo com 147 pacientes com SCB, 29\% da amostra apresentava disartria (Kompoliti et al., 1998). No estudo de Levin et al. (2015), a disartria foi encontrada em $24 \%$ da amostra $(n=38)$. Frequência maior foi encontrada no estudo de Di Stefano et al. (2016): em um grupo de 45 pacientes, 37\% tinha disartria.

Quanto à caracterização da disartria, encontramos alterações em todas as bases motoras da fala, sendo que, nas bases articulatória, fonatória e de prosódia, os quatro pacientes têm alteração e, na ressonância, apenas um paciente apresenta alteração (hipernasalidade). De modo geral, os pacientes têm quadros diferentes, de disartria mista, porém, têm em comum a imprecisão na articulação de consoantes e a redução da intensidade vocal, que são 
características da disartria hipocinética, encontrada na doença de Parkinson. Além disso, três dos quatro pacientes têm, também, diminuição da taxa de fala.

O estudo de Özsancak, Auzou e Hannequin (2000) buscou caracterizar a disartria em pacientes com SCB. Dez pacientes foram avaliados quanto a disartria e apraxia orobucofacial, dos quais nove foram diagnosticados com disartria, a partir de um teste de inteligibilidade de fala. A pontuação máxima desse teste era de 24 pontos e os autores consideraram qualquer valor abaixo disso como indicativo de quadro de disartria, o que pode explicar a alta frequência de disártricos nesse grupo. Dos nove pacientes disártricos, sete tinham um quadro leve de disartria, resultando em uma fala lenta, disprosódica ou hipofônica. Essas alterações são semelhantes às encontradas em nossos pacientes, sobretudo a hipofonia e a fala disprosódica. Outra característica encontrada na amostra de Özsancak, Auzou e Hannequin (2000) foram alterações na mobilidade de língua e lábios, o que pode resultar em uma imprecisão articulatória de consoantes, aspecto esse também observado nos pacientes deste estudo.

Um estudo do mesmo grupo teve por objetivo identificar as principais características perceptivas da disartria em um grupo de pacientes com SCB e outro com doença de Parkinson (Özsancak et al., 2006). Ambos os grupos apresentaram alterações na prosódia, como monoloudness, monopitch e diminuição da taxa de fala. Porém, o grupo com doença de Parkinson tinha, também, alterações na qualidade vocal, o que ocorreu em menor grau no grupo com SCB. Os autores concluíram que a disartria na SCB afeta sobretudo aspectos prosódicos e temporais da fala, tais como aprosódia, diminuição da taxa de fala e aumento da duração dos fonemas. No presente estudo, foram observadas alterações nesses mesmos aspectos, concomitantes a outras alterações.

\subsection{Funcionalidade da comunicação}

Em relação ao impacto da SCB na funcionalidade da comunicação (Tabela 7), verificamos que os pacientes apresentaram prejuízo nos quatro domínios avaliados, com maior comprometimento da "Leitura, escrita e conceitos numéricos", e no valor total de independência comunicativa. Esses dados 
mostram uma heterogeneidade das dificuldades comunicativas na SCB. Carvalho (2006) aplicou a escala ASHA-FACS em um grupo com DA e em um grupo-controle, de idosos brasileiros saudáveis. Nos indivíduos com DA foi encontrado impacto em todos os domínios comunicativos, assim como no presente estudo.

As dificuldades em leitura e escrita podem decorrer não apenas das alterações de linguagem e cognição, mas também das alterações motoras e visuais, que são frequentes na SCB (Peterson; Patterson; Rowe, 2019). No GSCB, há pacientes com graves alterações motoras e alguns com agnosia visual.

Outro domínio comunicativo bastante prejudicado no GSCB foi o "Planejamento diário". Esse domínio inclui atividades que dependem não só da linguagem como também da função executiva, exigindo planejamento e organização, como cumprir compromissos agendados e usar calendários e mapas (Carvalho, 2006). Déficits de função executiva são descritos em, ao menos, 50\% dos pacientes com SCB (Kertesz; McMonagle, 2010; Oliveira et al., 2017). Desse modo, acreditamos que o impacto nesse domínio pode estar relacionado tanto aos déficits linguísticos quanto à função executiva.

\subsection{Gravidade das alterações de linguagem}

Os resultados da Escala PASS (Tabela 8) mostram alteração grave em "leitura" e "escrita". Esses dados estão em consonância com o que foi discutido a respeito da Escala ASHA-FACS, sobre os déficits em leitura e escrita.

O segundo domínio mais afetado foi a "comunicação funcional" (alteração moderada). A comunicação funcional refere-se à habilidade de se comunicar apesar dos déficits de fala e linguagem (Sapolsky; Domoto-Reilly; Dickerson, 2014). Essa dificuldade moderada em compensar os déficits pode decorrer de alterações em função executiva, algo frequente na SCB (Pillon et al., 1995; Kertesz; McMonagle, 2010; Oliveira et al., 2017), mas que não foi aprofundado no presente estudo.

Os demais domínios linguísticos têm déficits "questionáveis/muito leves", "leves" ou "ausente", no caso da "compreensão de palavras isoladas". Assim como os testes de linguagem, a Escala PASS mostra alterações abrangendo todos os processamentos linguísticos. 
Em relação à compreensão de palavras isoladas, dois testes avaliam essa habilidade: "reconhecimento auditivo da palavra", do WAB-R, e "emparelhamento semântico", da Bateria UDS (Tabelas 3 e 4). Em ambos os testes, houve diferença estatisticamente significante entre o GSCB e ० GC, indicando comprometimento dessa habilidade. Essa divergência entre os testes de linguagem e a escala PASS pode ser explicada pelo fato de a escala ser preenchida com base em diversas fontes: a impressão clínica do examinador, os testes formais e as informações fornecidas pelo cuidador (Sapolsky; DomotoReilly; Dickerson, 2014). Portanto, a escala leva em consideração situações funcionais, nas quais o paciente pode contar com pistas contextuais, o que não ocorre na avaliação formal de linguagem. Além do mais, a percepção do déficit de compreensão de palavras isoladas em situações reais pode ser bastante desafiadora para um cuidador, especialmente na população estudada, na qual o cuidador, na maior parte das vezes, tem um nível socioeconômico e cultural equivalente ou abaixo do paciente.

\subsection{Correlações entre habilidades cognitivas, de linguagem e fala $x$ idade, escolaridade e duração da doença}

Foi encontrada correlação positiva entre a duração da doença e o valor total da escala de apraxia de fala (Tabela 9). Por se tratar de uma doença neurodegenerativa progressiva, é esperado que, quanto maior a duração da doença, mais graves sejam as alterações, aí incluídas as alterações de fala. A escala de apraxia de fala engloba características presentes na apraxia, mas que podem ocorrer também em quadros de disartria e afasia (Strands et al., 2014). Portanto, esse resultado pode indicar que, em estágios avançados da doença, os pacientes apresentam mais alterações de fala. A literatura mostra que pacientes com SCB que iniciam com sintomas motores, no decorrer dos anos, desenvolvem sintomas de fala e linguagem (McMonagle; Blair; Kertesz, 2006).

Foi encontrada correlação positiva entre a escolaridade e a pontuação total no teste ACE-R e correlação negativa entre o mesmo teste e a duração da doença (Tabela 9). Esses dados estão em consonância com a literatura no que se refere à influência positiva da escolaridade no desenvolvimento de habilidades cognitivas (Rosselli; Ardila, 2003). Também podemos inferir a partir 
desses resultados que, com o avanço da doença, as habilidades cognitivas são comprometidas. Por outro lado, não observamos correlação alguma com 0 quociente de afasia do WAB-R, o que pode indicar que os efeitos da doença nas habilidades linguísticas suplantam a influência da idade e da escolaridade. Também a duração da doença não se correlacionou com a gravidade da afasia, refletindo, possivelmente, a heterogeneidade da SCB, que pode, de início, atingir mais as habilidades motoras ou cognitivas (McMonagle; Blair; Kertesz, 2006).

\subsection{Comparação entre os grupos SCB+ e SCB-}

Os grupos SCB+ e SCB- estão equiparados em relação às características sociodemográficas e clínicas (Tabela 10).

No teste de rastreio cognitivo, houve uma tendência para maior comprometimento da atenção $(p=0,057)$ e das habilidades visuoespaciais $(p=0,051)$ no grupo SCB+. Burrell et al. (2013) compararam dois grupos de pacientes com SCB de acordo com o exame de PET-PiB no ACE-R. Diferentemente dos nossos resultados, eles encontraram diferença estatisticamente significante em todos os subtestes, com exceção da atenção.

Dentre os testes de fala e linguagem, as únicas variáveis que diferenciaram os grupos em nosso estudo foram o item 3.1 da escala de apraxia de fala ("Repetição de sequência de monossílabos mais lenta, segmentada e/ou distorcida na comparação com a repetição de monossílabos") e o valor total da seção 3 da mesma escala, que engloba, além do item 3.1, o 3.2: "ensaios articulatórios visíveis ou audíveis; dificuldade em iniciar a fala; falsos inícios/recomeços", sendo que o grupo SCB+ teve pior desempenho (Tabela 14). A diferença entre os grupos no valor total da seção 3 é, provavelmente reflexo do item 3.1, uma vez que o item 3.2 não diferenciou os grupos.

É interessante notar que o que diferenciou os grupos no item 3.1 não foi a velocidade da articulação das sílabas, uma vez que esse dado foi comparado na Tabela 15, e não apresentou significância estatística. O que os diferenciou foi, provavelmente, a quantidade de distorções de fonemas realizadas durante essa tarefa. Entretanto, o número de sujeitos incluídos nessa variável é bastante reduzido $\left(\mathrm{SCB}_{+}=5\right.$; $\left.\mathrm{SCB}-=9\right)$, sendo importante rever esse dado com um número maior de participantes. 
Outra variável que diferenciou os grupos SCB+ e SCB- foi o item "Recuperação de palavras e expressões" da Escala PASS (Tabela 18), que mensura a gravidade dos déficits linguísticos, com alteração mais grave no grupo SCB+. Uma das questões presentes no questionário da Escala PASS, na seção referente ao resgate de palavras, refere-se a mudanças no vocabulário. Seis dos sete pacientes do grupo SCB+ apresentaram vocabulário vago ou genérico, com uso excessivo de palavras semanticamente vazias durante o discurso. Essa é uma característica também descrita em pacientes com DA, que apresentam circunlóquios e uso de vocabulário inespecífico (Mueller et al., 2018). Uma limitação do presente estudo é a ausência de uma análise aprofundada do discurso dos pacientes, que permitiria uma investigação a respeito dessa questão.

O grupo SCB- tem maior incidência de disartria (os quatro pacientes com disartria estão nesse grupo), mas sem diferença estatística na comparação entre grupos. Quanto à apraxia de fala, os grupos estão equilibrados. O grupo SCB+ apresenta alterações mais graves em todas as variáveis de cognição, linguagem e funcionalidade, ainda que sem diferença estatística em relação ao grupo SCB-. Burrell et al. (2013) encontraram resultado semelhante, com maior comprometimento cognitivo e de funcionalidade nos pacientes com DA. Nesse mesmo estudo, os autores perceberam uma tendência para maior comprometimento da repetição em pacientes com DA em oposição à presença da apraxia de fala em pacientes com SCB decorrente de taupatias. Outro trabalho com desenho semelhante encontrou resultados diferentes, indicando alterações de linguagem mais graves em pacientes sem DA, principalmente na nomeação de figuras e na compreensão de palavras. Os pacientes com DA tinham, com mais frequência, síndrome de Gerstmann (disgrafia, acalculia, agnosia digital e confusão direita-esquerda) (Di Stefano et al., 2016).

\subsection{Limitações do estudo e perspectivas futuras}

Um fator que pode ser apontado como limitação ao presente estudo é o tamanho amostral. Apesar de muitos trabalhos contarem com número de sujeitos semelhante ou menor, já que se trata de uma doença rara (Frattali et al., 2000; Graham et al., 2003; Shelley et al., 2009; Troiani; Clark; Grossman, 2011; Burrell et 
al., 2013), uma amostra maior poderia aumentar o poder estatístico das análises. Outra limitação de nosso estudo refere-se às funções executivas. Observamos, durante as avaliações, influência importante de funções executivas nas tarefas de linguagem, mas não contamos com uma avaliação formal dessas habilidades, o que poderia enriquecer o trabalho. Por fim, teria sido interessante realizar um acompanhamento longitudinal de alguns pacientes, uma vez que, como em todas as síndromes neurodegenerativas, os perfis de linguagem podem se modificar ao longo do tempo (Mesulam et al., 2014b; Peterson; Patterson; Rowe, 2019).

Como perspectivas futuras, podemos apontar a análise aprofundada das narrativas orais dos pacientes, algo que se mostrou necessário durante a interpretação dos resultados. Essa análise poderá colaborar com a avaliação das habilidades morfossintáticas. Além disso, é interessante comparar os aspectos discursivos dos grupos SCB+ e SCB-, pois nossa avaliação aponta para um maior uso de palavras semanticamente vazias entre os pacientes com DA provável. 


\section{CONCLUSÕES}

Todos os pacientes com SCB apresentaram alterações de linguagem e fala. Confirmando uma das hipóteses iniciais, as alterações de linguagem são heterogêneas e abrangem todos os processamentos linguísticos. Em relação às habilidades motoras da fala, os pacientes apresentaram, também, quadros heterogêneos. Dentre os pacientes com disartria, os perfis são heterogêneos, exceto na imprecisão articulatória e na redução da intensidade vocal.

A hipótese inicial sobre o impacto da idade, escolaridade e tempo de doença na fala e linguagem de pacientes com SCB foi confirmada parcialmente. Verificou-se que houve correlação positiva entre a duração da doença e as alterações de fala, indicando que essas alterações tendem a se acentuar no decorrer da doença. Não houve correlações entre idade e escolaridade e gravidade da afasia, indicando que os efeitos da doença na linguagem suplantam a influência desses fatores. A duração da doença também não se correlacionou com a gravidade da afasia, refletindo, possivelmente, a heterogeneidade da SCB, que pode, de início, atingir mais profundamente as habilidades motoras ou cognitivas.

Em relação à comparação do perfil de fala e linguagem entre os grupos com e sem DA, a hipótese inicial, de que a dificuldade na repetição de sentenças estaria associada à DA como doença de base, não se confirmou, uma vez que, em nenhum dos testes de linguagem houve diferença estatisticamente significante entre os grupos. Quanto à associação de alterações na produção motora da fala com o grupo sem DA tampouco houve diferença estatisticamente significante, porém, os quatro pacientes com disartria encontravam-se nesse grupo.

Em relação à triagem cognitiva, verificou-se uma tendência para maior comprometimento da atenção e das habilidades visuoespaciais no grupo com DA. De modo geral, esse grupo apresentou alterações mais graves em todas as variáveis de cognição, linguagem e funcionalidade, ainda que sem diferença estatística em relação ao grupo sem DA. 
8. ANEXOS

ANEXO A - Parecer consubstanciado do Comitê de Ética em Pesquisa (CEP)

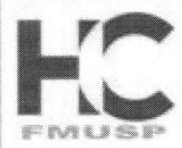

\section{USP - HOSPITAL DAS \\ CLÍNICAS DA FACULDADE DE MEDICINA DA UNIVERSIDADE}

\section{PARECER CONSUBSTANCIADO DO CEP}

\section{DADOS DO PROJETO DE PESQUISA}

Título da Pesquisa: Síndrome corticobasal: alterações de fala e linguagem

Pesquisador: Leticia Lessa Mansur

Área Temática:

Versão: 1

CAAE: 02874318.9 .0000 .0068

Instituição Proponente: Hospital das Clínicas da Faculdade de Medicina da USP

Patrocinador Principal: Financiamento Próprio

DADOS DO PARECER

Número do Parecer: 3.044 .663

\section{Apresentação do Projeto:}

O projeto de pesquisa intitulado: "Síndrome corticobasal: alterações de fala e linguagem" é prospectivo observacional e será desenvolvido no Departamento de Fisioterapia, Fonoaudiologia e Terapia Ocupacional da FMUSP e no Serviço de Neurologia do HC-FMUSP como pesquisa de Mestrado de Isabel Junqueira de Almeida. Será desenvolvido com pacientes com diagnóstico de Síndrome Corticobasal provável e com um grupo controle de indivíduos cognitivamente saudáveis. Serão aplicados testes já descritos na literatura e em estudos anteriores para avaliar a fala e a linguagem.

\section{Objetivo da Pesquisa:}

Este projeto de pesquisa tem como objetivo principal caracterizar a linguagem de pacientes com diagnóstico de síndrome corticobasal (SCB) provável, em seus aspectos fonético-fonológicos, morfológicos e sintáticos, buscando um padrão sugestivo da SCB.

Avaliação dos Riscos e Benefícios:

Os autores referem riscos mínimos, sendo o cansaço durante a aplicação dos testes um dos aspectos referenciados no TCLE, sendo que neste caso referem a interrupção da avaliação.

Como benefícios os autores salientam que a a pesquisa poderá contribuir com o conhecimento sobre as manifestações clínicas da SCB, mais especificamente com as alterações de fala e linguagem na população brasileira com SCB, colaborando com o diagnóstico clínico mais preciso.

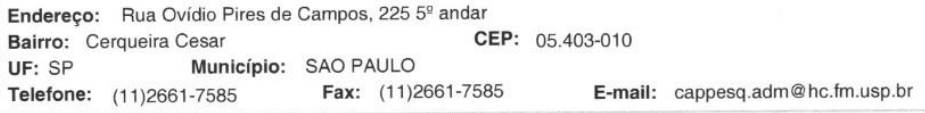




\section{USP - HOSPITAL DAS \\ CLÍNICAS DA FACULDADE DE MEDICINA DA UNIVERSIDADE}

Continuaçăo do Parecer: 3.044 .663

Comentários e Considerações sobre a Pesquisa:

O estudo apresenta relevância clínica, social e científica e os resultados poderão contribuir com a área investigada.

Considerações sobre os Termos de apresentação obrigatória:

Todos os documentos foram apresentados e estão de acordo com as normas.

Conclusões ou Pendências e Lista de Inadequações:

O estudo apresenta relevância clínica, social e científica e os resultados poderão trazer conhecimentos inovadores aos especialistas. Não há impedimentos éticos para sua realização e portanto, meu parecer é favorável à sua aprovação.

\section{Considerações Finais a critério do CEP:}

Em conformidade com a Resolução CNS n 466/12 - cabe ao pesquisador: a) desenvolver o projeto conforme delineado; b) elaborar e apresentar relatórios parciais e final; c)apresentar dados solicitados pelo CEP, a qualquer momento; d) manter em arquivo sob sua guarda, por 5 anos da pesquisa, contendo fichas individuais e todos os demais documentos recomendados pelo CEP; e) encaminhar os resultados para publicação, com os devidos créditos aos pesquisadores associados e ao pessoal técnico participante do projeto; f) justificar perante ao CEP interrupção do projeto ou a não publicação dos resultados.

Este parecer foi elaborado baseado nos documentos abaixo relacionados:

\begin{tabular}{|l|l|c|c|c|}
\hline \multicolumn{1}{|c|}{ Tipo Documento } & \multicolumn{1}{|c|}{ Arquivo } & Postagem & Autor & Situação \\
\hline Informações Básicas & PB_INFORMAÇÕES_BÁSICAS_DO_P & $13 / 11 / 2018$ & $16: 03: 38$ & \\
do Projeto & ROJETO_1242748.pdf & $13 / 11 / 2018$ & Leticia Lessa Mansur & Aceito \\
\hline TCLE / Termos de & TCLE_controles_e_pacientes.pdf & $16: 02: 49$ & & \\
Assentimento / & & & & \\
Justificativa de & & $13 / 11 / 2018$ & Leticia Lessa Mansur & Aceito \\
Ausência & & $16: 02: 22$ & \\
\hline Declaração de & Carta_pesq_exec.pdf & $13 / 11 / 2018$ & Leticia Lessa Mansur & Aceito \\
Pesquisadores & & $16: 01: 12$ & & \\
\hline Outros & Testes_entrevistas_questionarios.pdf & $13 / 11 / 2018$ & Leticia Lessa Mansur & Aceito \\
\hline Orçamento & Decl_Custos.pdf & $13 / 11 / 200: 08$ & Leticia Lessa & Aceito \\
\hline Cronograma & Cronograma_exec.pdf & & & \\
\hline
\end{tabular}

Endereço: Rua Ovídio Pires de Campos, $2255^{\circ}$ andar

Bairro: Cerqueira Cesar
UF: SP Município: SAO PAULO

Telefone: (11)2661-7585 Fax: (11)2661-7585 E-mail: cappesq.adm@hc.fm.usp.br 


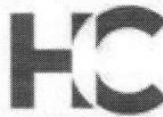

\section{USP - HOSPITAL DAS \\ CLIINICAS DA FACULDADE DE MEDICINA DA UNIVERSIDADE}

Continuaçăo do Parecer: 3.044 .663

\begin{tabular}{|c|c|c|c|c|}
\hline Cronograma & Cronograma_exec.pdf & $15: 59: 13$ & Mansur & Aceito \\
\hline Outros & PP_assinado.pdf & $\begin{array}{c}13 / 11 / 2018 \\
15: 52: 55\end{array}$ & Leticia Lessa Mansur & Aceito \\
\hline $\begin{array}{l}\text { Projeto Detalhado / } \\
\text { Brochura } \\
\text { Investigador }\end{array}$ & PP_detalhado_Isabel_J_Almeida.pdf & $\begin{array}{c}13 / 11 / 2018 \\
15: 52: 27\end{array}$ & Leticia Lessa Mansur & Aceito \\
\hline Folha de Rosto & FolhadeRosto.pdf & $\begin{array}{c}13 / 11 / 2018 \\
15: 51: 18 \\
\end{array}$ & Leticia Lessa Mansur & Aceito \\
\hline Outros & Cadastro_proj.pdf & $\begin{array}{c}31 / 10 / 2018 \\
12: 44: 10\end{array}$ & Leticia Lessa Mansur & Aceito \\
\hline Outros & Decl_pesq_resp.pdf & $\begin{array}{c}31 / 10 / 2018 \\
12: 18: 23\end{array}$ & Leticia Lessa Mansur & Aceito \\
\hline Outros & Decl_Dep_Neurologia.pdf & $\begin{array}{c}31 / 10 / 2018 \\
12: 17: 31\end{array}$ & Leticia Lessa Mansur & Aceito \\
\hline
\end{tabular}

Situação do Parecer:

Aprovado

Necessita Apreciação da CONEP:

Não

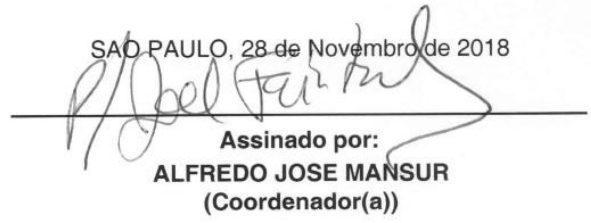

(Coordenador(a))

Endereço: Rua Ovídio Pires de Campos, $2255^{\circ}$ andar

Bairro: Cerqueira Cesar
UF: SP

Telefone: (11)2661-7585 Fax: (11)2661-7585 E-mail: cappesq.adm@ @ h.fm.usp.br 
ANEXO B - TCLE (grupo-controle e pacientes)

\section{TERMO DE CONSENTIMENTO LIVRE E ESCLARECIDO \\ Controles \\ DADOS DA PESQUISA}

TÍTULO DO PROTOCOLO DE PESQUISA: Síndrome corticobasal: alterações de fala e linguagem.

PESQUISADOR: Leticia Lessa Mansur

CARGO/FUNÇÃO: fonoaudióloga/ professora associada do Departamento de Fisioterapia, Fonoaudiologia e Terapia Ocupacional.

INSCRIÇÃO CONSELHO REGIONAL №: 0856

UNIDADE DO HCFMUSP: Faculdade de Medicina da Universidade de São Paulo

AVALIAÇÃO DO RISCO DA PESQUISA:

$\begin{array}{lll}\text { RISCO MÍNIMO } & X & \text { RISCO MÉDIO } \\ \text { RISCO BAIXO } & \square & \text { RISCO MAIOR }\end{array}$

DURAÇÃO DA PESQUISA: 16 meses.

Convidamos o(a) senhor(a) a participar de uma pesquisa científica. Essa pesquisa procura aumentar o conhecimento sobre a linguagem e fala na doença chamada síndrome corticobasal. Esses conhecimentos podem ser úteis para que no futuro possamos tratar ou mesmo evitar essa doença. Para decidir se aceita ou não participar da pesquisa, o(a) senhor(a) precisa entender o suficiente sobre os riscos e benefícios, para que possa fazer um julgamento consciente. Inicialmente explicaremos as razões da pesquisa. A seguir, forneceremos um termo de consentimento livre e esclarecido (TCLE), documento que contém informações sobre a pesquisa, para que leia e discuta com familiares e ou outras pessoas de sua confiança. Uma vez compreendido o objetivo da pesquisa e havendo seu interesse em participar, será solicitada a sua rubrica em todas as páginas do TCLE e sua assinatura na última página. Uma via assinada deste termo deverá ser retida pelo senhor(a) ou por seu representante legal e uma cópia será arquivada pelo pesquisador responsável.

É essencial conhecer a fundo as características clínicas da síndrome corticobasal, pois essa doença não é completamente conhecida. Este estudo está associado à outra pesquisa sobre o mesmo assunto, porém tem o objetivo dirigido às alterações de fala e linguagem na população brasileira com síndrome corticobasal, colaborando assim para o diagnóstico clínico. Para isso, o senhor(a) será orientado(a) a realizar algumas tarefas como: dizer o nome de figuras, responder a questões, seguir orientações, repetir palavras e sentenças, olhar uma figura e contar uma história, fazer movimentos com 
lábios, língua e bochecha, copiar desenho e escrever seu nome, números, letras. É importante que registremos em vídeo sua avaliação, para melhor analisar os resultados. É preciso que você dê seu consentimento para isso.

Caso o senhor(a) fique cansado(a), interromperemos e remarcaremos a sessão. A avaliação será marcada no dia de sua conveniência e realizada em duas sessões de 1 hora e meia. Caso esse período se estenda a mais de duas horas, o senhor(a) terá direito a um lanche. Não há benefício direto para o(a) senhor(a). Sua participação contribuirá para que possamos compreender melhor a síndrome corticobasal e assim ajudar outras pessoas que têm a doença.

Caso seja notada alguma alteração de linguagem durante a sua avaliação, o senhor será encaminhado para avaliação especializada e orientado.

Em qualquer etapa do estudo, o(a) senhor(a) terá acesso aos profissionais responsáveis pela pesquisa. O investigador principal é Leticia Lessa Mansur, que pode ser encontrada na Cidade Universitária, rua Cipotânea, número 51, sala 1- térreo. Telefone: (11) 30918414, entre 8h e 17 horas, às segundas, quartas e sextas-feiras ou na Divisão de Clínica Neurológica, no telefone 2661-7877, às quintas-feiras. O investigador executante é Isabel Junqueira de Almeida, que pode ser encontrada na rua Cipotânea, número 51, sala 1- térreo. Telefone: (11) 3091-8414, entre 8 h e 17 horas, às terças-feiras ou na Divisão de Clínica Neurológica, no telefone 2661-7877, às quintas-feiras. Outros investigadores envolvidos são Dra Jacy Parmera e Dra Sonia Maria Dozzi Brucki, que podem ser encontrados na Divisão de Clínica Neurológica do Hospital das Clínicas, no Instituto Central do Hospital das Clínicas, 5ํaㅁ an no ambulatório de Neurologia no Prédio dos ambulatórios, 6ำ andar, bloco 4, às quintas-feiras, no horário das 14 às 17 horas.

Se o senhor(a) tiver alguma consideração ou dúvida sobre a ética da pesquisa, entre em contato com o Comitê de Ética em Pesquisa (CEP) - Rua Ovídio Pires de Campos, 225 $5^{\circ}$ andar- tel: (11) 2661-7585, (11) 2661-1548, (11) 2661-1549. E-mail: cappesq.adm@hc.fm.usp.br.

A escolha de entrar ou não nesse estudo é inteiramente sua. Caso o(a) senhor(a) se recuse a participar deste estudo, o(a) senhor(a) receberá o tratamento habitual, sem qualquer tipo de prejuízo ou represália. $\mathrm{O}(\mathrm{A})$ senhor(a) também tem o direito de se retirar deste estudo a qualquer momento sem qualquer prejuízo ou represália.

Os seus dados serão analisados em conjunto com outros participantes, não sendo divulgada a identificação de nenhum participante, sob qualquer circunstância.

Todos os dados de sua avaliação ficarão sob a guarda do pesquisador responsável e do pesquisador executante. Os registros, vídeos e anotações não serão divulgados.

Solicitamos sua autorização para que os dados obtidos nesta pesquisa sejam utilizados em uma publicação científica, que é a maneira de divulgar e compartilhar os resultados com a comunidade científica.

O (A) senhor(a) receberá uma via deste Termo de Consentimento Livre e Esclarecido. 
$\mathrm{O}$ (A) senhor(a) não terá qualquer custo, pois o custo desta pesquisa será de responsabilidade dos pesquisadores. $O(A)$ senhor(a) tem direito a ressarcimento em caso de despesas decorrentes da sua participação na pesquisa.

Acredito ter sido suficientemente informado a respeito das informações que li ou que foram lidas para mim, descrevendo o estudo Síndrome corticobasal: alterações de fala e linguagem.

Eu discuti com Isabel Junqueira de Almeida e Leticia Lessa Mansur sobre a minha decisão em participar nesse estudo. Ficaram claros para mim quais são os propósitos do estudo, os procedimentos a serem realizados, seus desconfortos, as garantias de confidencialidade e de esclarecimentos permanentes. Ficou claro também que minha participação é isenta de despesas. Concordo voluntariamente em participar deste estudo e poderei retirar o meu consentimento a qualquer momento, antes ou durante 0 mesmo, sem penalidades ou prejuízos.

Assinatura do paciente/ representante legal

Data

\section{Seticia destar \&uansur}

Assinatura do responsável pelo estudo

Data

Assinatura da testemunha

Data

para casos de pacientes menores de 18 anos, analfabetos, semi-

analfabetos ou portadores de deficiência auditiva ou visual.

(Somente para o responsável do projeto)

Declaro que obtive de forma apropriada e voluntária o Consentimento Livre e

Esclarecido deste paciente ou representante legal para a participação neste estudo. 
DADOS DE IDENTIFICAÇÃO (OU ETIQUETA INSTITUCIONAL DE IDENTIFICAÇÃO) DO

PARTICIPANTE DA PESQUISA OU RESPONSÁVEL LEGAL

1. NOME:

DOCUMENTO DE IDENTIDADE № :

$$
\text { SEXO : .M } \square \text { F } \quad \text { DATA NASCIMENTO: }
$$

.................../.

2. ENDEREÇO

№ APTO:

BAIRRO:

CIDADE

CEP:.

TELEFONE: DDD

(.............)

3. 2.RESPONSÁVEL LEGAL

.... NATUREZA (grau de parentesco, tutor, curador etc.)

DOCUMENTO DE

IDENTIDADE : ..SEXO: $\mathrm{M} \square \mathrm{F} \square \quad$ DATA NASCIMENTO.:

..................... ENDEREÇO: № APTO: BAIRRO: CIDADE: CEP: TELEFONE: DDD .). 


\title{
TERMO DE CONSENTIMENTO LIVRE E ESCLARECIDO
}

\author{
Pacientes
}

\section{DADOS SOBRE A PESQUISA}

TÍTULO DO PROTOCOLO DE PESQUISA: Síndrome corticobasal: alterações de fala e linguagem.

PESQUISADOR: Leticia Lessa Mansur

CARGO/FUNÇÃO: fonoaudióloga/ professora associada. Departamento de Fisioterapia, Fonoaudiologia e Terapia Ocupacional - FMUSP.

INSCRIÇÃO CONSELHO REGIONAL №: 0856

UNIDADE DO HCFMUSP: Faculdade de Medicina da Universidade de São Paulo

AVALIAÇÃO DO RISCO DA PESQUISA:

$\begin{array}{lll}\text { RISCO MÍNIMO } & X & \text { RISCO MÉDIO } \\ \text { RISCO BAIXO } & \square & \text { RISCO MAIOR }\end{array}$

DURAÇÃO DA PESQUISA: 16 meses.

Convidamos o(a) senhor(a) a participar de uma pesquisa científica. Essa pesquisa procura aumentar o conhecimento sobre a linguagem e fala em que o senhor(a) recebeu diagnóstico - síndrome corticobasal. Esses conhecimentos podem ser úteis para que no futuro possamos tratar ou mesmo evitar essa doença. Para decidir se aceita ou não participar desta pesquisa, o(a) senhor(a) precisa entender o suficiente sobre os riscos e benefícios, para que possa fazer um julgamento consciente. Inicialmente explicaremos as razões da pesquisa. A seguir, forneceremos um termo de consentimento livre e esclarecido (TCLE), documento que contém informações sobre a pesquisa, para que leia e discuta com familiares e ou outras pessoas de sua confiança. Uma vez compreendido o objetivo da pesquisa e havendo seu interesse em participar, será solicitada a sua rubrica em todas as páginas do TCLE e sua assinatura na última página. Uma via assinada deste termo deverá ser retida pelo senhor(a) ou por seu representante legal e uma cópia será arquivada pelo pesquisador responsável.

É essencial conhecer a fundo as características clínicas da síndrome corticobasal, pois essa doença não é completamente conhecida. Este estudo está associado à outra pesquisa sobre o mesmo assunto, porém tem o objetivo dirigido às alterações de fala $e$ linguagem na população brasileira com síndrome corticobasal, colaborando assim para o diagnóstico clínico. Para isso, o senhor(a) será orientado(a) a realizar algumas tarefas como: dizer o nome de figuras, responder a questões, seguir orientações, repetir palavras e sentenças, olhar uma figura e contar uma história, fazer movimentos com lábios, língua e bochecha, copiar desenho e escrever seu nome, números, letras. É 
importante que registremos em vídeo sua avaliação, para melhor analisar os resultados. É preciso que você dê seu consentimento para isso.

Caso o senhor(a) fique cansado(a), interromperemos e remarcaremos a sessão. A avaliação será marcada no dia de sua conveniência e realizada em duas sessões de 1 hora e meia. Caso esse período se estenda a mais de duas horas, o senhor(a) terá direito a um lanche. Ao participar da pesquisa o senhor será orientado sobre como manejar as alterações de fala e linguagem. Além disso, sua participação contribuirá para que possamos compreender melhor a síndrome corticobasal.

$\mathrm{O}$ (A) senhor(a) será acompanhado pela equipe médica da Divisão de Neurologia do Hospital das Clínicas da Faculdade de Medicina da USP, durante o estudo e após o término do mesmo.

Em qualquer etapa do estudo, o(a) senhor(a) terá acesso aos profissionais responsáveis pela pesquisa. O investigador principal é Leticia Lessa Mansur, que pode ser encontrada na Cidade Universitária, rua Cipotanea, número 51, sala 1- térreo. Telefone: (11) 30918414, entre 8h e 17 horas, às segundas, quartas e sextas-feiras ou na Divisão de Clínica Neurológica, no telefone 2661-7877, às quintas-feiras. O investigador executante é Isabel Junqueira de Almeida, que pode ser encontrada na rua Cipotanea, número 51, sala 1- térreo. Telefone: (11) 3091-8414, entre 8 h e 17 horas, às terças-feiras ou na Divisão de Clínica Neurológica, no telefone 2661-7877, às quintas-feiras. Outros investigadores envolvidos são Dra Jacy Parmera e Dra Sonia Maria Dozzi Brucki, que podem ser encontrados na Divisão de Clínica Neurológica do Hospital das Clínicas, no Instituto Central do Hospital das Clínicas, 5ํaㅁ andar no ambulatório de Neurologia no Prédio dos ambulatórios, 6ำ andar, bloco 4, às quintas-feiras, no horário das 14 às 17 horas.

A escolha de entrar ou não nesse estudo é inteiramente sua. Caso o(a) senhor(a) se recuse a participar deste estudo, o(a) senhor(a) receberá o tratamento habitual no Hospital das Clínicas, sem qualquer tipo de prejuízo ou represália. $O(A)$ senhor(a) também tem o direito de retirar-se deste estudo a qualquer momento e, se isso acontecer, seu médico continuará a tratá-lo(a) sem qualquer prejuízo ao tratamento ou represália.

Os seus dados serão analisados em conjunto com outros pacientes, não sendo divulgada a identificação de nenhum participante, sob qualquer circunstância.

Todos os dados de sua avaliação ficarão sob a guarda do pesquisador responsável e do pesquisador executante. Os registros, vídeos e anotações não serão divulgados.

Solicitamos sua autorização para que os dados obtidos nesta pesquisa sejam utilizados em uma publicação científica, que é a maneira de divulgar e compartilhar os resultados com a comunidade científica.

O (A) senhor(a) receberá uma via deste Termo de Consentimento Livre e Esclarecido. 
$\mathrm{O}$ (A) senhor(a) não terá qualquer custo, pois o custo desta pesquisa será de responsabilidade dos pesquisadores. $O(A)$ senhor(a) tem direito a ressarcimento em caso de despesas decorrentes da sua participação na pesquisa.

Não há danos previstos, mas o(a) senhor(a) tem direito à indenização diante de eventuais danos decorrentes da pesquisa.

Acredito ter sido suficientemente informado a respeito das informações que li ou que foram lidas para mim, descrevendo o estudo Síndrome corticobasal: alterações de fala e lingugem.

Eu discuti com Leticia Lessa Mansur e Isabel Junqueira de Almeida sobre a minha decisão em participar nesse estudo. Ficaram claros para mim quais são os propósitos do estudo, os procedimentos a serem realizados, seus desconfortos, as garantias de confidencialidade e de esclarecimentos permanentes. Ficou claro também que minha participação é isenta de despesas e que tenho garantia do acesso a tratamento hospitalar, quando necessário. Concordo voluntariamente em participar deste estudo e poderei retirar o meu consentimento a qualquer momento, antes ou durante o mesmo, sem penalidades ou prejuízo ou perda de qualquer benefício que eu possa ter adquirido, ou no meu atendimento neste Serviço.

Assinatura do paciente/ representante legal

Data

\section{Seticia destar Sulansur}

Assinatura do responsável pelo estudo

Data

Data

Assinatura da testemunha

para casos de pacientes menores de 18 anos, analfabetos, semi-

analfabetos ou portadores de deficiência auditiva ou visual.

(Somente para o responsável do projeto)

Declaro que obtive de forma apropriada e voluntária o Consentimento Livre e

Esclarecido deste paciente ou representante legal para a participação neste estudo.

\section{Seticia destar Ullansur}


DADOS DE IDENTIFICAÇÃO (OU ETIQUETA INSTITUCIONAL DE IDENTIFICAÇÃO) DO PARTICIPANTE DA PESQUISA OU RESPONSÁVEL LEGAL

NOME: .DOCUMENTO DE IDENTIDADE № : .. SEXO : .M $\square \square \quad$ DATA NASCIMENTO: ......................

ENDEREÇO № APTO:

BAIRRO: CIDADE CEP:. TELEFONE: DDD (......)

\section{RESPONSÁVEL LEGAL}

NATUREZA (grau de parentesco, tutor, curador etc)

DOCUMENTO DE IDENTIDADE № SEXO: $\mathrm{M} \square \mathrm{F} \square \quad$ DATA NASCIMENTO.: ....................

ENDEREÇO: № APTO:.......

BAIRRO: CIDADE: CEP: ..TELEFONE: DDD (.....) 
ANEXO C - TCLE "Síndrome corticobasal: estudo longitudinal dos perfis clínicos e fisiopatológicos" Dra. Jacy Parmera / Profa. Dra. Sonia Maria Dozzi Brucki

\author{
HOSPITAL DAS CLÍNICAS DA FACULDADE DE MEDICINA DA \\ UNIVERSIDADE DE SÃO PAULO \\ HCFMUSP
}

TERMO DE CONSENTIMENTO LIVRE E ESCLARECIDO

\title{
DADOS DA PESQUISA
}

Título da pesquisa - SÍNDROME CORTICOBASAL: ESTUDO LONGITUDINAL DOS PERFIS CLÍNICOS E FISIOPATOLÓGICOS.

Pesquisador principal - Profa. Dra. Sonia Maria Dozzi Brucki

Pesquisador executante - Dra. Jacy Bezerra Parmera

Departamento/Instituto - Neurologia / Instituto Central

De acordo com a resolução 466/2012 os seguintes conteúdos devem fazer parte das explicações sobre a pesquisa

Convidamos o(a) Sr(a). para participar da pesquisa SíNDROME CORTICOBASAL: ESTUDO LONGITUDINAL DOS PERFIS CLÍNICOS E FISIOPATOLÓGICOS.

O objetivo do estudo é analisar o perfil neuropsicológico de pacientes com a síndrome Corticobasal e comparar a presença de biomarcadores da doença de Alzheimer (PET-CT com marcador amiloide, PET com marcador fluordeoxiglicose e ressonância magnética estrutural) e da patologia TAU (ressonância magnética estrutural e PET com marcador fluordeoxiglicose) neste grupo, a fim de encontrar aspectos sugestivos destas patologias. Portanto, este presente projeto propõe-se a colaborar com esse crescente conhecimento, fundamental para compreendermos tal enfermidade, sua evolução e seu substrato patológico, e assim direcioná-los como alvos de futuras intervenções terapêuticas. A primeira avaliação ocorrerá de acordo com sua disponibilidade, englobando questionários e testes que envolvem raciocínio, atenção e memória. Não deverá ocorrer desconforto durante a execução das tarefas. O tempo previsto para a realização dos testes é de 2 horas, podendo durar um pouco mais em cada caso. Essa avaliação será feita por um neurologista e por uma fonoaudióloga.

De acordo com o seu resultado nesses testes, você será convocado a realizar três exames de imagem (ressonância magnética, PET com marcador para glicose e PET com marcador para amiloide, que é a proteína que estar presente na doença de Alzheimer). O exame de ressonância magnética não causa nenhum mal conhecido à saúde, sendo contraindicado na presença de alguns metais, e para isto, é 
necessário o preenchimento de um questionário de verificação antes do exame. Há um ruído desconfortável, mas haverá um protetor de ouvido. O médico estará o tempo todo observando o exame e pode se comunicar com a pessoa dentro do aparelho. A qualquer momento você poderá apertar um botão para conclusão deste exame. Se este for o caso, basta pedir e você será retirado (a) prontamente. $O$ aparelho possui diversos microfones e você irá se comunicar com o pesquisador em alguns intervalos durante o exame. O túnel é iluminado e tem um ventilador. Você não poderá ter problemas de ficar em ambiente fechado (claustrofobia). Apesar das imagens deste experimento não terem a finalidade de fazer diagnóstico, algumas vezes podem mostrar alterações. Caso isto aconteça, você será comunicado e, se desejar, encaminhado para acompanhamento no Hospital das Clínicas. Os exames de PET são exames tomográficos que utiliza material radioativo para formar as imagens. Todos esses exames já são utilizados na prática médica há vários anos e não causam nenhum mal às pessoas. A exposição à radiação é baixa e por isso são exames considerados seguros, com risco mínimo. Antes do início do exame você precisará receber uma picada na veia para a coleta do exame e para injeção dos materiais (glicose marcada e marcador para amiloide). Você precisará vir em jejum para realização do exame de PET. Os exames de PET e ressonância duram cerca de 30 a 45 minutos cada. Trata-se de uma pesquisa de risco mínimo. Você será reconvocado a repetir os testes neuropsicológicos (os mesmos da primeira avaliação) após um, dois e três anos dos primeiros testes.

Não há benefício direto para o participante e não há ganho financeiro para participação na pesquisa. A sua participação na pesquisa contribuirá ao conhecimento sobre a Síndrome Corticobasal doença de Alzheimer e, portanto, no futuro ajudar no desenvolvimento de novos tratamentos. Você terá acesso aos profissionais responsáveis pela pesquisa para esclarecimento de eventuais dúvidas durante todo o período da pesquisa. Após o término da pesquisa, os participantes permanecerão em acompanhamento neurológico no ambulatório de Neurologia Cognitiva do Hospital das Clínicas. Não há despesas decorrentes da pesquisa, incluindo exames e consultas. Em eventuais danos à saúde decorrentes da pesquisa, o participante terá toda assistência médica da instituição. Todos os dados pessoais serão mantidos em sigilos e os dados da pesquisa serão divulgados de forma impessoal, sem identificação do participante. Também serão garantidas as condições de plena liberdade a(o) senhor(a) de recusar-se a participar ou retirar o seu consentimento em qualquer fase da pesquisa sem penalização alguma, de sigilo e privacidade. Em qualquer momento do estudo você poderá solicitar sua retirada do protocolo de pesquisa sem que isso apresente qualquer consequência no seu acompanhamento no Hospital das Clínicas da Faculdade de Medicina da Universidade de São Paulo. A (o) senhor(a) será entregue uma via original do termo de consentimento.

O principal investigador é o Professora Dra. Sonia Maria Dozzi Brucki e a pesquisadora executante é a Dra. Jacy Bezerra Parmera, que podem ser encontrados no endereço Av. Dr. Enéas de Carvalho Aguiar, 255, CEP 05403-900, Cerqueira César, 5o andar. Telefone(s): 26616401 ou 26617877. Se você tiver alguma consideração ou dúvida sobre a ética da pesquisa, entre em contato com o Comitê de Ética em Pesquisa (CEP) - Rua Ovídio Pires de Campos, 225, 5a andar, telefones: (11) 2661-7585, (11) 2661-1548, (11) 2661-1549; e-mail: cappesq.adm@hc.fm.usp.br.

Fui suficientemente informado a respeito do estudo "SíNDROME CORTICOBASAL: ESTUDO LONGITUDINAL DOS PERFIS CLÍNICOS E FISIOPATOLÓGICOS.”. Eu discuti as informações acima com a Pesquisadora Responsável (Profa. Dra. Sonia Maria Dozzi Brucki) ou pessoa (s) por ele delegada (s) (Dra. Jacy Bezerra Parmera) sobre a minha decisão em participar nesse estudo. Ficaram claros para mim os objetivos, os procedimentos, os potenciais desconfortos e riscos e as garantias. Concordo 
voluntariamente em participar deste estudo, assino este termo de consentimento e recebo uma via rubricada pelo pesquisador.

Assinatura do paciente/representante legal:

Data:

Declaro que obtive de forma apropriada e voluntária o Consentimento Livre e Esclarecido deste paciente ou representante legal para a participação neste estudo.

Profa. Dra. Sonia Maria Dozzi Brucki:

Data:

Dra Jacy Bezerra Parmera:

Data: I

DADOS DE IDENTIFICAÇÃO DO SUJEITO DA PESQUISA OU RESPONSÁVEL LEGAL

1. NOME:

DOCUMENTO DE IDENTIDADE №:

SEXO: $M \square F \square$

DATA NASCIMENTO: 1

ENDEREÇO:

BAIRRO: CIDADE:

CEP: TELEFONE:

\section{RESPONSÁVEL LEGAL:}

NATUREZA (grau de parentesco, tutor, curador etc.):

DOCUMENTO DE IDENTIDADE №:

SEXO: $M \square F$

DATA NASCIMENTO:

1

ENDEREÇO:

BAIRRO: CIDADE:

CEP: TELEFONE: 
ANEXO D - Estudos Normativos de Idosos Americanos (Mayo Older American Normative Studies - MOANS)

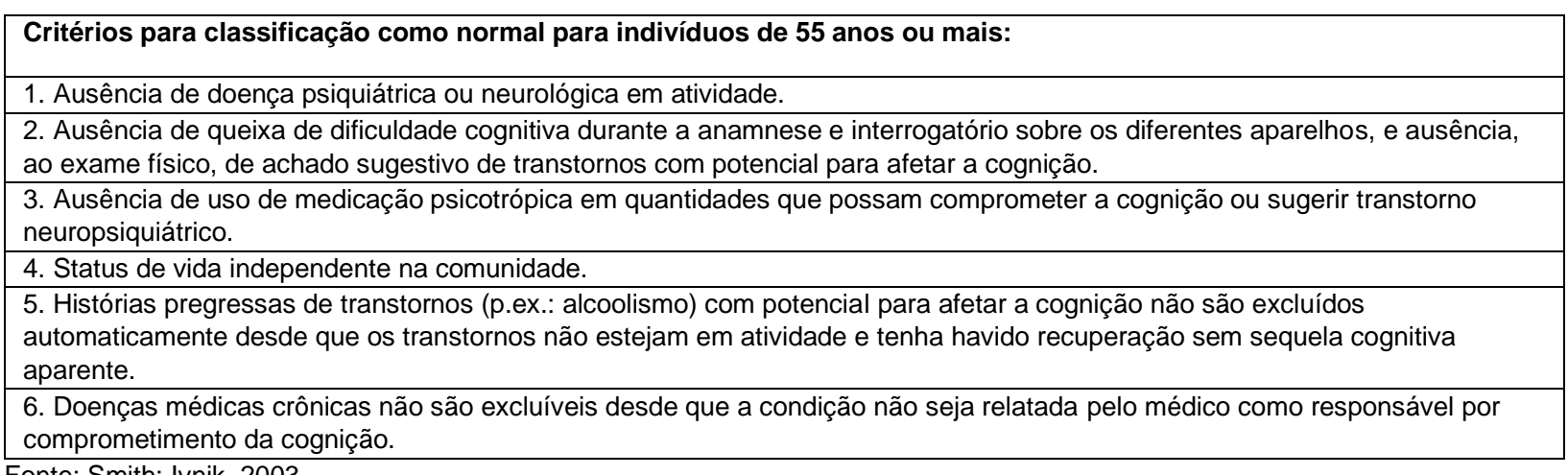
Fonte: Smith; Ivnik, 2003.

ANEXO E - Exame Cognitivo de Addenbrooke - Versão Revisada (Addenbrooke's Cognitive Examination-Revised - ACE-R)

\begin{tabular}{|l|l|}
\hline \multicolumn{1}{|c|}{ Seções } & \multicolumn{1}{|c|}{ Exemplos } \\
\hline Orientação & Responder a questões que exijam orientação: "Qual o dia da semana?". \\
\hline Registro & Repetir: "carro", "vaso", "tijolo". \\
\hline Atenção/ Concentração & Realizar cálculos: 100-7, 93-7, 86-7, 79-7, 72-7. \\
\hline Memória (recordação) & Recordar as palavras da tarefa "Registro". \\
\hline Memória (anterógrada) & Memorizar nome e endereço - resgate imediato e tardio. \\
\hline Memória (retrógrada) & $\begin{array}{l}\text { Responder a questões (conhecimento episódico): "Qual é o nome do atual presidente da } \\
\text { República?". }\end{array}$ \\
\hline Fluência verbal & Enunciar o maior número de palavras que iniciam com a letra "p", em 1 minuto. \\
\hline Linguagem (compreensão) & $\begin{array}{l}\text { Realizar comandos: "Pegue este papel com a mão direita, dobre-o ao meio e coloque-o no } \\
\text { chão". }\end{array}$ \\
\hline Linguagem (escrita) & Escrever uma frase. \\
\hline Linguagem (repetição) & Repetir: "hipopótamo"; "excentricidade"; "ininteligível"; "estatístico". \\
\hline Linguagem (nomeação) & Nomear figuras. \\
\hline Linguagem (leitura) & Ler palavras irregulares: "táxi”; "testa"; "saxofone"; "fixar"; "ballet". \\
\hline Habilidades visuo-espaciais & Desenhar um mostrador de relógio com os números, e ponteiros marcando 5:10 h. \\
\hline Habilidades perceptivas & Contar os pontos de uma imagem, sem apontá-los. \\
\hline
\end{tabular}

Fonte: Mioshi et al., 2006; Carvalho, 2009; César et al., 2017.

ANEXO F - Bateria de Avaliação de Western - Versão Revisada (Western Aprasia BatteryRevised - WAB-R)

\begin{tabular}{|l|l|l|}
\hline \multicolumn{2}{|c|}{ Seções } & \multicolumn{1}{c|}{ Exemplos } \\
\hline \multirow{4}{*}{ Fala espontânea } & $\begin{array}{l}\text { A. Conteúdo da } \\
\text { informação }\end{array}$ & $\begin{array}{l}\text { - Qual o seu endereço completo? } \\
\text { - Conte uma história com base nessa figura }\end{array}$ \\
\cline { 2 - 3 } & $\begin{array}{l}\text { B. Fluência, competência } \\
\text { gramatical e parafasias }\end{array}$ & $\begin{array}{l}\text { Análise realizada a partir das sentenças produzidas no item A: extensão, } \\
\text { complexidade, presença de parafasias e hesitações }\end{array}$ \\
\hline $\begin{array}{l}\text { Compreensão } \\
\text { verbal auditiva }\end{array}$ & A. Questões Sim/Não & $\begin{array}{l}\text { - Seu nome é João? } \\
\text { - Março vem antes de Junho? }\end{array}$ \\
\hline
\end{tabular}




\begin{tabular}{|c|c|c|}
\hline & $\begin{array}{l}\text { B. Reconhecimento } \\
\text { auditivo de palavra }\end{array}$ & $\begin{array}{l}\text { - Aponte para a janela } \\
\text { - Aponte para a cadeira }\end{array}$ \\
\hline & $\begin{array}{l}\text { C. Comandos } \\
\text { sequenciados }\end{array}$ & - Coloque o pente do outro lado da caneta e vire o livro \\
\hline Repetição & $\begin{array}{l}\text { Repetição de palavras e } \\
\text { sentenças }\end{array}$ & $\begin{array}{l}\text { - O pão está delicioso } \\
\text { - Nem aqui, nem ali, nem lá. }\end{array}$ \\
\hline \multirow{4}{*}{$\begin{array}{l}\text { Nomeação e word } \\
\text { Finding }\end{array}$} & A. Nomeação de objetos & Nomear objetos: Livro / Bola \\
\hline & B. Fluência verbal & Enunciar o maior número de nomes de animais que puder, durante 1 minuto \\
\hline & C. Completar sentenças & $\begin{array}{l}\text { - A grama é_ } \\
\text { - O açúcar é }\end{array}$ \\
\hline & $\begin{array}{l}\text { D. Denominação } \\
\text { responsiva }\end{array}$ & $\begin{array}{l}\text { - Com o que você escreve? } \\
\text { - Qual a cor da neve? }\end{array}$ \\
\hline \multirow{9}{*}{ Leitura } & $\begin{array}{l}\text { A. Compreensão de } \\
\text { sentenças }\end{array}$ & $\begin{array}{l}\text { Ler e identificar a alternativa correta: } \\
\text { - João conserta carros e caminhões. Ele é um } \\
\text { a) alfaiate b) máquina c) mecânico d) ônibus }\end{array}$ \\
\hline & B. Leitura de comandos & - Apontar para a cadeira e para a porta \\
\hline & $\begin{array}{l}\text { C. Pareamento palavra } \\
\text { escrita-objetos }\end{array}$ & $\begin{array}{l}\text { Apontar para o objeto que corresponde à palavra escrita apresentada num } \\
\text { cartão }\end{array}$ \\
\hline & $\begin{array}{l}\text { D. Pareamento palavra } \\
\text { escrita-figuras }\end{array}$ & $\begin{array}{l}\text { Apontar para a figura que corresponde à palavra escrita apresentada num } \\
\text { cartão }\end{array}$ \\
\hline & $\begin{array}{l}\text { E. Pareamento figura- } \\
\text { palavras escritas }\end{array}$ & $\begin{array}{l}\text { Apontar para a palavra escrita que corresponde à figura apresentada num } \\
\text { cartão }\end{array}$ \\
\hline & $\begin{array}{l}\text { F. Pareamento palavra } \\
\text { falada-palavras escritas }\end{array}$ & $\begin{array}{l}\text { Apontar para a palavra escrita que corresponde à palavra dita pelo } \\
\text { examinador }\end{array}$ \\
\hline & G. Discriminação de letras & Utilizar a pontuação do reconhecimento auditivo de letras \\
\hline & $\begin{array}{l}\text { H. Reconhecimento de } \\
\text { palavras soletradas }\end{array}$ & Identificar a palavra soletrada pelo examinador \\
\hline & I. Soletração & Soletrar palavras \\
\hline \multirow{7}{*}{ Escrita } & A. Escrita sob comando & Escrever seu nome e endereço \\
\hline & B. Output de escrita & Escrever narrativa com base em uma figura \\
\hline & $\begin{array}{l}\text { C. Escrita a partir de } \\
\text { ditado }\end{array}$ & Escrever sob ditado uma sentença de dez palavras \\
\hline & $\begin{array}{l}\text { D. Escrita de palavras } \\
\text { ditadas }\end{array}$ & Escrever sob ditado palavras \\
\hline & E. Alfabeto e números & Escrever as letras do alfabeto e números de 1 a 20 \\
\hline & $\begin{array}{l}\text { F. Ditado de letras e } \\
\text { números }\end{array}$ & Escrever letras e números ditados \\
\hline & G. Cópia de sentença & Copiar sentença com dez palavras, que contém todas as letras do alfabeto \\
\hline Apraxia & $\begin{array}{l}\text { Praxias de membro, facial, } \\
\text { instrumental e complexa }\end{array}$ & $\begin{array}{l}\text { Realizar gestos: } \\
\text { - Dar tchau } \\
\text { - Colocar a língua para fora da boca }\end{array}$ \\
\hline
\end{tabular}




\begin{tabular}{|l|l|l|}
\hline \multirow{2}{*}{$\begin{array}{l}\text { Tarefas } \\
\text { construtivas, } \\
\text { visuo-espaciais e } \\
\text { de cálculo }\end{array}$} & A. Desenho & $\begin{array}{l}\text { - Desenhar um cubo } \\
\text { - Desenhar um relógio }\end{array}$ \\
\cline { 2 - 3 } & B. Construção com cubos & $\begin{array}{l}\text { Reproduzir desenhos apresentados num cartão, utilizando quatro cubos } \\
\text { com duas faces brancas, duas faces vermelhas e duas faces metade branca } \\
\text { metade vermelha. }\end{array}$ \\
\cline { 2 - 3 } & C. Cálculo & Realizar somas, subtrações, multiplicações e divisões \\
\hline
\end{tabular}

Fonte: Kertesz, 2007.

ANEXO G - Base Unificada de Dados versão 3.0 - Bateria Neuropsicológica (NACC Uniform Data Set - UDS Neuropsychological Battery)

\begin{tabular}{|l|l|}
\hline Seções & Exemplos \\
\hline $\begin{array}{l}\text { Cópia da Figura Complexa de Benson } \\
\text { (imediata) }\end{array}$ & Realizar a cópia de uma figura complexa \\
\hline Fluência verbal (fonêmica e semântica) & $\begin{array}{l}\text { Dizer palavras que se iniciem pelas letras "P" e "A" (critério fonêmico); dizer nomes } \\
\text { de animais e verduras (critério semântico), durante um minuto }\end{array}$ \\
\hline Leitura de palavras & Ler palavras regulares e irregulares \\
\hline Emparelhamento semântico & Apontar para a figura que corresponde à palavra ouvida, dentre quatro opções \\
\hline Associação semântica & Relacionar semanticamente duas figuras \\
\hline $\begin{array}{l}\text { Figura Complexa de Benson (replicação } \\
\text { tardia) }\end{array}$ & $\begin{array}{l}\text { Replicar de memória o desenho da figura complexa apresentada no início da } \\
\text { avaliação }\end{array}$ \\
\hline Northwestern Anagram Test - NAT & Construir sentenças com base em uma figura, utilizando palavras recortadas \\
\hline Repetição de sentenças & Repetir sentenças de até 10 palavras \\
\hline Denominação de substantivos e verbos & Nomear verbos e substantivos representados por figuras \\
\hline Leitura de sentenças & Ler sentenças de até 10 palavras \\
\hline
\end{tabular}

Fonte: Weintraub et al., 2018.

\section{ANEXO H - Protocolo de Avaliação Clínica da Disartria}

\begin{tabular}{|l|l|}
\hline \multicolumn{1}{|c|}{ Seções } & \multicolumn{1}{c|}{ Exemplos } \\
\hline 1. Reflexos & $\begin{array}{l}\text { Perguntar ao paciente, familiar ou cuidador se há dificuldades relacionadas ao reflexo } \\
\text { de tosse, deglutição ou controle de saliva }\end{array}$ \\
\hline 2. Respiração & Observar a respiração em repouso e durante a fala \\
\hline 3. Lábios & $\begin{array}{l}\text { Avaliar a posição dos lábios em repouso e durante a realização de movimentos } \\
\text { alternados e de estiramento }\end{array}$ \\
\hline 4. Mandíbula & Observar a posição da mandíbula em repouso e durante a fala \\
\hline 5. Véu palatino & $\begin{array}{l}\text { Observar e perguntar se há escape de alimento pelo nariz. Observar a ressonância } \\
\text { nasal durante a fala }\end{array}$ \\
\hline 6. Laringe & $\begin{array}{l}\text { Avaliar o tempo máximo de fonação, o controle de volume, de frequência e a fonação } \\
\text { durante a fala }\end{array}$ \\
\hline 7. Língua & $\begin{array}{l}\text { Avaliar a língua em repouso e em movimentos de protrusão, retração e lateralização. } \\
\text { Avaliar a articulação durante a fala }\end{array}$ \\
\hline 8. Inteligibilidade de fala & $\begin{array}{l}\text { O paciente sorteia 10 palavras e 10 frases recortadas e as lê em voz alta. Computar o } \\
\text { número de palavras e frases corretamente compreendidas }\end{array}$ \\
\hline
\end{tabular}

Fonte: Auzou et al., 2006.

ANEXO I - Protocolo de Avaliação da Apraxia de Fala

\begin{tabular}{|l|l|}
\hline \multicolumn{1}{|c|}{ Tarefas } & \multicolumn{1}{c|}{ Exemplos } \\
\hline Conversação & Conversação espontânea durante 5 minutos \\
\hline Prolongamento de vogais & Emissão da vogal /a/ prolongada \\
\hline Repetição de monossílabos & Repetição rápida: /papapa/, /tatata/ e /kakaka/ \\
\hline Repetição de sequência de monossílabos & Repetição rápida: /pataka/ \\
\hline Repetição de polissílabos & Repetir palavras polissílabas \\
\hline Ensaios múltiplos de repetição da mesma palavra & Repetir por cinco vezes a mesma palavra \\
\hline Repetição de palavras que aumentam a extensão & Repetir: "bola", "bolada", embolada" \\
\hline
\end{tabular}




\begin{tabular}{|l|l|}
\hline Repetição de dissílabos & Repetir: "coca", "dedo" \\
\hline Repetição de sentenças & Repetir sentenças \\
\hline Contar em ordem direta e inversa & Contar de 1 a 20 e de 20 a 1 \\
\hline Descrição de figura & Descrever uma figura \\
\hline $\begin{array}{l}\text { Repetição de sentenças usadas voluntariamente para } \\
\text { determinar a consistência da produção }\end{array}$ & $\begin{array}{l}\text { Repetir sentenças enunciadas voluntariamente na } \\
\text { conversação }\end{array}$ \\
\hline
\end{tabular}

Fonte: Wertz; LaPointe; Rosenbeck, 1984.

ANEXO J - Escala de apraxia de fala (Apraxia of Speech Rating Scale)

\begin{tabular}{|l|l|}
\hline 1. & $\begin{array}{l}\text { Apraxia de fala - principais características distintivas (não há sobreposição com disartria ou afasia). } \\
\text { Uma ou mais devem estar presentes para o diagnóstico da apraxia de fala }\end{array}$ \\
\hline 1.1 & Substituições distorcidas \\
\hline 1.2 & Adição de som distorcido \\
\hline 1.3 & $\begin{array}{l}\text { Aumento das distorções ou substituições distorcidas na medida em que aumenta o enunciado ou a } \\
\text { complexidade articulatória das sílabas/palavras }\end{array}$ \\
\hline 1.4 & Aumento das distorções de som ou substituições distorcidas com o aumento da taxa de fala \\
\hline 1.5 & Imprecisão na repetição de monossílabos (no local ou no modo) \\
\hline 2. & Características distintivas a menos que a disartria esteja presente \\
\hline 2.1 & Segmentação silábica dentro de palavras > 1 sílaba \\
\hline 2.2 & Segmentação silábica em palavras inseridas em sentenças \\
\hline 2.3 & Distorção de sons \\
\hline 2.4 & Diminuição da taxa de fala \\
\hline 2.5 & Aumento da duração de vogais e/ou segmentos consonantais \\
\hline 2.6 & $\begin{array}{l}\text { Prolongamento da duração entre os segmentos (entre fonemas, sílabas, palavras ou frases; possivelmente } \\
\text { preenchido) }\end{array}$ \\
\hline 3. & Características distintivas a menos que a afasia esteja presente \\
\hline 3.1 & $\begin{array}{l}\text { Repetição de sequência de monossílabos (/pataka/) mais lenta, segmentada e/ou distorcida (incluindo } \\
\text { substituições distorcidas) na comparação com a repetição de monossílabos (/papapa/) }\end{array}$ \\
\hline 3.2 & Ensaios articulatórios visíveis ou audíveis; dificuldade em iniciar a fala; falsos inícios/recomeços \\
\hline 4. & Características distintivas a menos que a disartria e/ou a afasia estejam presentes \\
\hline 4.1 & Repetição de som ou de sílaba \\
\hline 4.2 & Prolongamentos de som (além dos segmentos vocálicos e consonantais cuja duração está aumentada) \\
\hline
\end{tabular}

Escala para pontuação das características da apraxia de fala:

$0=$ ausente;

1 = detectável mas não frequente;

2 = frequente mas não constante;

3 = quase sempre evidente mas não chama a atenção pela gravidade;

4 = quase sempre evidente e chama a atenção pela gravidade.

Fonte: Strands et al., 2014.

ANEXO K - Escala de Avaliação Funcional das Habilidades de Comunicação - ASHA-FACS

\begin{tabular}{|l|l|}
\hline \multicolumn{1}{|c|}{ Seções } & \multicolumn{1}{c|}{ Exemplos } \\
& O paciente ... \\
\hline Comunicação social & - é capaz de se referir a conhecidos pelo nome? \\
& - participa de uma conversação em grupo? \\
\hline Comunicação de necessidades básicas & - reconhece faces de familiares? \\
& - solicita ajuda quando necessário? \\
\hline Leitura, escrita, conceitos numéricos & - preenche pequenos formulários? \\
\hline Planejamento diário & - anota recados? \\
\hline & - cumpre compromissos agendados? \\
\hline
\end{tabular}

Fonte: Carvalho; Mansur, 2008. 
ANEXO L - Escala de gravidade da afasia progressiva primária (Progressive Aphasia Severity Scale - PASS)

\begin{tabular}{|c|c|c|c|c|c|c|}
\hline \multirow{3}{*}{ Exemplos } & \multicolumn{5}{|c|}{ DÉFICIT } & \multirow[b]{2}{*}{$\mathrm{n} / \mathrm{a}$} \\
\hline & 0 & 0,5 & 1 & 2 & 3 & \\
\hline & normal & $\begin{array}{c}\text { Questionável / déficit } \\
\text { muito leve }\end{array}$ & Déficit leve & $\begin{array}{c}\text { Déficit } \\
\text { moderado }\end{array}$ & $\begin{array}{l}\text { Déficit } \\
\text { grave }\end{array}$ & $\begin{array}{c}\text { Não } \\
\text { avaliado }\end{array}$ \\
\hline $\begin{array}{l}\text { ARTICULAÇÃO: } \\
\text { Habilidade de pronunciar } \\
\text { sons e sílabas de modo } \\
\text { preciso e sem esforço }\end{array}$ & $\begin{array}{l}\text { Articulação } \\
\text { normal }\end{array}$ & $\begin{array}{c}\text { Má articulação ocasional } \\
\text { e/ou fala com esforço, ou } \\
\text { hesitante, ou disartria; } \\
\text { dificuldade na repetição } \\
\text { do /pataka/ e na } \\
\text { pronúncia de palavras } \\
\text { multissilábicas; } 100 \% \\
\text { inteligível }\end{array}$ & $\begin{array}{l}\text { Leve e consistente } \\
\text { dificuldade com a } \\
\text { articulação; a maioria } \\
\text { das declarações são } \\
\text { inteligíveis }\end{array}$ & $\begin{array}{l}\text { Dificuldade } \\
\text { moderada com } \\
\text { a articulação; } \\
\text { metade das } \\
\text { emissões são } \\
\text { inteligíveis }\end{array}$ & $\begin{array}{c}\text { Fala } \\
\text { mínima ou } \\
\text { ininteligível }\end{array}$ & $\begin{array}{c}\text { Impossível } \\
\text { avaliar }\end{array}$ \\
\hline $\begin{array}{c}\text { RECUPERAÇÃO DE } \\
\text { PALAVRAS E } \\
\text { EXPRESSÕES: } \\
\text { Capacidade de expressar } \\
\text { a palavra pretendida } \\
\text { através da modalidade } \\
\text { mais utilizada (fala ou } \\
\text { escrita) }\end{array}$ & $\begin{array}{c}\text { Dificuldade } \\
\text { limitada a } \\
\text { raro } \\
\text { problema } \\
\text { de word- } \\
\text { finding ou } \\
\text { sensação } \\
\text { de "ponta- } \\
\text { de-língua" }\end{array}$ & $\begin{array}{l}\text { Dificuldade do tipo word- } \\
\text { finding observável, } \\
\text { ocasionando dificuldade } \\
\text { na conversação ou teste, } \\
\text { ou relato de dificuldade; } \\
\text { pode haver substituição } \\
\text { por uma palavra mais } \\
\text { comum ou fornecimento } \\
\text { de uma descrição da } \\
\text { palavra; expressa } \\
\text { mensagens com a } \\
\text { maioria dos detalhes; } \\
\text { pode usar expressões } \\
\text { estereotipadas }\end{array}$ & $\begin{array}{c}\text { A dificuldade do tipo } \\
\text { word-finding ocorre } \\
\text { várias vezes em uma } \\
\text { conversa de } 5 \\
\text { minutos; dificuldade } \\
\text { de nomear objetos } \\
\text { comuns; ocasionais } \\
\text { parafasias } \\
\text { semânticas ou } \\
\text { fonêmicas; expressa } \\
\text { a mensagem global } \\
\text { com poucos detalhes }\end{array}$ & $\begin{array}{l}\text { A maioria dos } \\
\text { enunciados não } \\
\text { têm conteúdo } \\
\text { significativo; } \\
\text { expressa um } \\
\text { sentido geral, } \\
\text { sem detalhes }\end{array}$ & $\begin{array}{c}\text { Os } \\
\text { enunciados } \\
\text { raramente } \\
\text { contêm } \\
\text { significado } \\
\text { e podem } \\
\text { ser } \\
\text { neologístic } \\
\text { os; incapaz } \\
\text { de chegar à } \\
\text { palavra ou } \\
\text { emprego } \\
\text { de } \\
\text { circunlóqui } \\
\text { o na } \\
\text { maioria dos } \\
\text { casos }\end{array}$ & $\begin{array}{c}\text { Impossível } \\
\text { avaliar }\end{array}$ \\
\hline $\begin{array}{c}\text { REPETIÇÃO: } \\
\text { Capacidade de repetir } \\
\text { palavras, expressões e } \\
\text { sentenças; a dificuldade } \\
\text { não deve ser atribuída a } \\
\text { um problema de memória } \\
\text { de trabalho; não } \\
\text { penalizar as distorções } \\
\text { de sons resultantes de } \\
\text { apraxia de fala ou } \\
\text { disartria }\end{array}$ & $\begin{array}{c}\text { Não há } \\
\text { dificuldade } \\
\text { para repetir } \\
\text { palavras, } \\
\text { expressões } \\
\text { e } \\
\text { sentenças }\end{array}$ & $\begin{array}{l}\text { Dificuldade para repetir } \\
\text { sentenças complexas ou } \\
\text { extensas }\end{array}$ & $\begin{array}{c}\text { Dificuldade para } \\
\text { repetir sentenças } \\
\text { simples (p. ex.; "O dia } \\
\text { está quente em São } \\
\text { Paulo") e/ou } \\
\text { expressões (por ex.: } \\
\text { "nem aqui, nem ali, } \\
\text { nem lá") }\end{array}$ & $\begin{array}{l}\text { Dificuldade } \\
\text { para repetir } \\
\text { palavras } \\
\text { multissilábicas; } \\
\text { pode repetir } \\
\text { palavras } \\
\text { monossilábicas } \\
\text {, sempre }\end{array}$ & $\begin{array}{l}\text { Incapaz de } \\
\text { repetir } \\
\text { mesmo } \\
\text { palavras } \\
\text { monossilábi } \\
\text { cas }\end{array}$ & $\begin{array}{c}\text { Impossível } \\
\text { avaliar }\end{array}$ \\
\hline
\end{tabular}

Fonte: Sapolsky; Domoto-Reilly; Dickerson, 2014. 


\section{REFERÊNCIAS}

Abe Y, Kimura N, Goto M, Aso Y, Matsubara E. Brain perfusion in corticobasal syndrome with progressive aphasia. Dement Geriatr Cogn Dis Extra. 2016;6(1):133-41.

Albrecht F, Bisenius S, Morales Schaack R, Neumann J, Schroeter ML. Disentangling the neural correlates of corticobasal syndrome and corticobasal degeneration with systematic and quantitative ALE meta-analyses. npj Park Dis. 2017;3(1):1-7.

Ali F, Josephs KA. Corticobasal degeneration: key emerging issues. $J$ Neurol. 2018;265(2):439-45.

Almeida OP, Almeida AS. Confiabilidade da versão brasileira da escala de depressão em geriatria (GDS) versão reduzida. Arq Neuropsiquiatr 1999;57(2-B): 421-426.

Ardila A, Bertolucci PH, Braga LW, Castro-Caldas A, Judd T, Kosmidis MH, et al. Illiteracy: The neuropsychology of cognition without reading. Arch Clin Neuropsychol. 2010;25(8):689-712.

Armstrong MJ, Litvan I, Lang AE, Bak TH, Bhatia KP, Borroni B, et al. Criteria for the diagnosis of corticobasal degeneration. Neurology. 2013;80(5): 496-503.

Armstrong MJ, Litvan I. Corticobasal degeneration. In: Tröster Al (ed.). Clinical, neuropsychological and cognitive neurology of Parkinson's disease and other movement disorders. Nova York: Oxford University Press, 2015.

Ash S, Ternes K, Bisbing T, Min NE, Moran E, York C, et al. Dissociation of quantifiers and object nouns in speech in focal neurodegenerative disease. Neuropsychologia. 2016;89:141-52.

Audacity ${ }^{\circledR}$ software is copyright (C) 1999-2018 Audacity Team. Web site: https://audacityteam.org/. It is free software distributed under the terms of the GNU General Public License. The name Audacity ${ }^{\circledR}$ is a registered trademark of Dominic Mazzoni. 
Auzou P, Gaillard MJ, Özsancak C, Léonardon S, Jan M, Hannequin D. Batterie d'Evaluation Clinique de la Dysarthrie. Isbergues. Ortho edition. 2006.

Bak TH, Hodges JR. Corticobasal degeneration: clinical aspects. In: Handbook of Clinical Neurology. Elsevier B.V.; 2008. p. 509-21.

Beyer L, Meyer-Wilmes J, Schönecker S, Schnabel J, Brendel E, Prix C, et al. Clinical routine FDG-PET imaging of suspected progressive supranuclear palsy and corticobasal degeneration: A gatekeeper for subsequent tau-PET imaging? Front Neurol. 2018;9:1-9.

Boeve BF. Corticobasal Degeneration: the syndrome and the disease. In: Litvan I, editor. Atypical parkinsonian disorders: clinical and research aspects. Totowa, New Jersey: Humana Press; 2005. p. 309-34.

Borroni B, Premi E, Agosti C, Alberici A, Cerini C, Archetti S, et al. CSF Alzheimer's disease-like pattern in corticobasal syndrome: Evidence for a distinct disorder. $\mathrm{J}$ Neurol Neurosurg Psychiatry. 2011;82(8):834-8.

Brandão L. Produção da linguagem e envelhecimento. In: Parente MAMP, editor. Cognição e envelhecimento. Porto Alegre: Artmed; 2006. p.133-52.

Burrell JR, Hodges JR, Rowe JB. Cognition in corticobasal syndrome and progressive supranuclear palsy: a review. Mov Disord. 2014;29(5):684-93.

Burrell JR, Hornberger M, Villemagne VL, Rowe CC, Hodges JR. Clinical profile of PiBpositive corticobasal syndrome. PLoS ONE. 2013;8(4):e61025.

Cardoso MCAF. Sistema estomatognático e envelhecimento: associando as características clínicas miofuncionais orofaciais aos hábitos alimentares [tese]. Porto Alegre: Pontifícia Universidade Católica do Rio Grande do Sul; 2010.

Carvalho IAM, Bahia VS, Mansur LL. Functional communication ability in frontotemporal lobar degeneration and Alzheimer's disease. Dement Neuropsychol. 2008;2(1):31-6.

Carvalho IAM, Mansur LL. Validation of ASHA FACS-Functional assessment of communication skills for alzheimer disease population. Alzheimer Dis Assoc Disord. 2008;22(4):375-81. 
Carvalho IAM. Avaliação Funcional das Habilidades de Comunicação - ASHA FACS para população com doença de Alzheimer [tese]. São Paulo: Faculdade de Medicina, Universidade de São Paulo; 2006.

Carvalho VA. Addenbrooke's Cognitive Examination-Revised (ACE-R): adaptação transcultural, dados normativos de idosos cognitivamente saudáveis e de aplicabilidade como instrumento de avaliação cognitiva breve para pacientes com doença de Alzheimer provável leve [dissertação]. São Paulo, Faculdade de Medicina, Universidade de São Paulo; 2009.

Caso F, Onofrio F, Falautano M, Todeschini P, Migliaccio R, Comi G, et al. From primary progressive aphasia to corticobasal syndrome: Two clinical and rCBF functional reports. Neurocase. 2012;19(2):1-7.

César K, Yassuda M, Porto F, Brucki S, Nitrini R. Addenbrooke's cognitive examinationrevised: normative and accuracy data for seniors with heterogeneous educational level in Brazil. Int Psychogeriatr. 2017;29(8): 1345-53.

Chahine LM, Rebeiz T, Rebeiz JJ, Grossman M, Gross RG. Corticobasal syndrome: five new things. Neurol Clin Pract. 2014;4(4): 304-12.

Cohen J. A power primer. Psychol Bull. 1992 Jul;112(1):155-9.

Constantinides VC, Paraskevas GP, Paraskevas PG, Stefanis L, Kapaki E. Corticobasal degeneration and corticobasal syndrome: A review. Clin Park Relat Disord [Internet]. 2019;1:66-71.

Cotelli M, Borroni B, Manenti R, Alberici A, Calabria M, Agosti C, et al. Action and object naming in frontotemporal dementia, progressive supranuclear palsy, and corticobasal degeneration. Neuropsychology. 2006;20(5):558-65.

Cotelli M, Borroni B, Manenti R, Ginex V, Calabria M, Moro A, et al. Universal grammar in the frontotemporal dementia spectrum: Evidence of a selective disorder in the corticobasal degeneration syndrome. Neuropsychologia. 2007;45:3015-23.

Coyle-Gilchrist ITS, Dick KM, Patterson K, Vázquez Rodríquez P, Wehmann E, Wilcox $A$, et al. Prevalence, characteristics, and survival of frontotemporal lobar degeneration syndromes. Neurology. 2016;86(18):1736-43. 
Di Stefano F, Kas A, Habert MO, Decazes P, Lamari F, Lista S, et al. The phenotypical core of Alzheimer-related and nonrelated variants of the corticobasal syndrome: a systematic clinical, neuropsychological, imaging, and biomarker study. Alzheimer's Dement. 2016;12(7):786-95.

Diamond A. Executive functions. Annu Rev Psychol. 2013;64:135-68.

Dodich A, Cerami C, Inguscio E, lannaccone S, Magnani G, Marcone A, et al. The clinicometabolic correlates of language impairment in corticobasal syndrome and progressive supranuclear palsy. Neurolmage Clin. 2019;24(March):102009.

Donovan NJ, Kendall DL, Moore AB, Rosenbek JC, Rothi LJG. Why consider impaired social language usage in a case of corticobasal degeneration? Clin Neuropsychol. 2007;21(1):190-203.

Dopper EGP, Seelaar H, Chiu WZ, De Koning I, Van Minkelen R, Baker MC, et al. Symmetrical corticobasal syndrome caused by a novel c.314dup progranulin mutation. J Mol Neurosci. 2011;45(3):354-8.

Dubois B, Slachevsky A, Litvan I, Pillon B. The FAB: A frontal assessment battery at bedside. Neurology. 2000;55(11):1621-6.

Duffy RJ. Motor Speech Disorders: substrates, differential diagnosis, and management. $3^{\mathrm{a}}$ ed. St. Louis, Missouri: Elsevier; 2013.

Fleury V, Brindel P, Nicastro N, Burkhard PR. Descriptive epidemiology of parkinsonism in the Canton of Geneva, Switzerland. Park Relat Disord [Internet]. 2018;54:30-9.

Fonseca RP, Parente MAMP. Compreensão da linguagem no envelhecimento. In: Parente MAMP, editor. Cognição e envelhecimento. Porto Alegre: Artmed; 2006. p.153-67.

Frattali CM, Duffy JR. Characterizing and assessing speech and language disturbances. In: Litvan I, editor. Atypical parkinsonian disorders: clinical and research aspects. Totowa, New Jersey: Humana Press; 2005. p. 255-76.

Frattali CM, Grafman J, Patronas N, Makhlouf F, Litvan I. Language disturbances in corticobasal degeneration. Neurology. 2000; 54:990-992. 
Gibb WR, Luthert PJ, Marsden CD. Corticobasal degeneration. Brain. 1989;112 (Pt5): 1171-1192.

Gorno-Tempini M-L, Hillis AE, Weintraub S, Kertesz A, Mendez M, Cappa SF, et al. Classification of primary progressive aphasia and its variants. Neurology. 2011;76(11):1006-14.

Gorno-Tempini M-L, Murray RC, Rankin KP, Weiner MW, Miller BL. Clinical, cognitive and anatomical evolution from nonfluent progressive aaphasia to corticobasal syndrome: A Case Report. Neurocase. 2004;10(6):426-36.

Graham NL, Bak T, Patterson K, Hodges JR. Language function and dysfunction in corticobasal degeneration. Neurology. 2003;61:493-9.

Graham NL, Leonard C, Tang-Wai DF, Black S, Chow TW, Scott CJM, et al. Lack of frank agrammatism in the nonfluent agrammatic variant of primary progressive aphasia. Dement Geriatr Cogn Dis Extra. 2016;6(3):407-23.

Grijalvo-Perez AM, Litvan I. Corticobasal degeneration. Semin Neurol. 2014;34:160-73.

Gross RG, Ash S, McMillan CT, Gunawardena D, Powers C, Libon DJ, et al. Impaired Information Integration Contributes to Communication Difficulty in Corticobasal Syndrome. Gon Bahv Neurol. 2010;23(1):1-7.

Helm-Estabrooks N. Treating attention to improve auditory comprehension deficits associated with aphasia. Perspect Neurophysiol Neurogenic Speech Lang Disord. 2011;21(2):64-71.

Henry JD, Crawford JR. A meta-analytic review of verbal fluency performance following focal cortical lesions. Neuropsychology. 2004;18(2):284-95.

Huey ED, Goveia EN, Paviol S, Pardini M, Krueger F, Zamboni G, et al. Executive dysfunction in frontotemporal dementia and corticobasal syndrome. Neurology. 2009;72(5):453-9.

Josephs KA, Duffy JR. Apraxia of speech and nonfluent aphasia: A new clinical marker for corticobasal degeneration and progressive supranuclear palsy. Curr Opin Neurol. 2008;21(6):688-92. 
Kertesz A, Martinez-Lage P, Davidson W, Munoz D. The corticobasal degeneration syndrome overlaps progressive aphasia and frontotemporal dementia. Neurology. 2000;55:1.368-75.

Kertesz A, McMonagle P. Behavioral and cognition in corticobasal degeneration and progressive supranuclear palsy. J Neurol Sci. 2010;289: 138-143.

Kertesz A. Western Aphasia Battery - Revised (WAB-R). Indianapolis, United States: Pearson, 2007.

Kompoliti K, Goetz CG, Boeve BF, Maraganore DM, Ahlskog JE, Marsden CD, et al. Clinical presentation and pharmacological therapy in corticobasal degeneration. Arch Neurol. 1998;55(7):957-61.

Kouri N, Whitwell JL, Josephs KA, Rademakers R, Dickson DW. Corticobasal degeneration: a pathologically distinct $4 \mathrm{R}$ tauopathy. Nat Rev Neurol [Internet]. 2011;7(5):263-72.

Kurland J. The role that attention plays in language processing. Perspect Neurophysiol Neurogenic Speech Lang Disord. 2011;21(2):47-54.

Lamb R, Rohrer JD, Lees AJ, Morris HR. Progressive supranuclear palsy and corticobasal degeneration: pathophysiology and treatment options. Curr Treat Options Neurol. 2016;18(9):42.

Levin J, Bak TH, Rominger A, Mille E, Arzberger T, Giese A, et al. The association of aphasia and right-sided motor impairment in corticobasal syndrome. J Neurol. 2015;262(10):2241-6.

Litvan I. What is an atypical parkinsonian disorder? In: Litvan I (ed.). Atypical parkinsonian disorders: clinical and research aspects. Totowa, New Jersey: Humana Press; 2005. p. 1-9.

Mahapatra RK, Edwards MJ, Schott JM, Bhatia KP. Corticobasal degeneration. Lancet Neurol. 2004;3:736-43.

Maia ALG, Godinho C, Ferreira ED. Aplicação da versão brasileira da escala de avaliação clínica da demência (Clinical Dementia Rating - CDR) em amostras de pacientes com demência. Arq Neuropsiquiatr 2006;64(2-B):485-489. 
Malloy-Diniz LF, Sedo M, Funetes D, Leite WB. Neuropsicologia das funções executivas. In: Fuentes D, Malloy-Diniz LF, Camargo CHP, Cosenza RM et al. (eds.). Neuropsicologia: teoria e prática. Porto Alegre: Artmed, 2008. 430 p.

Mansur LL, Radanovic M. Neurolinguística: princípios para a prática clínica. São Paulo: Edições Inteligentes, 2004.

Marshall CR, Guerreiro R, Thust S, Fletcher P, Rohrer JD, Fox NC. A novel MAPT mutation causing corticobasal syndrome led by progressive apraxia of speech. $\mathrm{J}$ Alzheimer's Dis. 2015;48(4):923-6.

Mathew R, Bak TH, Hodges JR. Diagnostic criteria for corticobasal syndrome: a comparative study. J Neurol Neurosurg Psychiatry. 2012;83(4): 405-410.

Mathew R, Bak TH, Hodges JR. Screening for cognitive dysfunction in corticobasal syndrome: Utility of addenbrooke's cognitive examination. Dement Geriatr Cogn Disord. 2011;31(4):254-8.

McMillan CT, Clark R, Moore P, Grossman M. Quantifier comprehension in corticobasal degeneration. Brain Cogn. 2006;62(3):250-60.

McMonagle P, Blair M, Kertesz A. Corticobasal degeneration and progressive aphasia. Neurology. 2006;67(8):1444-51.

Mesulam MM, Rogalski EJ, Wieneke C, Hurley RS, Bigio EH, Thompson CK, et al. Primary progressive aphasia and the evolving neurology of the language network. Nat Rev Neurol. 2014a;10(10):554-69.

Mesulam MM, Weintraub S, Rogalski EJ, Wieneke C, Geula C, Bigio EH. Asymmetry and heterogeneity of Alzheimer's and frontotemporal pathology in primary progressive aphasia. Brain. 2014b;137(4):1176-92.

Meulemans T. Les fonctions executives: approche théorique. In: Pradat-Diehl P; Azouvi P; Brun V. Foctions executives et reeducation. Paris: Masson; 2006.

Mioshi E, Dawson K, Mitchell J, Arnold R, Hodges JR. The Addenbrooke's Cognitive Examination Revised (ACE-R): a brief cognitive test battery for dementia screening. Int J Geriatr Psychiatry. 2006;21:1078-85. 
Moghbel M, Newberg A, Alavi A. Positron emission tomography: ligand imaging. In: Masdeu J, González R, editors. Handbook of Clinical Neurology. 1st ed. Elsevier B.V.; 2016. p. 229-40.

Mousinho R, Correa J. Habilidades linguístico-cognitivas em leitores e não-leitores. ProFono. 2009;21(2):113-8.

Mueller KD, Hermann B, Mecollari J, Turkstra LS. Connected speech and language in mild cognitive impairment and Alzheimer's Disease: A review of picture description tasks. J Clin Exp Neuropsychol. 2018;40(9):917-39.

Murray LL. Attention and other cognitive deficits in aphasia: Presence and relation to language and communication measures. Am J Speech-Language Pathol. 2012;21(2):51-65.

Murray R, Neumann M, Forman MS, Farmer J, Massimo L, Rice A, et al. Cognitive and motor assessment in autopsy-proven corticobasal degeneration. Neurology. 2007;68(16):1274-83.

Niccolini F, Politis M. A systematic review of lessons learned from PET molecular imaging research in atypical parkinsonism. Eur J Nucl Med Mol Imaging [Internet]. 2016;43(12):2244-54.

Nitrini R, Caramelli P, Porto CS, et al. Brief cognitive battery in the diagnosis of mild Alzheimer's disease in subjects with medium and high levels of education. Dementia \& Neuropsychologia 2007; 1:32-6.

Obler LK, Pekkala S. Language and communication in aging. In: Temmer B, Whitaker HA (eds.). The handbook of the neuroscience of language. United States of America: Elsevier, 2008. 463 p.

Oliveira LM, Barcellos I, Teive HAG, Munhoz RP. Cognitive dysfunction in corticobasal degeneration. Arq. Neuro-Psiquiatr. 2017;75(8):570-79.

Osaki Y, Morita Y, Kuwahara T, Miyano I, Doi Y. Prevalence of Parkinson's disease and atypical parkinsonian syndromes in a rural Japanese district. Acta Neurol Scand. 2011;124(3):182-7. 
Özsancak C, Auzou P, Hannequin D. Dysarthria and orofacial apraxia in corticobasal degeneration. Mov Disord. 2000;15(5):905-10.

Özsancak C, Auzou P, Jan M, Defebvre L, Derambure P, Destee A. The place of perceptual analysis of dysarthria in the differential diagnosis of corticobasal degeneration and Parkinson's disease. J Neurol. 2006;253(1):92-7.

Padovani M, Gielow I, Behlau M. Phonarticulatory diadochokinesis in young and elderly individuals. Arq Neuropsiquiatr. 2009;67(1):58-61.

Pardini M, Huey ED, Spina S, KreisI WC, Morbelli S, Wassermann EM, et al. FDG-PET patterns associated with underlying pathology in corticobasal syndrome. Neurology. 2019;92(10):1-15.

Parente MADMP, Saboskinsk AP, Ferreira E, Nespoulous J-L. Memória e compreensão da linguagem. Estud Interdiscip sobre o Envelhec. 1999;1:57-76.

Parmera JB, Rodriguez JD, Studart Neto A, Nitrini R, Brucki SMD. Corticobasal Syndrome: a diagnostic conundrum. Dement Neuropsychol. 2016;10(4):267-75.

Peterson KA, Patterson K, Rowe JB. Language impairment in progressive supranuclear palsy and corticobasal syndrome. J Neurol [Internet]. 2019; Available from: https://doi.org/10.1007/s00415-019-09463-1.

Pfeffer RI, Kurosaki TT, Harrah CH Jr et al. Measurement of functional activities in older adults in the community. Journal of Gerontology. 1982;37(3):323-9.

Pillon B, Blin J, Vidailhet M, Deweer B, Sirigu A, Dubois B, et al. The neuropsychological pattern of corticobasal degeneration: Comparison with progressive supranuclear palsy and Alzheimer's disease. Neurology. 1995;45(8):1477-83.

Radanovic M, Azambuja M, Mansur LL, Porto CS, Scaff M. Thalamus and language: Interface with attention, memory and executive functions. Arq Neuropsiquiatr. 2003;61(1):34-42.

Rebeiz JJ, Kolodny EH, Richardson EP. Corticodentatonigral Degeneration with Neuronal Achromasia. Arch Neurol. 1968;18(1):20-33.

Rosenthal R. Meta-analytic procedures for social research. 2nd ed. Newbury Park, CA: Sage; $1991.168 \mathrm{p}$. 
Rosselli M, Ardila A. The impact of culture and education on non-verbal neuropsychological measurements: A critical review. Brain Cogn. 2003;52(3):326-33.

Sakurai Y, Ishii K, Sonoo M, Saito Y, Murayama S, Iwata A, et al. Progressive apraxic agraphia with micrographia presenting as corticobasal syndrome showing extensive Pittsburgh compound B uptake. J Neurol. 2013;260(8):1982-91.

Sapolsky D, Domoto-Reilly K, Dickerson BC. Use of the Progressive Aphasia Severity Scale (PASS) in monitoring speech and language status in PPA. Aphasiology. 2014;28(8-9):993-1003.

Shelley BP, Hodges JR, Kipps CM, Xuereb JH, Bak TH. Is the pathology of corticobasal syndrome predictable in life? Mov Disord. 2009;24(11):1593-9.

Smith GE, Ivnik RJ. Normative neuropsychology. In: Petersen RC. Mild Cognitive Impairment, New York: Oxford; 2003, 63-88.

Stover NP, Walker HC, Watts RL. Corticobasal degeneration. In: Koller WC, Melamed E, editors. Handbook of Clinical Neurology: Parkinson's disease and related disorders. Birmingham, AL: Elsevier B.V.; 2007. p. 351-72.

Strand EA, Duffy JR, Clark H, Josephs KA. The apraxia of speech rating scale: A tool for diagnosis and description of apraxia of speech. J Commun Disord. 2014;51:43-50.

Thompson CK, Bastiaanse R. Introduction to agrammatism. In: Bastiaanse R., Thompson CK (eds.). Perspectives on agrammatism. New York: Psychology Press, 2012. $235 \mathrm{p}$.

Troiani V, Clark R, Grossman M. Impaired verbal comprehension of quantifiers in corticobasal syndrome. Neuropsychology. 2011;25(2):159-65.

Turaga S, Mridula R, Borgohain R. Cerebral glucose metabolism, clinical, neuropsychological, and radiological profile in patients with corticobasal syndrome. Neurol India. 2013;61(1):7.

Wadia PM, Lang AE. The many faces of corticobasal degeneration. Park Relat Disord. 2007;13:336-40. 
Weintraub S, Besser L, Dodge HH, Teylan M, Ferris S, Goldstein FC, et al. Version 3 of the Alzheimer Disease Centers' Neuropsychological Test Battery in the Uniform Data Set (UDS). Alzheimer Dis Assoc Disord. 2018;32(1):10-7.

Wenning GK, Litvan I, Jankovic J, Granata R, Mangone CA, McKee A, et al. Natural history and survival of 14 patients with corticobasal degeneration confirmed at postmortem examination. J Neurol Neurosurg Psychiatry [Internet]. 1998;64(2):184-9.

Wertz RT, LaPointe LL, Rosenbeck JC. Apraxia of speech: the disorder and its management. New York: Grune \& Straton, 1984.

Winter Y, Bezdolnyy Y, Katunina E, Avakjan G, Reese JP, Klotsche J, et al. Incidence of Parkinson's disease and atypical parkinsonism: Russian population-based study. Mov Disord. 2010;25(3):349-56.

Zalewski N, Botha H, Whitwell JL, Lowe V, Dickson DW, Josephs KA. FDG-PET in pathologically confirmed spontaneous 4R-tauopathy variants. J Neurol. 2014;261(4):710-6.

Ziegler, W. Task-related factors in oral motor control: Speech and oral diadochokinesis in dysarthria and apraxia of speech. Brain Lang. 2002;80(3): 556-75. 